\title{
WestVirginiaUniversity
}

THE RESEARCH REPOSITORY @ WVU

Graduate Theses, Dissertations, and Problem Reports

2004

\section{Current issues in empirical trade estimation}

Matthew Quinn McPherson

West Virginia University

Follow this and additional works at: https://researchrepository.wvu.edu/etd

\section{Recommended Citation}

McPherson, Matthew Quinn, "Current issues in empirical trade estimation" (2004). Graduate Theses, Dissertations, and Problem Reports. 2080.

https://researchrepository.wvu.edu/etd/2080

This Dissertation is protected by copyright and/or related rights. It has been brought to you by the The Research Repository @ WVU with permission from the rights-holder(s). You are free to use this Dissertation in any way that is permitted by the copyright and related rights legislation that applies to your use. For other uses you must obtain permission from the rights-holder(s) directly, unless additional rights are indicated by a Creative Commons license in the record and/ or on the work itself. This Dissertation has been accepted for inclusion in WVU Graduate Theses, Dissertations, and Problem Reports collection by an authorized administrator of The Research Repository @ WVU.

For more information, please contact researchrepository@mail.wvu.edu. 


\title{
Current Issues in Empirical Trade Estimation
}

\author{
Matthew Quinn McPherson \\ Dissertation submitted to the \\ College of Business and Economics \\ at West Virginia University \\ in partial fulfillment of the requirements \\ for the degree of \\ Doctor of Philosophy \\ in \\ Economics
William N. Trumbull, Ph.D., Chair
Ashok Abbott, Ph.D.
Ronald J. Balvers, Ph.D.
Subhayu Bandyopadhyay, Ph.D.
Stratford M. Douglas, Ph.D.

Division of Economics and Finance

Morgantown, West Virginia

2004

Keywords: International Trade, Gravity Model, Exchange-Rate Volatility

Copyright 2004 Matthew Quinn McPherson 


\section{Abstract \\ Current Issues in Empirical Trade Estimation}

\section{Matthew Q. McPherson}

The study of empirical trade estimation has been a staple in international economics literature since the early 1960s. I focus on three current topics in empirical trade estimation. In chapter 1, I use a time-series approach and in the context of the effect of exchange-rate volatility on trade, provide both theoretical and empirical explanations for positive volatility effects. My results show a clear pattern; when the effect of exchange-rate uncertainty on trade volume is positive [negative] for importers, the effect for exporters is negative [positive]. In addition, the U.K. provides evidence that trade balance is an important factor in determining the effect of volatility. If changes in the sign of trade balance are not taken into account, the effect of volatility may go undetected. Finally, the sensitivity of imports and exports to exchange-rate volatility is affected similarly by changes in market conditions; trade is more sensitive to volatility when the trade terms are expected to improve. In chapter 2 , I turn to cross-sectional analysis and following a growing trend in the literature, I examine the impact of adding non-standard variables, ones that measure cultural or ideological differences, to the basic gravity model. In the context of United States trade with Latin America, I show that in the case of Brazil, Nicaragua, and El Salvador, as the number of foreign-born peoples in the United States increases, U.S. exports to their country of origin increases. This finding sheds important light on the fact that the determinants of trade may go beyond standard economic and descriptive variables. In Chapter 3 I compare the Hausman-Taylor method for estimating the unrealized US-Cuban trade potential to the OLS, fixed-effects, and random-effects methods using the out-of-sample approach. The HausmanTaylor method is ideal because it allows for the inclusion of time-invariant variables in trade projections and circumvents the problem of an ad hoc estimation of the country-specific dummy variable needed for a projection based on the fixed-effects estimator. In addition, it removes the correlation between the error term and included variables which often plagues random-effects estimation. 


\section{Acknowledgements}

There are many people who deserve recognition for their part in this Dissertation. This project would not have been possible without the support, input, and comments from my classmates and especially my Dissertation Committee.

Specially, I would like to thank my officemate of three years, Tomi Ovaska, for his constant support of and, at times, necessary diversion from this project. The moral, spiritual, and mathematical guidance of Aziz Saglam was certainly priceless. I hope all is well. Finally Ryo Takashima, who listened to all my complaints in the final stages in this project, and found something positive in each one.

I would like to recognize Dr. William Trumbull, my dissertation advisor, for his willingness to take on this endeavor midstream and see it to conclusion. He was able to help me pick up the pieces when it seemed all was lost, and finish a project for which I am truly proud. Also, without the support and guidance from Dr. Stratford Douglas, I would be floundering around like a man in a boat without a paddle.

Of course the idea of even entering a Doctorial program would have been impossible without the love and support of my family. My wife Jennifer's constant sacrifices may have at times gone un-thanked, but they were never unnoticed. Although they may not understand now, the ever present smiling faces of my children, Liam and Katelynn, were a constant reminder that the fruits of this labor would be worthwhile. My mother, Williann, always knew I would finish, and gave support in any and every way possible. I cannot thank you enough.

In the end, however, it is the people who are no longer with us which I owe the most. My father, Dr. Kenard McPherson, always pushed me to be the best in everything I did and had belief in my skills when even I did not. I thank Dr. Jon Vilasuso, my first dissertation advisor, for his tireless effort and constant encouragement. Jon, your fingerprints are on all my work. 


\section{Table of Contents}

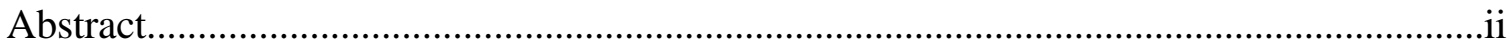

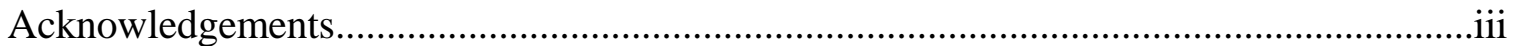

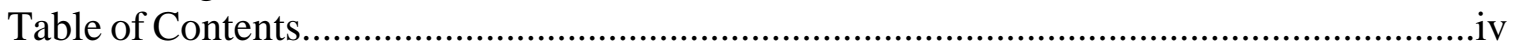

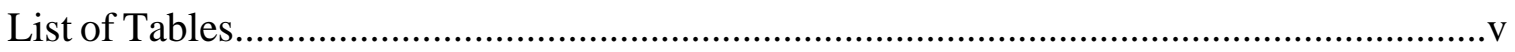

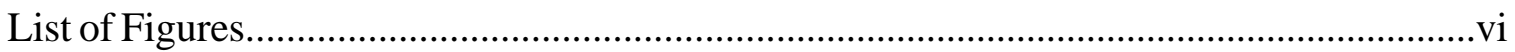

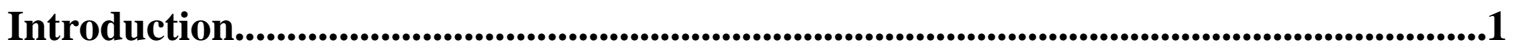

Chapter 1 Does Exchange-Rate Uncertainty Affect International Trade Flows........11

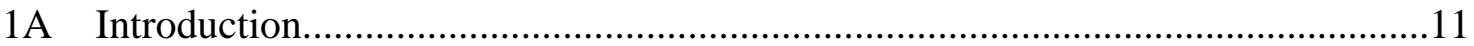

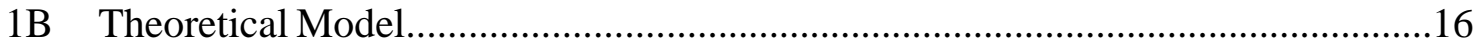

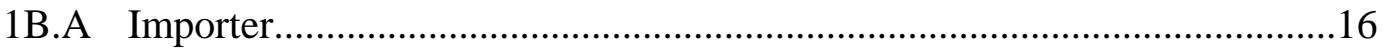

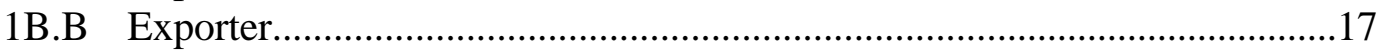

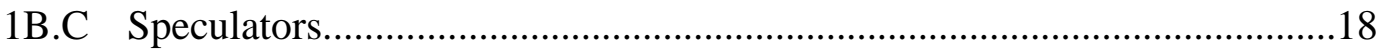

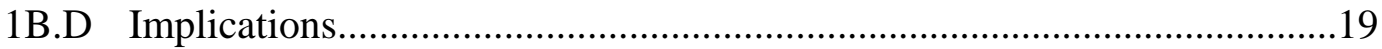

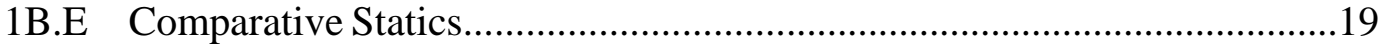

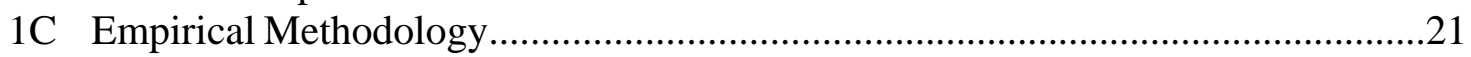

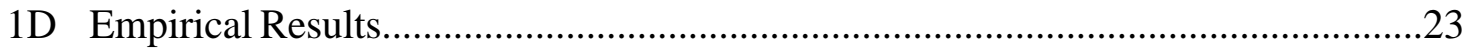

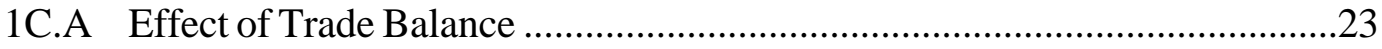

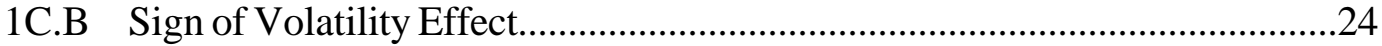

1C.C Changes in Market Conditions...................................................................25

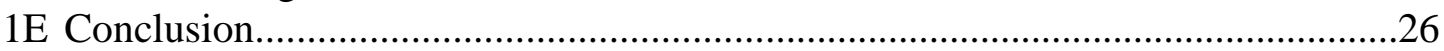

Chapter 2 Can Foreign-Born Populations Reduce Informal Trade Barriers?

An Examination of US State Level Exports to Latin America............................................29

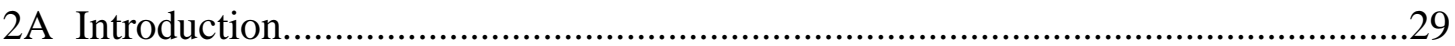

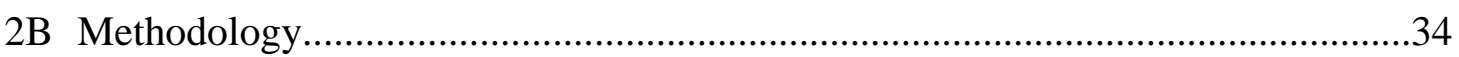

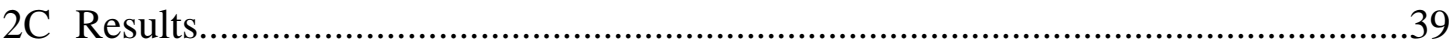

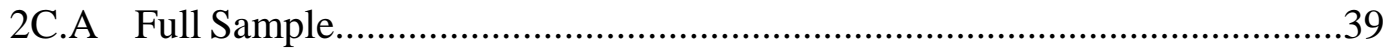

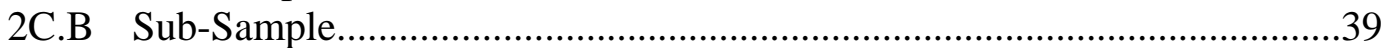

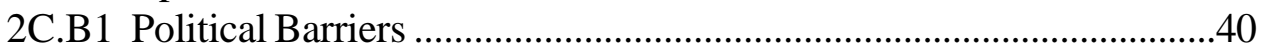

2C.B2 Cultural Barriers.....................................................................41

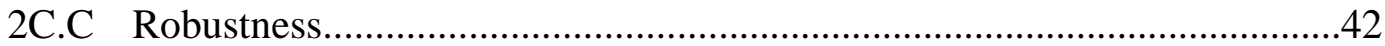

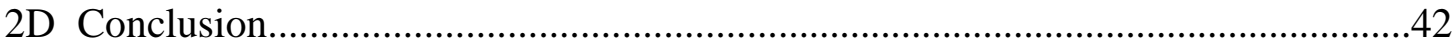

Chapter 3 Using the Gravity Model to Estimate Trade Potential: Evidence in Support of the Hausman Taylor Method.........................................................................44

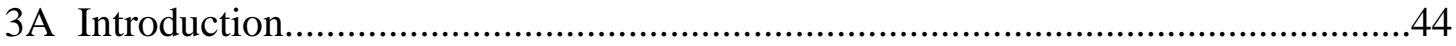

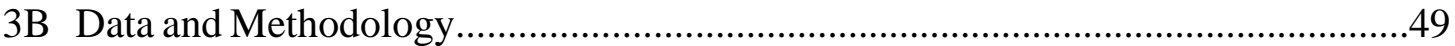

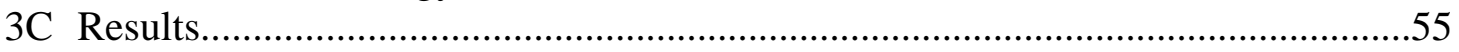

3C.A Comparison of Estimators' Econometric Properties....................................56

3C.B Comparison of Parameter Estimates.........................................................58

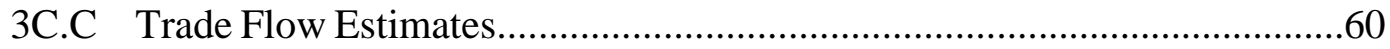

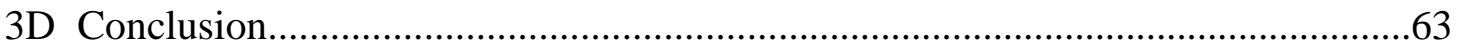

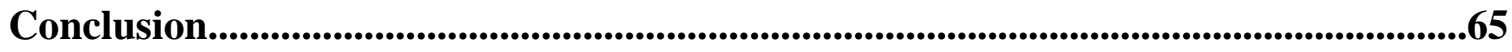

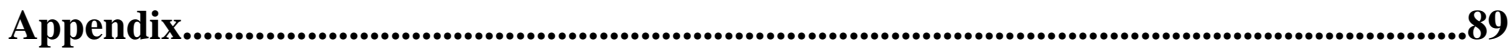

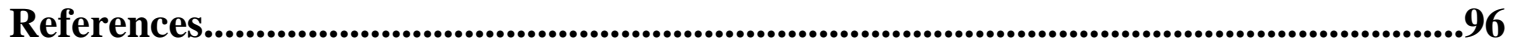




\section{List of Tables}

Table1a. United Kingdom parameter estimates..............................................................67

Table 1b. Parameter estimates......................................................................................68

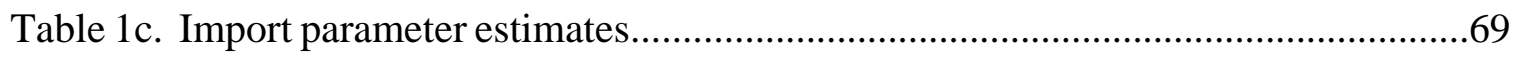

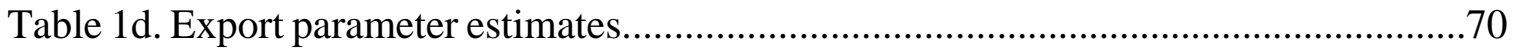

Table 2a. Parameter estimates by Country .................................................................... 71

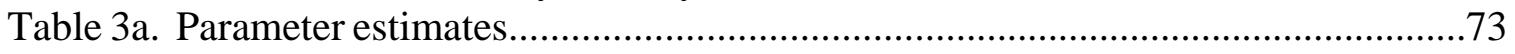

Table 3b. Cuban trade flow estimates by estimation type.................................................74

Table 3c. Country comparison of percentage trade with the United States, 2000................75 


\section{List of Figures}

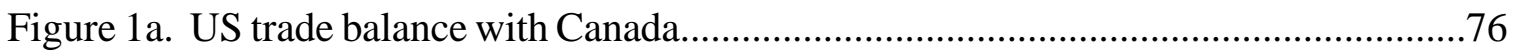

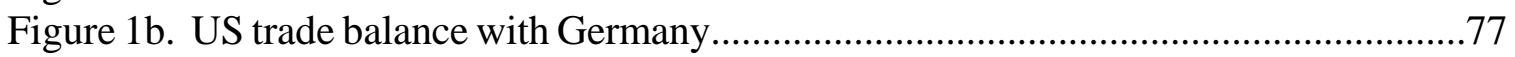

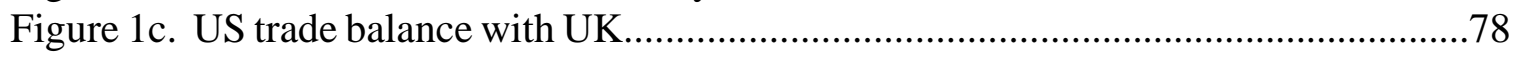

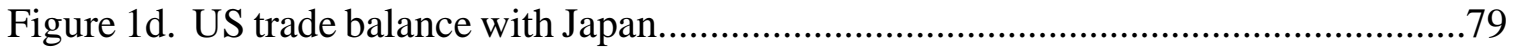

Figure 1e. US trade balance with Canada in real US dollars..............................................80

Figure 1f. US trade balance with Germany in real US dollars...........................................81

Figure 1g. US trade balance with UK in real US dollars................................................82

Figure 1h. US trade balance with Japan in real US dollars................................................83

Figure 2a. Latin American ethnic population by country (percent)....................................84

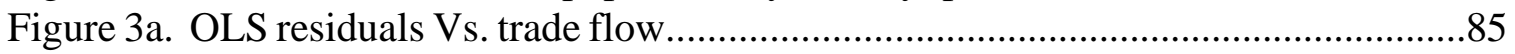

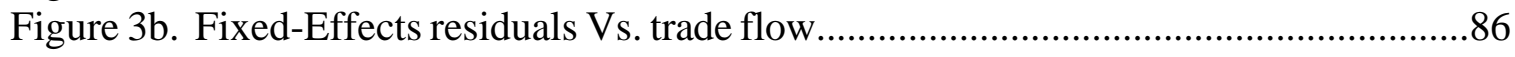

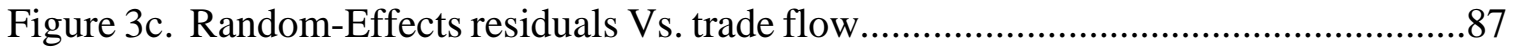

Figure 3d. Hausman-Taylor Method residuals Vs. trade flow.........................................88 


\section{Introduction}

The study of empirical trade estimation has been a staple in international economics literature since the early 1960s. I address three current topics in empirical trade estimation. In chapter 1 , I use a time-series approach to address the anomalous empirical result of positive volatility effects on trade flows. In Chapter 2, I use a crosssectional panel-data analysis to extend the basic gravity trade model and examine the effect of informal trade barriers in Latin America. Chapter 3 focuses on the proper economic estimation of the gravity trade model for estimating trade potentials using the out-of-sample approach.

Since the breakdown of the Bretton-Woods exchange-rate system, the time series trade-flow literature has been consumed by the effect of exchange-rate volatility on trade flows. This strand of the literature began as a simple exercise to confirm that the increased exchange-rate volatility which accompanied the breakdown of the Bretton-Woods fixed exchange-rate system would reduce trade flows. Traditional thinking suggests that the increased exchange-rate volatility accompanying the new flexible exchange-rate system should reduce trade because of the additional uncertainty in international transactions. This literature began to expand when, empirically, the effect of exchange-rate volatility on trade was often found to be small in magnitude or

statistically insignificant. In addition, some authors documented statistically significant 
positive volatility effects. ${ }^{1}$

This literature is based on the following basic model:

$$
\ln T F_{t}=\alpha+\ln I P_{t}+\ln R P_{t}+V_{t}+\varepsilon_{t}
$$

where $T F_{t}$ is trade flow (either imports, exports, or net trade flows), $I P_{t}$ is domestic

industrial production or GDP, $R P_{t}$ is relative prices of domestic goods and foreign

goods (the real exchange rate), $V_{t}$ is some measure of exchange-rate volatility, and $\varepsilon_{t}$

is an error term which is expected to be mean-zero. The variables can be either all in

nominal or all in real terms.

McKenzie (1999) provides a comprehensive review of how this basic model has

been extended in an attempt to confirm negative volatility effects, while discounting

positive effects. This expansion includes the use of innovative estimation techniques

such as seemingly unrelated regressions, ${ }^{2}$ vector auto regression, ${ }^{3}$ and instrumental

variable techniques. ${ }^{4}$ In addition, authors have experimented with the addition of

variables to the basic model, such as capacity utilization, production costs, trade

${ }^{1}$ McKenzie and Brooks (1997) find positive volatility effects for German trade flows between 1973 and 1992. Qian and Varangis (1994) find positive volatility effects for exports from the United Kingdom, Sweden, and the Netherlands. Asseery and Peel (1991) find both positive and negative volatility effects for exports between Australia, Japan, the United Kingdom, the United States, and West Germany. Cushman (1988) estimates the effect of volatility on imports and exports between the United States and the United Kingdom, the Netherlands, France, Germany, Canada, and Japan. Statistically significant positive and negative volatility effects are documented. Kroner and Lastrapes (1993) document both positive and negative effects for U.S., U.K., West German, Japanese, and French exports.

2 See De Grauwe (1987 and 1988) and De Grauwe and Bellefroid (1986).

3 See Koray and Lastrapes (1989), Lastrapes and Koray (1990), and Chowdhury (1993).

4 See Belanger et al (1992) and Caballero and Corbo (1989). 
integrations variables, money supply, interest rates, wages, tariff levels, transport costs, importer hedging variables, and consumer taste measures. ${ }^{5}$

The overall failure to consistently document negative volatility effects led to an attempt to theoretically explain the empirical finding of positive volatility effects. Bailey, Tavlas, and Ulan (1987) theorize that, under certain assumptions, profits based on specialized knowledge of factors affecting exchange rates can offset the tradevolume effects of exchange-rate volatility.

Sercu (1992) shows in a small-country, short-term model that increased volatility implies a higher probability that ex post deviations from Commodity Price Parity will exceed tariffs and transportation costs. Sercu and Vanhulle (1992) find that increased exchange-rate volatility positively affects the value of exporting firms via the price and volume impact of exchange rates, and makes an exporting strategy more attractive relative to direct investment. Investment in export production capacity could therefore be a positive function of exchange-rate volatility.

Broll and Eckwert (1999) focus on export production. In this model, an international firm decides upon production before the exchange-rate uncertainty materializes and decides whether to sell in the domestic market or the world market upon the realization of the spot exchange rate. In this case, as the exchange-rate volatility increases, so does the value of the real option to export to the world market. Therefore, higher volatility increases the potential gains from trade.

Qian and Varangis (1994) provide a theoretical model which predicts that

\footnotetext{
${ }^{5}$ See McKenzie (1999).
} 
exports invoiced in the importer=s currency are affected negatively by exchange-rate volatility, and exports invoiced in the exporter=s currency are affected positively.

The work of Viaene and de Vries (1992) stands apart from the current literature in that it includes implications for both imports and exports and has empirically testable propositions. Their work examines exchange-rate volatility effects in the presence of a well-developed forward market, based on explicitly solving for the forward exchange rate. The authors find that since importers and exporters are on opposite sides of the forward market, so is their exposure towards exchange-rate volatility. Therefore, in the presence of a well-developed forward market, one trade flow benefits and the other trade flow necessarily loses from exchange-rate volatility. The net currency position of the country is a crucial factor in determining the potential positive or negative effects of exchange-rate volatility. The authors do not provide empirical support for their model. In Chapter 1, I present the theoretical model of Viaene and de Vries (1992) and provide empirical confirmation of its implications concerning the effects of exchangerate volatility. I document positive exchange-rate effects in the presence of a welldeveloped forward market. I find that when exporters [importers] benefit from changes in exchange-rate volatility, then importers [exporters] necessarily lose. Therefore, the sign of the effect of exchange-rate volatility on trade can, and in some situations should, be positive.

In addition, I provide evidence that trade balance (as a proxy for net currency position) is essential in determining the effect of exchange-rate volatility on trade flows. If the sign of trade balance changes throughout the time-series in question, then typical 
estimation techniques may yield the erroneous result that exchange-rate volatility does not affect trade flows.

Further, I find the effect of exchange-rate volatility on trade is asymmetric, depending on changes in expected terms of trade. Failing to take trade balance and expectations into account may help explain why the effect of exchange-rate uncertainty on trade has often been small in magnitude and/or statistically insignificant in numerous prior studies. Therefore, I empirically confirm the theoretical foundations for not only positive volatility effects, but also for the finding that the effect of exchange-rate volatility is small in magnitude and/or statistically insignificant. I am also able to show the importance of trade balance in the understanding and predicting the effect of exchange-rate volatility on trade.

In chapters 2 and 3, I focus on the cross-sectional or panel data approach to estimating trade flows. This literature is based on the gravity trade model, which in its most basic form "posits that the volume of exports between any two trading partners is an increasing function of their national incomes, and a decreasing function of the distance between them.” ${ }^{6}$ Similar to the evolution of the time series trade estimation detailed above, the gravity model has evolved both econometrically and in the types of variables included in the model.

Recent research has explored expanding the basic gravity model to include variable that reflect cultural, ideological, and economic differences. For example, membership in a preferential trading agreement and measures of economic freedom are

\footnotetext{
${ }^{6}$ Wall (2000)
} 
now standard in the literature. In addition, the gravity model has been utilized to determine the effect of removing trade barriers. ${ }^{7}$

Current literature has provided evidence that trade barriers are not limited to tangible obstacles such as tariffs, quotes, or embargos. Cultural, ideological, and political differences can be informal barriers to trade. These informal trade barriers arise when the cost of trade is increased or the opportunity to trade is reduced because of cultural or ideological differences. One way to reduce or overcome this type of barrier is through immigration. A foreign-born population could have important business contacts with citizens of their home country, and could therefore facilitate trade. In addition, the foreign-born population may increase trade to their country of origin by exposing their new country of residence to their culture, and, as a result, reduce informal cultural trade barriers. Therefore, reducing informal barriers to trade can increase trade, just as reducing formal barriers to trade would increase trade flows.

A number of studies have focused on this foreign-born effect of trade. Gould (1994) notes that immigrants who become bilingual diminish trading costs due to reducing communication barriers. The function of ethnic populations, therefore, is to facilitate business relations when the market structure is not well-developed or when cultural differences (such as language or business norms) become informal trade barriers.

More recently, the work of Rauch and Trindade (2002) emphasize the impact of the ethnic Chinese network on reducing informal trade barriers. They find that ethnic

\footnotetext{
${ }^{7}$ See Pakko and Wall (2001).
} 
Chinese networks increased bilateral trade more for differentiated than for homogeneous products. This suggests that business and social networks have a considerable quantitative impact on international trade by helping to match buyers and sellers in characteristics space, in addition to their effect through enforcement of community sanctions that deter opportunistic behavior.

Similar results are provided by Head and Reis (1998) in their study of Canadian trading patterns from 1980 to 1992. They conclude immigrants have a positive effect on trade flows based on their superior knowledge of and preferential access to market opportunities For the United States, Dunlevy and Hutchinson (1999) provide evidence of a positive foreign-born effect in historical data (1870-1910).

The analysis of the effect of foreign-born population has also been extended to sub-national data. Dunlevy (2003) focuses on United States exports to 87 countries to examine the effect of foreign-born populations on trade and provide evidence in support of the proposition that immigrants' possession of knowledge of both trading partners and their strong ties to their home country lower transaction costs of exporters. Therefore immigrants have a positive effect on trade between the United States and their country of origin. Evidence is also provided with indicates that immigrants' ties are: (1) more important when the export destination economy and legal system are less transparent, and (2) less important when the skills and information held by the foreignborn population is less unique.

I extend the current literature by focusing on the Latino population in the United States. As this population continues to grow, understanding its trade effect has because 
more important. According to U.S. census of 2000, the Latino population in the United Status was 35 million people, or 12.5 percent of the total population.

I use a panel data approach, with annual U.S. State level exports for 1990 and 2000 from the 48 contiguous states to 13 Latin American countries. ${ }^{8}$ The data set also includes gross domestic product, gross state product, country population, state population, the Economic Freedom Index of the world, and the number of foreign-born Latinos (by country) living in each state.

Since the countries of Latin America are heterogeneous, I undertake a subsample analysis to isolate the effect of foreign-born population across countries. Not surprisingly, I find that the foreign-born effect is not homogeneous across countries. Instead, the effect of the foreign-born population on trade is concentrated in Brazil, El Salvador, and Nicaragua.

Next, in chapter 3, I turn to the proper econometric estimation of the gravity model in the context of out-of-sample trade projections. Among others, Cheng and Wall (2002) demonstrate that OLS estimation of the gravity model is susceptible to heterogeneity biases. That is, if trading partners are heterogeneous in ways not accounted for in the model, and if that heterogeneity is somehow related to the variables that are included in the regression, then the resulting estimates will be biased. To eliminate this bias, they suggest the fixed-effects estimator based on a data panel, that is, cross-sectional observations on two or more years.

\footnotetext{
8 These include Argentina, Bolivia, Brazil, Chile, Colombia, Costa Rico, Dominion Republic, Ecuador, El Salvador, Honduras, Mexico, Nicaragua, Panama, Peru, and Venezuela.
} 
Fixed-effects estimation allows for individual effects by estimating a separate intercept for each country pair. However, this technique does not allow for the inclusion of time-invariant variables. Their effect on trade is captured by country-pairspecific constant terms. This modeling assumes that Athere are fixed pair-specific factors that may be correlated with levels of [trade] and with the right-hand-side variables. It is in this sense fixed-effects modeling is a result of ignorance: we do not have a good idea which variables are responsible for the heterogeneity bias, so we simply allow each trading pair to have its own dummy variable.”9

Another method that allows for the inclusion of individual effects is the randomeffects estimator. Random-effects has the advantage that the time-invariant variables are not excluded from the model. This specification is based on the assumption that individual effects can be included as part of the error term; however, this method is susceptible to bias if there is correlation between these effects and the regressors. This is often the case empirically.

In Chapter 3, I present an alternative to both the fixed-effects and randomeffects specifications, the Hausman-Taylor Method. Hausman and Taylor’s (1981) alternative combines the beneficial aspects of both the random-effects and fixed-effects estimators. The major shortcoming of the random-effects model is the assumption that the included explanatory variables are uncorrelated with the error term. The HausmanTaylor method is an instrumental-variable technique that uses only information already contained in the model to eliminate the correlation between country-specific effects and

\footnotetext{
${ }^{9}$ Wall (2000)
} 
the error term. Unlike the fixed-effects estimator, this approach does not necessitate the elimination of time-invariant explanatory variables. Using the out-of-sample trade flow projection technique, I compare the OLS, fixed effects, random effects, and HausmanTaylor methods in estimating potential trade with Cuba, and find the Hausman-Taylor method to be the superior choice in this context. 


\section{Chapter 1: Does Exchange-Rate Uncertainty Affect}

\section{International Trade Flows?}

\section{A. Introduction}

The breakdown of the Bretton-Woods agreement in the early 1970s marked the beginning of a floating exchange-rate system characterized by increased exchange-rate uncertainty. Traditional thinking suggests that exchange-rate uncertainty should reduce trade. ${ }^{10}$ An increase in exchange-rate volatility would introduce additional uncertainty in international transactions, thus reducing trade. Empirically, the effect of exchangerate volatility on trade has often been found to be small in magnitude or statistically insignificant. In addition, statistically significant positive volatility effects have been documented. ${ }^{11}$ I provide explanations for these seemingly anomalous results in the presence of a well-developed forward market. I find that when exporters [importers] benefit from changes in exchange-rate volatility, then importers [exporters] necessarily lose. Therefore, the sign of the effect of exchange-rate volatility on trade can, and in some situations should, be positive. In addition, I provide evidence that trade balance,

\footnotetext{
${ }^{10}$ See McKenzie (1999) for a comprehensive review of the empirical literature.

11 McKenzie and Brooks (1997) find positive volatility effects for German trade flows between 1973 and 1992. Qian and Varangis (1994) find positive volatility effects for exports from the United Kingdom, Sweden, and the Netherlands. Asseery and Peel (1991) find both positive and negative volatility effects for exports between Australia, Japan, the United Kingdom, the United States, and West Germany. Cushman (1988) estimates the effect of volatility on imports and exports between the United States and the United Kingdom, the Netherlands, France, Germany, Canada, and Japan. Statistically significant positive and negative volatility effects are documented. Kroner and Lastrapes (1993) document both positive and negative effects for U.S., U.K., West German, Japanese, and French exports.
} 
as a proxy for net currency position, is essential in determining the effect of exchangerate volatility on trade flows. If the sign of trade balance changes throughout the timeseries in question, then typical estimation techniques may yield the erroneous result that exchange-rate volatility does not affect trade flows. Further, I find the effect of exchange-rate volatility on trade is asymmetric, depending on changes in expected terms of trade. Failing to take trade balance and expectations into account may help explain why the effect of exchange-rate uncertainty on trade has often been small in magnitude or statistically insignificant in numerous prior studies.

A number of authors have contributed theoretical foundations for positive volatility effects. Bailey, Tavlas, and Ulan (1987) conclude that the effect of exchangerate volatility on exports can be positive under two assumptions. First, the trader in real goods has specialized knowledge which allows profits by varying transactions in the spot or forward exchange markets or varying rates of production or sales. Second, the size of the profit is positively correlated with the volume of business in real goods transacted with that foreign currency as the medium of exchange. Under these assumptions, profits based on specialized knowledge of factors affecting exchange rates can offset the trade-volume effects of exchange-rate volatility.

Sercu (1992) shows in a small-country, short-term model (under the alternative assumptions of perfect competition and of a monopolist trader-producer), that increased exchange-rate uncertainty may on average create trade. In this framework, increased volatility implies a higher probability that ex post deviations from Commodity Price Parity will exceed tariffs and transportation costs. 
Sercu and Vanhulle (1992) examine the effect of volatility on the relative attractiveness of exports and foreign direct investment. They find the effect of exchange-rate volatility on trade value and volume is ambiguous. Increased exchangerate volatility positively affects the value of exporting firms via the price and volume impact of exchange rates, and makes an exporting strategy more attractive relative to direct investment. Investment in export production capacity could therefore be a positive function of exchange-rate volatility.

Neumann (1995) develops a model based on the assumption that trade flows are, to some extent, driven by capital movements. Because the change in the level of domestic capital in response to increased exchange-rate volatility depends on whether the country is a debtor or creditor, Neumann concludes that the long-run effect of volatility on trade balance cannot be determined unequivocally.

Broll and Eckwert (1999) focus on export production. In this model, an international firm decides upon production before the exchange-rate uncertainty materializes. However, the decision whether to sell in the domestic market or the world market can be made contingent on the realization of the spot exchange rate. In this case, as the exchange-rate volatility increases, so does the value of the real option to export to the world market. Therefore, higher volatility increases the potential gains from trade.

As a group, this work is concentrated on providing theoretical foundations for the possibility of positive volatility effects. The implications do not lend themselves to 
empirical tests, and in general, the authors offer no empirical support for their claims. ${ }^{12}$ In contrast, there are two papers that are distinguished from the aforementioned literature in that they present empirically testable propositions and predictions concerning positive volatility effects.

In the context of an imperfect competition, profit maximization model, Qian and Varangis (1994) examine the impact of currency invoicing on export volumes under exchange-rate volatility. They provide a theoretical model which predicts that exports invoiced in the importer=s currency are affected negatively by exchange-rate volatility, and exports invoiced in the exporter=s currency are affected positively. The authors provide evidence in support of their model using trade flows for Australia, Canada, Japan, the United Kingdom, the Netherlands, and Sweden.

Viaene and de Vries (1992) examine exchange-rate volatility effects in the presence of a well-developed forward market, based on explicitly solving for the forward exchange rate. Their work stands apart from the current literature in that it includes implications for both imports and exports and has empirically testable propositions. The authors find that since importers and exporters are on opposite sides of the forward market, so is their exposure towards exchange-rate volatility. Therefore, in the presence of a well-developed forward market, one trade flow benefits and the other trade flow necessarily loses from exchange-rate volatility. The net currency position of the country is a crucial factor in determining the potential positive or

\footnotetext{
${ }^{12}$ Bailey, Tavlas, and Ulan (1987) is an exception. In an empirical examination of 11 OECD countries and 33 regressions, only 3 supported negative exchange-rate volatility effects.
} 
negative effects of exchange-rate volatility. The authors do not provide empirical support for their model.

My study expands the previous literature in two ways. First, the preponderance of studies provides only a theoretical framework for the possibility of positive volatility effects, without providing empirical evidence. Comparative statics of the theoretical model (due to Viaene and de Vries, 1992) presented in this paper provide clear and testable hypotheses concerning the effect of volatility on trade. Within this framework, I provide empirical support for positive volatility effects. Second, this model addresses the common empirical finding of a weak link between exchange-rate volatility and trade. Previous literature on this topic has centered on econometric issues concerning the choice of proxy for exchange-rate volatility. ${ }^{13}$ I provide empirical evidence that the weak link may, in part, be due to reasons outside of the choice of proxy.

This paper examines the effect of exchange-rate volatility on trade in the context of trade between the United States and the other G-5 countries. The theoretical derivation and comparative statics rely on Viaene and de Vries (1992) and are presented in section 1B. The empirical methodology is detailed in section 1C. Results are reported in section $1 \mathrm{D}$, and in section $1 \mathrm{E}$, I conclude and offer areas for future research.

\footnotetext{
13 Qian and Varangis (1994) note that exchange-rate volatility as measured by the moving standard deviation of past growth rates of exchange rates may incorrectly specify the stochastic process that generates exchange rates. Kroner and Lastrapes (1993) argue that the moving standard deviation approach is a two step process. First the volatility measure is estimated and then the relationship is estimated. This may lead to inefficient estimators. Medhora (1990) critics various proxies for exchangerate uncertainty: standard deviation, deviations from trend, difference between previous forward and current spot rates, Gini mean difference coefficient, coefficient of variation, and the scale measure of variability.
} 


\section{B. Theoretical Model}

The theoretical model is based on explicitly solving for the forward exchange rate. The behavior of importers, exporters, and speculators are examined endogenously. The behavior of the central bank is assumed to be exogenous to the model. It is assumed that individual merchants do not significantly influence the world market

price. However, the domestic demand curve is downward sloping and the supply curve is upward sloping. The behavior of merchants is that of a trading house. They buy some commodities internationally and retain them locally, or vice versa. For simplicity, all invoicing occurs in the foreign currency.

\section{A. Importer}

The domestic importer faces an inverted demand function, $S=a-\frac{Y}{2}$, and returns are $a Y-\frac{Y^{2}}{2}$. The importer receives trade credit for one period. In order to hedge against exchange-rate uncertainty, the importer may buy a forward foreign currency contract L against the forward rate $f$. Therefore, the domestic importer has the following profit function:

$$
\widetilde{P}=a Y-\tilde{w} Y+(\tilde{w}-f) L-\frac{1}{2} Y^{2}
$$

Where $\mathrm{Y}$ is the quantity demanded at price $\mathrm{S}$. The one period ahead spot foreign exchange rate is $\tilde{w}$, where the tilde refers to the random nature of $w$. The imported commodity $\mathrm{Y}$ costs one unit of foreign currency, and therefore costs $\widetilde{w} Y$ in the domestic currency. 
Expected utility is assumed to be a function of the expected mean and risk (variance) of profits; therefore, any agent $i$ maximizes the following expected utility function:

$$
E \tilde{U}_{i}=\alpha_{i} E \tilde{P}_{i}-\frac{1}{2} \alpha_{i}^{2} \operatorname{var} \tilde{P}_{i}
$$

where $\alpha_{i}$ is the level of risk aversion. The importer is assumed to be risk adverse, $0<\alpha_{i}<\infty$.

Let $E \tilde{w}=\varepsilon$ and $\operatorname{var}(\tilde{w})=\sigma^{2}$. Assuming that a forward market exists $(L \neq 0)$, maximum expected utility occurs at:

$$
Y=a-f
$$

and

$$
L=(\varepsilon-f) / \alpha \sigma^{2}+Y
$$

Equation (3) is consistent with the separation theorem; imports depend only on the forward exchange rate. However, the hedge depends on the forward rate as well as the degree of risk aversion and exchange-rate volatility.

\section{B. Exporter}

Similarly, the profit function of the exporter is assumed to be:

$$
\widetilde{P}=\tilde{w} X+(\tilde{w}-f) K-d X-\frac{1}{2} X^{2}
$$

where $\mathrm{X}$ is the quantity being exported, $\mathrm{K}$ is the hedge, and $d X+\frac{1}{2} X^{2}$ are domestic purchase and production costs. The exporter sells on the world market at a price of

14 This specification assumes Constant Absolute Risk Aversion and normality. 
unity. The exporter extends one-period trade credit and is therefore exposed to exchange-rate uncertainty. This uncertainty may be hedged in the forward market.

The exporter=s expected utility function is assumed to be equation (2). Utility maximization occurs at

$$
X=f-d
$$

and

$$
K=(\varepsilon-f) / \alpha \sigma^{2}-X
$$

As with imports, the optimal level of exports is determined only by the forward exchange rate. The optimal level of the hedge is a function of the forward rate, the degree of risk aversion, and the volatility of the exchange rate.

\section{Speculators}

Assume that speculators try to maximize their expected utility of future wealth, $V(+1)$. Speculators invest current wealth $\mathrm{V}$ at the going interest rate $\mathrm{r}$, and take a speculative position $\mathrm{H}$ on the forward market.

$$
\tilde{V}(+1)=(1+r) V+(\tilde{w}-f) H
$$

Expected utility is assumed to be a function of the expected mean and risk (variance) of future wealth. Therefore any speculator $i$ maximizes the following expected utility function:

$$
E \tilde{U}_{i}=\alpha_{i} E V_{i}(+1)-\frac{1}{2} \alpha_{i}^{2} \operatorname{var} V_{i}(+1)
$$

The optimal speculative position becomes (assuming covered interest rate parity holds): 


$$
H=(\varepsilon-f) / \alpha \sigma^{2}
$$

\section{Implications}

Comparing equations (4) and (7), the speculative portions of the hedge, $(\varepsilon-f) / \alpha \sigma^{2}$, are the same for importers and exporters. The hedge parts, $\mathrm{X}$ and $\mathrm{Y}$ have opposite signs. This shows that exporters and importers take opposite hedge positions on the forward market. Formally, $\partial Y_{i} / \partial f=-1$ and $\partial X_{i} / \partial f=1 .{ }^{15}$ In addition, from equations (3), (4), (6), and (7), the only channel through which exchange-rate volatility can affect trade volume is through the forward rate $f$. Therefore, proposition 1 can be stated as follows:

Proposition 1: With a forward market, one trade flow benefits and the other trade flow necessarily loses from changes in the volatility of the exchange rate. Formally, $\partial X / \partial \sigma^{2}=-\partial Y / \partial \sigma^{2} \cdot{ }^{16}$

\section{E. Comparative Statics}

The equilibrium forward rate $f$ can be derived from the forward market clearing condition:

\footnotetext{
15 See Viaene and de Vries (1992), Lemma 2 page 1317.

16 See Viaene and de Vries (1992), Proposition 2 page 1318.
} 


$$
\sum_{i=1}^{n} l_{i}+\sum_{i=1}^{m} k_{i}+\sum_{i=1}^{s} h_{i}-F=0
$$

where $\mathrm{n}, \mathrm{m}$, and s are the number of importers, exporters, and speculators respectively. F is the central bank=s forward supply of foreign currency which is considered to be exogenous to the model. In addition, the trade balance is defined as:

$$
T B=\sum_{i=1}^{m} X_{i}-\sum_{i=1}^{n} Y_{i}
$$

The effect of a change in exchange-rate volatility on trade can be solved for explicitly:

$$
\frac{\partial X_{i}}{\partial \sigma^{2}}=-\frac{\partial Y_{i}}{\partial \sigma^{2}}=\frac{-\Omega[T B+F]}{1+(m+n) \Omega \sigma^{2}}
$$

where $\Omega$ is a measure of aggregate risk aversion.

Equation (13) has powerful implications. Proposition 2 follows:

Proposition 2: Trade balance (TB) and behavior of the central bank $(F)$ are essential to determining the effect of exchange-rate volatility on trade flows. ${ }^{17}$

Moreover, if the sign of trade balance changes throughout the time-series in question, the sign of the effect of volatility on trade flows may also change. In order for this to be true, however, the behavior of the central bank should be small in comparison to the trade balance or of the same sign. Otherwise, if trade balance and the behavior of the central bank are of opposite signs and of the same order of magnitude, trade balance alone will not determine the effect of volatility on trade flows. None-the-less, typical

\footnotetext{
${ }^{17}$ See Viaene and de Vries (1992), Proposition 3 page 1318. For a formal derivation, see appendix 1a.
} 
estimation techniques may yield the erroneous result that exchange-rate volatility does not affect trade flows if the combination of trade balance and the behavior of the central bank changes signs throughout the time series.

Equation (13) predicts that the only difference between the effect of volatility on imports and exports is the sign of the effect. This implies proposition 3:

Proposition 3: Changes in market conditions should affect the sensitivity of imports and exports to exchange-rate volatility in a similar fashion.

\section{C. Empirical Methodology}

The following demand equation is estimated separately for both U.S. ${ }^{18}$ imports from and exports to the other G-5 countries (Japan, Germany, United Kingdom, and Canada):

$T F_{i}=\alpha+\beta_{1} I P_{t}+\beta_{2} R P_{t}+\beta_{3} V_{t}+\sum_{i=1}^{11} \eta_{i} D_{i}+\beta_{4} N A F T A+\beta_{5} F T A+\beta_{6} G R+\tilde{\omega}_{t}$

where $T F_{i}, I P_{t}$, and $R P_{t}$, are in natural logs. ${ }^{19} T F_{i}$ is trade flow (either imports or exports) in real terms, $I P_{t}$ is domestic real industrial production, $R P_{t}$ is relative prices of domestic goods and foreign goods (the real exchange rate), $V_{t}$ is a measure of

\footnotetext{
${ }^{18}$ Trade flow data were obtained from the Federal Reserve Bank of St. Louis, industrial production and consumer price levels are from the IMF=s International Financial Statistics, and forward and spot exchange rates are from the Harris Bank.

${ }^{19}$ This specification is consistent which numerous previous studies. For example see Caporale and Dorodian (1994), Kenen and Rodrik (1986), Klein (1990), and Pozo (1992).
} 
exchange-rate uncertainty (these measures, $V O L_{t}$ and $G V O L_{t}$, are defined below), $D_{i}$ is a set of monthly seasonal dummies, and $\varpi_{t}$ is a mean-zero disturbance term. FTA and NAFTA are dummy variables representing the 1990 Free Trade Agreement and the 1994 North American Free Trade Agreement between the U.S. and Canada. For Canada/U.S. trade flows, these variables take on the volume of one before the agreement and zero after. GR is a dummy variable indicating German reunification. For Germany/U.S. trade flows this variable takes on a value of one before reunification and zero after.

In estimating equation 14, there is the potential for endogeneity bias. The fully modified least squares estimator - in contrast to ordinary least squares - corrects for endogeneity bias. However, Senhadji and Montenegro (1999) show that there is little difference between OLS and fully modified least squares parameter estimates for similar trade flow models. Therefore, I report OLS estimates so as to facilitate comparison with existing studies.

For each country, I use the moving sample standard deviation of the growth in the real exchange rate to measure volatility. ${ }^{20}$

$$
V O L_{t}=\left[(1 / m) \sum_{i=1}^{m}\left(P_{t-i-1}+P_{t-i-2}\right)^{2}\right]^{\frac{1}{2}}
$$

where $\mathrm{m}=12$ and $P_{t}=$ growth of the real spot exchange rate.

For robustness, I also use a GARCH (Bollerslev, 1990) measure of volatility. I

\footnotetext{
${ }^{20}$ This specification is consistent with numerous previous studies: Lastrapes and Koray (1990), Koray and Lastrapes (1989), Arize (1997), Arize et al. (2000), Chowdhury (1993), and Aristotelous (2001).
} 
test for GARCH effects by examining the squares of the least square residuals. I find that for Canada, Japan, and in some cases Germany, no GARCH effects are present.

Therefore, I also estimate volatility using GARCH for the United Kingdom

only:

$$
\begin{gathered}
r_{t}=\mu+\rho r_{t-1}+\varepsilon_{t} \\
G V O L_{t}=k+\gamma \varepsilon_{t-1}^{2}+\eta G V O L_{t-1}
\end{gathered}
$$

where $r_{t}$ is growth in the real exchange rate, $\varepsilon_{t}$ is the disturbance term, and $G V O L_{t}$ is the conditional variance.

\section{D. Empirical Results}

\section{A. Effect of Trade Balance (Proposition 2)}

I estimate equation (14) with monthly data from 1974/1 to 2001/8. The first result of interest is the effect of volatility on trade flows between the U.S. and the United Kingdom. The U.K. is the only country in the sample with a trade balance that changes sign often during the time-series in question (See Figures 1a-1h). As Table 1a shows, the effect of volatility is not significantly different from zero for imports and statistically significant at the 10 percent level for exports.

To allow for the effect of a changing trade balance, equation (14) is augmented as follows:

$$
T F_{i}=\alpha+\beta_{1} I P_{t}+\beta_{2} R P_{t}+\beta_{3} V_{t}+\sum_{i=1}^{11} \eta_{i} D_{i}+\beta_{7} P B T^{*} V_{t}+\tilde{\omega}_{t}
$$

where PTB is a dummy variable taking on the value of 1 when trade balance is positive 
and zero elsewhere. When the volatility effect is allowed to change when the trade balance is positive (equation 18), the effect of volatility on trade is statistically significant at the 1 percent level for both imports and exports. This result is robust to both measures of volatility. This, along with the strong volatility effects for the countries with trade balances which do not change in the time series, supports the implication of equation (13) and proposition 2; trade balance is essential in determining the effect of exchange-rate volatility on trade flows. This result should be interpreted with caution. As mentioned earlier, trade balance in combination with the behavior of the central bank determine the sign of the effect of volatility. Official reserves is a measure of central bank behavior suggested by Viaene and de Vries (1992). At the aggregate level, trade balance and official reserves are of the same order of magnitude and therefore the behavior of the central bank could be of importance in signing the effect of volatility on trade. ${ }^{21}$ However, since country level data on official reserves is not available for the time series examined here, I use trade balance as a somewhat noisy proxy of the combined effect of trade balance and central bank behavior.

\section{B. Sign of Volatility Effect (Proposition 1)}

Trade flows for Japan, Canada, and Germany are estimated using equation (14). Table $1 \mathrm{~b}$ displays these results, along with the results of estimating equation (18) for the U.K. In general, both measures of volatility yielded similar results. For trade flows

\footnotetext{
${ }^{21}$ This conclusion was drawn based on official reserve data contained in the IMF's International Financial Statistics tables.
} 
with Japan and Germany, the effect of volatility on imports and exports is opposite in sign and significant at the 1 percent level. For the U.K., once the changes in the sign of trade balance are allowed for, the effect of volatility on trade flows is statistically significant at the 1 percent level and opposite in sign. In contrast, for trade flows with Canada, the volatility effect is positive for both imports (1 percent level) and exports (5 percent level) before NAFTA and opposite in sign (at the 10 percent level) after.

\section{Changes in Market Conditions (Proposition 3)}

Proposition 3 predicts that the only difference between the effect of volatility on imports and exports is the sign of the effect. This implies that changes in market conditions should affect the sensitivity of imports and exports to exchange-rate volatility in a similar fashion. To test this, I estimate equation (14) for the full sample ${ }^{22}$ and two sub-samples. Sub-sample 1 contains only data where a favorable change in the terms of trade is expected. Sub-sample 2 contains only data where an unfavorable change in the terms of trade is expected. ${ }^{23}$ Table $1 c$ contains the parameter estimates for imports. For all countries, the magnitude of the volatility effect was largest in subsample 1 . In addition, the volatility effect was significant at the 1 percent level for Canada and Japan and significant at the 10 percent level for Germany and the United Kingdom for this sub-sample. In contrast, only in the case of Japan was the volatility

\footnotetext{
${ }^{22}$ The sample period is reduced to $1984 / 12$ to 2001/6 because of forward exchange rate data considerations. Also, the sample data for Germany ends 1998/12, reflecting the switch to a common European currency.

${ }^{23}$ As a proxy for expected changes in the terms of trade, I use appreciation and depreciation of the
} 
effect statistically significant at standard levels for sub-sample 2 .

Table 1d displays the results for exports. Volatility is significant at the 10 percent level only for Canada in sub-sample 2; however it is significant at the 1 percent level for Canada and Germany, and the 10 percent level for Japan in sub-sample 1. Volatility was not significantly different from zero for the U.K. in all cases. ${ }^{24}$ For each country, the magnitude of the volatility effect was larger for sub-sample 1 than for the full sample and sub-sample 2 .

Taken together, Tables 1c and 1d provide strong evidence in support of Proposition 3, that the sensitivity of imports and exports to exchange-rate volatility is affected similarly by changes in market conditions. In fact, the effect of volatility is asymmetric, depending on changes in expected terms of trade. In every case, when the terms of trade were expected to improve, the sensitivity of trade flows to exchange-rate volatility increased. Also, volatility is statistically significant for all countries, except U.K. exports, in sub-sample 1. In contrast, in only two cases is volatility statistically significant in sub-sample 2.

\section{E. Conclusion}

I examine the effect of exchange-rate volatility on trade between the U.S. and the G-5 countries, and shed light on two important anomalies. With the exception of trade flows with Canada before NAFTA, a consistent pattern emerges. Empirically,

forward exchange rate.

${ }^{24}$ This is not surprising given that the trade balance for the U.K. changes sign often; see Figure 1c. 
when the effect of exchange-rate uncertainty on trade volume is positive [negative] for importers, the effect for exporters is negative [positive]. In addition, the U.K. provides evidence that trade balance is an important factor in determining the effect of volatility. If changes in the sign of trade balance are not taken into account, the effect of volatility may go undetected. Finally, the sensitivity of imports and exports to exchange-rate volatility is affected similarly by changes in market conditions; trade is more sensitive to volatility when the trade terms are expected to improve.

In light of the recent evidence that the effect of exchange-rate volatility on trade differs across sectors or commodity classes, ${ }^{25}$ this analysis can be extended by incorporating disaggregate trade flow data. For example, Rapp and Reddy (2000) examine U.S. sectoral exports to Canada, France, Germany, Italy, Japan, and the United Kingdom using cointegration and an error correction model. Klein (1990) focuses on the effect of exchange-rate volatility on proportions of exports of nine categories of goods from the U.S. to seven major industrialized countries. Six of the nine categories had significant volatility effects, with five being positive. Doyle (2001) examines disaggregate Irish exports to the United Kingdom and finds significant positive volatility effects for the majority of sectors.

In addition, an important element in the effect of volatility on trade has been the presence of a well-developed forward exchange market. This model predicts that in the absence of a well-developed forward exchange-rate market, the effect of exchange-rate volatility will always be negative. It would be interesting to determine if the model's 
predictions are robust and to this alternative market setting. I leave this to future research. 


\section{Chapter 2: Can Foreign-Born Populations Reduce Informal Trade Barriers? An Examination of US State Level Exports to Latin American.}

\section{A. Introduction}

The importance of ethnic populations in reducing informal trade barriers has received increasing attention in the recent literature. ${ }^{26}$ I extend this developing literature by estimating the effect of the Latino ethnic population on U.S. state-level exports to Latin America. I find that the number of foreign-born Latinos has a significant impact on exports to their country of origin. More importantly, I find that the effect is not uniform across Latino countries. Upon a sub-sample analysis, I find that only in El Salvador, Nicaragua, and Brazil does the foreign-born population have a statistically significant impact on reducing informal trade barriers; and these countries are therefore the driving force of the full sample result.

Recent research underscores the reality that cultural or political differences can be an informal barrier to trade. Unlike formal trade barriers, such as tariffs, quotes, or embargos, informal trade barriers arise when the cost of trade is increased or the opportunity to trade is reduced because of cultural or ideological differences. Reducing these informal barriers can increase trade, just as reducing formal barriers to trade would increase trade flows.

\footnotetext{
${ }^{26}$ See Rauch and Casella (1998), Greif (1993), Boisso and Ferrantino (1997), and Rauch and Trindade (2003)
} 
This concept is explored by Gould (1994), who shows that an ethnic community can help exhaust trade potential to its country of origin by reducing transaction costs, influencing preferences, and overcoming language barriers; thus lessening the effect of informal trade barriers. One of the mechanisms for increased trade explored in this work is that immigrants bring foreign market information and contacts that can reduce barriers to trade, especially in countries with unstable governments or political unrest. Trade is dependant on contracts for delivery and payment, and the development of trust through immigrant contacts can decrease the costs associated with negotiating trade contracts and ensuring their enforcement. In less stable or under-developed economies trade might otherwise be impossible or extremely difficult. In addition, Gould (1994) notes that immigrants who become bilingual diminish trading costs due to reducing communication barriers. The function of ethnic populations, therefore, is to facilitate business relations when the market structure is not well-developed or when cultural differences (such as language or business norms) become informal trade barriers.

The impact of ethnic populations on economic, financial, and commercial transactions has been the focus of numerous other empirical and theoretical studies focusing on the ethnic Chinese. More recently, the work of Rauch and Trindade (2002) emphasizes the impact of the ethnic Chinese network on reducing informal trade barriers. They find that ethnic Chinese networks increased bilateral trade more for differentiated than for homogeneous products. This suggests that business and social networks have a considerable quantitative impact on international trade by helping to match buyers and sellers in characteristics space, in addition to their effect through 
enforcement of community sanctions that deter opportunistic behavior. For trade between countries with ethnic Chinese population shares at the levels prevailing in Southeast Asia, the smallest estimated average increase in bilateral trade in differentiated products attributable to ethnic Chinese networks is nearly 60 percent, suggesting that the informal trade barriers these networks help to overcome are economically important.

Similar results are provided by Head and Reis (1998) in their study of Canadian trading patterns from 1980 to 1992. They conclude that immigrants have a positive effect on trade flows based on their superior knowledge of or preferential access to market opportunities. Using an augmented form of the gravity model, they show that a 10 percent increase in the immigrant population is associated with a 1 percent increase in Canadian exports to the immigrants country of origin and a 3 percent increase in imports from the immigrants' country of origin. ${ }^{27}$

For the United States, Dunlevy and Hutchinson (1999) provide evidence of a positive foreign-born effect in historical data (1870-1910). Using the gravity model, they find the foreign-born population had a significantly positive effect on U.S. imports from the foreign-borns' country of origin. In addition, by estimating the model at the commodity group and individual commodity level, they provide evidence in support of a "taste" linkage for finished or differentiated products.

The analysis of the effect of foreign-born population has been extended to subnational data. Dunlevy (2003) focuses on United States exports to 87 countries, 
examining the effect of foreign-born populations on trade using the concept of weak and strong ties developed by Granovetter (1973). Evidence in support of the proposition that immigrants' possession of knowledge of both trading partners and their strong ties to their home country lower transaction costs of exporters, and therefore have a positive effect on trade between the United States and their country of origin, is presented. In addition immigrants' ties are: (1) more important when the export destination economy and legal system are less transparent, and (2) less important when the skills and information held by the foreign-born population is less unique. ${ }^{28}$

I focus on the Latino population in the United States. As this population continues to grow, understanding its trade effect has because more important. According to the U.S. census of 2000, the Latino population in the United Status was 35 million people, or 12.5 percent of the total population. ${ }^{29}$ Since the countries of Latin America are heterogeneous; I undertake a sub-sample analysis to isolate the effect of foreign-born population across countries. Not surprisingly, I find that the foreign-born effect is not homogeneous across countries. Instead, the effect of foreign-born population on trade is concentrated in Brazil, El Salvador, and Nicaragua.

\footnotetext{
${ }^{27}$ Similar evidence has been provided for the United Kingdom by Girma and Yu (2002)

${ }^{28}$ Wagner, Head, and Ries (2002) have examined the positive effect of foreign-born on trade at the Province level in Canada. They find that the immigrant-trade link relies on networks of individuals and families.

${ }^{29}$ U.S. Census Bureau, The Hispanic Population Census 2000 Brief, Issue May 2000, p. 3.
} 
I use the gravity model of international trade for this analysis. Since the early 1960s, this model has been utilized to estimate trade flows. ${ }^{30}$ The gravity model is based on the assumption that trade can be explained by size (GDP or GDP per capita), distance (physical distance or various measures of economic distance), and other measures of preferences (common border, common language, etc.).

The model, in various forms, has been applied in diverse settings. The gravity model has proven useful in numerous studies analyzing the border effect on trade. ${ }^{31}$ In addition, the gravity model has been used in studies focused on the impact of currency unions, preferential trading agreements, free trade agreements, and the removal of trade barriers. $^{32}$

Recently the international trade literature has focused on the importance of incorporating variables that capture the effect of cultural and economic distance in the gravity trade model. For example, variables such as lingual distance, various freedom index measures, and ethnic populations have proven to be significant determinates of trade in many situations. In my analysis, I extend the basic gravity model to include the effect of the Latino foreign-born population on reducing informal trade barriers with the United States.

The remainder of this paper is organized as follows. In section 2B, I describe

\footnotetext{
${ }^{30}$ See Tinbergen (1962) and Poyhonen (1963).

31 See, among others, Helliwell (1998); Hillberry (2002); Wolf (2000); and Anderson and Wincoop (2003).

${ }^{32}$ See Pakko and Wall (2001) and McPherson and Trumbull (2003)
} 
the data and discuss methodological considerations. In section 2C, I provide results and examine the differences across Latino countries. Section 2D concludes and offers areas for future research.

\section{B. Methodology}

I use a panel data approach, with annual U.S. State level exports for 1990 and 2000 from the 48 contiguous states to 13 Latin American countries. ${ }^{33}$ The data set also includes gross domestic product, gross state product, country population, state population, the Economic Freedom Index of the world, and the number of foreign-born Latinos (by country) living in each state. ${ }^{34}$ As is standard in the literature, I expect the effect of gross domestic product, gross state product, country population, and state population to be positive.

The Economic Freedom Index of the World, which ranks 123 countries, is a joint venture involving fifty-nine research institutes in fifty-nine countries around the world. This index determines economic freedom based on a weighted average of five sub-categories: size of government; legal structure and security of property rights; access to sound money; freedom to exchange with foreigners; and regulation of credit,

\footnotetext{
${ }^{33}$ These include Argentina, Bolivia, Brazil, Chile, Colombia, Costa Rica, Dominion Republic, Ecuador, El Salvador, Honduras, Mexico, Nicaragua, Panama, Peru, and Venezuela.

${ }^{34}$ Country GDP and population were obtained from the United Nations' World Development Indicators database. State level export data are original of movement and were obtained from the Miser trade database. State population and foreign-born data were obtained from the U.S. Census Bureau. In addition, the freedom index used is: Gwartney, James and Robert Lawson with Neil Emerick. Economic Freedom of the World: 1990 and 2000 Annual Report. Vancouver: The Fraser Institute. Data retrieved from www.freetheworld.com.
} 
labor, and business. A higher index number indicates a higher level of freedom. I therefore expect the sign of this variable to be positive; an increase in economic freedom leads to increased trade. I also expect the sign of the foreign-born population to be positive. As discussed in detail earlier, an increase in foreign-born population can reduce informal barriers and lead to increased trade.

An issue central to the gravity trade model is choosing the appropriate estimation technique. Among others, Cheng and Wall (2002) demonstrate that OLS estimation of the gravity model is susceptible to heterogeneity bias. That is, if trading partners are heterogeneous in ways not accounted for in the model, and if that heterogeneity is somehow related to the variables that are included in the regression, then the resulting estimates will be biased.

A Lagrange Multiplier (LM) technique indicates the data contain individual effects, which makes OLS estimation inappropriate. ${ }^{35}$ Further, I test for the joint significance of the individual state-country pairs and conclude that there is strong evidence of individual effects in the data. ${ }^{36}$ The same computations are undertaken to test for time effects. Assuming that there are no significant state-country effects, I find evidence that indicates there are significant export differences across time periods that are not accounted for by my included explanatory variables. ${ }^{37}$ In addition, I find that

\footnotetext{
${ }^{35}$ Based on the least squares residuals, we obtain a test statistic of 28,285.25 which is far larger than the critical value of 3.84 for a chi-squared with one degree of freedom. OLS with a single constant term is inappropriate for these data.

${ }^{36}$ A F[1071,10705] statistic used. The test statistic of 28.07 is far greater than the critical value.

${ }^{37}$ I find an $F[10,11765]$ statistic of 10.56 . This is considerably more than the critical value
} 
the period effects are jointly significant once allowing for individual effects. ${ }^{38}$ Based on the potential for heterogeneity bias and the detection of individual and time effects, I conclude that OLS estimation is not appropriate in this context.

There are two alternatives to consider given the evidence above, the randomeffects and fixed-effects models. This model does allow for individual effects. The model is based on the assumption that individual and time effects can be included as part of the error term. This model is susceptible to bias if there is correlation between these effects and the regressors. In addition, this specification does not correct for heterogeneity bias.

The fixed-effects model, on the other hand, allows for individual and time effects by estimating a separate intercept for each individual and time period. The fixed- effects specification has the advantage that the separate intercept terms control for omitted variables that are difficult to measure or are unobservable. Therefore, the effect of these variables, such as cultural past, historical links or historical conflicts, are captured in the country-specific constant term. A second widely recognized advantage of the fixed-effects specification is that time-invariant variables are also included in the country-specific constant term. The need to measure troublesome variables such has geographic distance or border is avoided. These variables have been extremely different to accurately measure. ${ }^{39}$ This model also corrects for heterogeneity bias. In

\footnotetext{
${ }^{38}$ I test for time effects allowing for the presence of individual effects, an F[10,10705] statistic produces a test statistic of 16.09 .

${ }^{39}$ See Trumbull (2001) for a discussion of the limitation of distance and border as variables in the gravity model.
} 
summary, this modeling assumes that "there are fixed pair-specific factors that may be correlated with levels of [state exports] and with the right-hand-side variables. It is in this sense fixed effects modeling is a result of ignorance: we do not have a good idea which variables are responsible for the heterogeneity bias, so we simply allow each trading pair to have its own dummy variable.”40

Hausman’s (1978) test is widely used to determine which specification, either fixed-effects or random-effects, is appropriate given the data. The hypothesis that the individual and time effects are uncorrelated with the other regressors in the model can be rejected, ${ }^{41}$ thus indicating the fixed-effects specification is appropriate for these data. The fixed-effects specification is as follows (all variables are in natural logs):

$$
Y_{i j t}=\lambda+\delta_{t}+\alpha_{i j}+\beta^{\prime} X_{i j t}+\eta F B_{i j t}+\varepsilon_{i j t}
$$

where $Y_{i j t}$ is exports from state $\mathrm{i}$ to country $\mathrm{j}$ in year $\mathrm{t}$; $\lambda$ is the overall constant: the portion of the intercept that is constant through time and constant for each country-state pair; $\delta_{t}$ is the portion of the intercept that changes through time, and $X_{i j t}^{\prime}=\left[x_{i t} x_{j t} \ldots\right]$ is a 1 x 4 row vector of country specific variables which change through time. These include the state's per capita gross product, the country’s per capita gross state product, the population of the state, and the population of the country. $F B_{i j t}$ is the number of foreign-born residents from country j residing in state $\mathrm{i}$ at time $\mathrm{t}$. The term $\alpha_{i j}$ is the country-state specific constant term discussed earlier.

\footnotetext{
${ }^{40}$ Wall (2000)

${ }^{41}$ Allowing for individual and time effects, the Hausman test produces a test statistic of 114.28. This is
} 
In order to isolate the effect the foreign born variable to determine if there are differences across countries, I perform the following sub-sample analysis. Equation (19) is augmented as follows:

$$
Y_{i j t}=\lambda+\delta_{t}+\alpha_{i j}+\beta_{1}^{\prime} X_{i j t}+\beta_{2}^{\prime} D_{i} X_{i j t}+\eta_{1} F B_{1}+\eta_{2} F B C I_{i}+\varepsilon_{i j t}
$$

where $D_{i}$ is a dummy variable which equals 1 for the country of interest and zero elsewhere. Statistically significant values of $\beta_{2}$ indicate deviations in the effect of $X_{i j t}$ on trade flow. In this way, we are able to allow for the effect of the control variables on trade flow to be different for the country of interest and the rest of Latin American. To allow for differences in the effect of the foreign-born population between the country of interest and the rest of Latin American, I introduce two new variables. $F B C I_{i}$ (foreignborn country of interest) is equal to $F B_{i j t} * D_{i}$. Therefore, $F B C I_{i}$ captures foreign-born effect for only the country of interest, $i . F B_{1}$ is equal to $F B_{i j t}$ when $D_{i}=0$. Therefore, $F B_{1}$ captures the foreign born effect for Latin America, excluding the country of interest. Equation (20) is estimated for $i=1$ to 13 , that is, individually for each country. The parameter estimates for $F B C I_{i}$ isolate the effect of the foreign-born population in each country individually, and the parameter estimates for $F B_{1}$ reflect the effect for the rest of Latin America. 


\section{C. Results}

\section{A. Full Sample}

Table 2a, Panel A, contains results for the estimation of equation (19) over the entire sample of Latin American countries. The results of the estimation of equation (20) for each country are included in Table 2a, Panel B. All significant parameter estimates are of the expected sign. ${ }^{42}$ For the entire sample, the effect of the foreignborn population is significant at the 1 percent level, and indicates a 1 percent increase in the foreign-born population is associated with an increase in exports to their home country of 0.23 percent.

\section{B. Sub-sample}

The estimation of equation (20) individually for each country sheds interesting light on the overall results. In only three cases, when specific countries are isolated, is the effect of the foreign-born population significantly different from zero. The magnitude of the effect is strongest in Nicaragua (significant at the 1 percent level), where a 1 percent increase in the foreign-born population is associated with a 1.31 percent increase in U.S. state-level exports. The magnitude of the foreign-born effect is also extremely large in Brazil (significant at the 1 percent level), where a 1 percent increase in the foreign-born population is associated with a 1.27 percent increase in

\footnotetext{
42 The vast majority of estimates of $\beta_{2}$ were not significant; for space considerations these estimates are not reported, but available upon request.
} 
exports. For El Salvador, the foreign-born effect is only marginally significant (10 percent level), and is much smaller in magnitude (elasticity of 0.36). In no other country is there a significant foreign-born effect.

\section{B1. Political Barriers}

El Salvador and Nicaragua set themselves apart from the rest of Latin America in their histories with the United States. Although many countries in Latin America have had periods of unstable government, military coops, and active guerrilla movements, the United States took direct action in Nicaragua and El Salvador. In the 1980s, these two countries were central in the United States' effort to stop the spread of Marxism in Latin American. The United States actively supported the efforts of groups fighting within Nicaragua to overthrow the Marxist regime. In addition, the U.S. government was active in supporting the El Salvador government in its 12 year civil war against Marxist opposition groups. Although Nicaragua is currently not governed by a Marxist regime, a Marxist political party still commands considerable power. In El Salvador, the civil war was ended with a compromise agreement brokered by the United Nations. This agreement ended fighting, and gave the Marxist rebels a considerable role in the new government. The residual effects of these countries' unique and intertwined Marxist affiliations, as well as the level of direct United States intervention, may constitute an informal trade barrier not present in the other Latin American countries. 


\section{B2. Cultural Barriers}

The case of Brazil is much different. In the recent past, Brazil has had a stable democratic government and has been characterized as "South America’s leading

economic power and a regional leader." ${ }^{43}$ There are, however, aspects of Brazil that set it apart from the rest of Latin America and may create an informal barrier to trade. Brazil is the only Latin American country that originated as a Portuguese possession and it is the only Latin American country where Portuguese is the predominant language. In a recent study examining the effect of immigrants on the export performance of the 50 United States and the District of Columbia to 87 foreign countries, Dunlevy (2003) documents a statistically significant language effect. That is, they find that "the role of ethnic networks is more valuable when the native population in the host country [United States] is less able to master the language of the potential trading partner." This result is also supported by the work of Gould (1994), who identifies lingual differences as a specific area where the foreign-born population can reduce informal trade barriers.

In addition, with the exception of Argentina and the Dominican Republic, Brazil is the only Latin American country that does not have a large Amerindian or Mestizo population (see figure 2a). Argentina's population is almost entirely white, while Brazil and the Dominican Republic have substantial mulatto and black populations. The absence of an indigenous population, combined with a unique language, may culturally separate Brazil from the rest of Latin America. If this is the case, there may be a unique 
barrier to trade with Brazil that is not present in other Latin American countries. That is, for example, a Colombian working for a firm may be able to facilitate trade with firms in Peru, as well as Colombia; whereas, only a Brazilian may be beneficial in increasing exports to Brazil.

\section{Robustness}

To check the robustness of the sub-sample result, equation (20) is estimated with $D_{i}=1$ for $\mathrm{i}=\mathrm{El}$ Salvador, Nicaragua, and Brazil and zero elsewhere. In this way, the effect of the foreign-born population without the inclusion of the countries found to be significant in the sub-sample analysis can be estimated. Results are contained in Table 2a. Panel $\mathrm{C}$ and provide evidence that the sub-sample results are robust. The combined effect of El Salvador, Nicaragua, and Brazil (ESNB) is 0.71 and significant at the 1 percent level. In contrast, the parameter estimate for the remaining countries (RC) is 0.03 and not significantly different from zero.

\section{D. Conclusion}

In a continuation of the literature examining the role of foreign-born populations in reducing informal trade barriers, I examine if the foreign-born Latino population helps exhaust trade potential with the United States. Overall, I am able to document a statistically significant effect of the foreign-born population of Latin America to their

${ }^{43}$ CIA World Fact Book, 2003. Http://www.cia.gov/cia/publications/factbook/geos/br.html 
country of origin. However, my results show the need for caution in using aggregate data, and also suggest that the effect of foreign-born populations on trade is not uniform across countries. My results support the notion that foreign-born population can reduce informal trade barriers, and help exhaust trade potential where significant cultural or political barriers exists. In situations where no informal barriers exist, the presence of a foreign-born population may not have a significant impact on trade.

The literature on the importance of foreign-born populations on trade is in the beginning stages of development. This analysis can be extended by disaggregating trade flows by commodity classes, similar to the work of Dunlevy (2003) for the United States and Wagner, Head, and Ries (2002) for Canada. It may be naive to assume that the effect of foreign-born population on trade is constant across all commodity classes. Just as the effect of the foreign-born population is concentrated in certain countries, the effect may differ across commodity class. In addition, this analysis extends the current literature by focusing on Latin America. It would be interesting to extend this analysis to include a larger set of countries. I leave these topics for future research 


\section{Chapter 3: Using the Gravity Model to Estimate Trade Potential: Evidence in Support of the Hausman Taylor}

\section{Method.}

\section{A. Introduction}

In this analysis, I compare several methods for estimating unrealized trade potential in the context of the gravity model of trade. I am the first to focus on the Hausman-Taylor method for out-of-sample trade projections, and find this method to be the superior choice. The Hausman-Taylor method eliminates the heterogeneity bias that plagues OLS estimation and the correlation between included variables and the individual error term that introduces bias in random-effects estimation. Further, unlike fixed-effects estimation, the Hausman-Taylor method allows for the inclusion of timeinvariant explanatory variables.

The gravity model of trade is the obvious choice for this analysis; since the early 1960s it has been utilized to estimate trade flows. ${ }^{44}$ The model is based on the assumption that trade can be explained by size (GDP or GDP per capita) and distance (physical distance and/or various measures of economic distance such as a common border, common language, etc.). In various forms, it has been applied in studies

\footnotetext{
${ }^{44}$ See Tinbergen (1962) and Poyhonen (1963).
} 
analyzing the border effect on trade ${ }^{45}$, as well as estimating the impact of currency unions, preferential trading agreements, free trade agreements, and removing trade barriers. ${ }^{46}$

In predicting trade potential, the gravity model has been used in two different ways. The first strategy is based on in-sample predictions. ${ }^{47}$ In this method, a country pair under examination is included in the sample. The residual is then interpreted as the difference between potential and actual bilateral trade relations. Recent research has been critical of this approach. In the context of trade potential between EU and former COMECON countries, Egger (2002) shows that large systematic differences between residuals among country groups are not found when the proper estimation technique (one with white-noise residuals) is used. Egger (2002) suggests Athat any systematic difference between observed and in-sample predicted trade flows indicates misspecification of the econometric model instead of unused (or overused) trade potentials.” This work focuses solely on the limitations of using the in-sample approach to estimating trade flow potentials.

A natural extension to the work of Egger (2002), and the one employed here, is to apply the Hausman-Taylor method to the out-of-sample approach. In this strategy, the gravity model of trade is estimated excluding the trade flows of interest. The model=s parameters are then used to project natural trade relations between countries

\footnotetext{
${ }^{45}$ See, among others, Helliwell (1998); Helliwell and Verdier (2001); Wolf (2000); and Anderson and Wincoop (2003).

${ }^{46}$ See Pakko and Wall (2001).
} 
outside the sample. The difference between the observed and the predicted trade flows can be interpreted as unrealized trade potential. This approach is similar to those used in Wang and Winters (1991), Hamilton and Winters (1992), and Brulhart and Kelley (1999).

As indicated earlier, the choice of estimation technique is extremely important in correctly estimating trade potentials. The most common techniques used to estimate the gravity model of trade have been questioned in the recent literature. Among others, Cheng and Wall (2002) demonstrate that OLS estimation of the gravity model is susceptible to heterogeneity biases. That is, if trading partners are heterogeneous in ways not accounted for in the model, and if that heterogeneity is somehow related to the variables that are included in the regression, then the resulting estimates will be biased. They suggest the fixed-effects estimator based on a data panel, that is, cross-sectional observations on two or more years.

Fixed-effects estimation allows for individual effects by estimating a separate intercept for each country pair. However, this technique does not allow for the inclusion of time invariant variables. Their effect on trade is captured by country-pairspecific constant terms. This modeling assumes that Athere are fixed pair-specific factors that may be correlated with levels of [trade] and with the right-hand-side variables. It is in this sense fixed-effects modeling is a result of ignorance: we do not have a good idea which variables are responsible for the heterogeneity bias, so we

\footnotetext{
${ }^{47}$ See Baldwin (1994) and Nilsson (2000)
} 
simply allow each trading pair to have its own dummy variable."48 This estimation method has severe limitations when estimating potential trade flows using the out-ofsample technique. Much information needed for an accurate prediction of potential trade flows is contained in the country-specific constant terms. The determination of a constant for out-of-sample countries is problematic, and at best ad hoc.

Another method which allows for the inclusion of individual effects is the random-effects estimator. Random-effects has the advantage that the time-invariant variables are not excluded from the model. This specification is based on the assumption that individual effects can be included as part of the error term. However, this method is susceptible to bias if there is correlation between these effects and the regressors. This is often the case empirically. Nonetheless, it has been used as an alternative to fixed-effects estimation when the effect of time-invariant explanatory variables is of importance or when no bias has been detected. ${ }^{49}$

Hausman and Taylor (1981) suggest an alternative that combines the beneficial aspects of both the random-effects and fixed-effects estimators. The major shortcoming of the random-effects model is the assumption that the included explanatory variables are uncorrelated with the error term. The Hausman-Taylor method is an instrumentalvariable technique that uses only information already contained in the model to eliminate the correlation between country-specific effects and the error term. Unlike the fixed-effects estimator, this approach does not necessitate the elimination of time-

\footnotetext{
${ }^{48}$ Wall (2000)

${ }^{49}$ See Baldwin (1994), Gros and Gonciarz (1996), Matyas (1997), and Egger (2000)
} 
invariant explanatory variables.

The US-Cuban trade relation provides a unique opportunity to estimate trade potentials. The economic relationship between the United States and Cuba was very strong prior to the socialist period. Sixty-seven percent of Cuban exports and 70 percent of imports were with the United States in $19588^{50}$ The US was also the main source of both private and official capital for Cuba. ${ }^{51}$ Since the Cuban revolution and the subsequent US-imposed economic sanctions, trade between the two countries has been effectively eliminated, at least until recently (in the case of agricultural exports to Cuba). In addition to analyzing competing estimators based on their economic properties, the unrealized trade potential between the US and Cuba allows for a more practical assessment. The final trade potential estimates should be comparable to those of similar countries in the region, as well as the historical (pre-1959) US-Cuban trading pattern.

In my analysis, I employ the out-of-sample approach to estimating the trade potential between the US and Cuba. I compare the OLS, fixed-effects, random-effects, and Hausman-Taylor estimation of the gravity model of trade and provide substantial evidence that the Hausman-Taylor estimator is the superior choice in this setting.

The remainder of the paper is organized as follows. Section 3B contains a detailed description of the methodology used and a description of my data set. In section 3C, I summarize results. Section 3D concludes with ideas for future research.

\footnotetext{
${ }^{50}$ United Nations Economic Commission for Latin America (ECLAC), Economic Survey of Latin America, 1963, (New York: United Nations, 1965), p.273.
} 


\section{B. Data and Methodology}

I estimate the gravity model separately using four different techniques: OLS, fixed-effects, random-effects, and the Hausman-Taylor method. The OLS (equation 21), fixed-effects (equation 22), and random-effects (equation 23) estimators are straightforward and are as follows:

$$
Y_{i j t}=\alpha_{0}+\beta^{\prime} X_{i j t}+\delta^{\prime} Z_{i j}+\varepsilon_{i j t}
$$

where $\alpha_{0}$ is an overall constant that is to be estimated, $X$ is a vector of time-varying explanatory variables, $Z$ is a vector of time-invariant explanatory variables, $\beta$ and $\delta$ are vectors of coefficients to be estimated, and $\varepsilon_{i j t}$ is the error term, assumed to have an expected value of zero;

$$
Y_{i j t}=\alpha_{i j}+\alpha_{0}+\beta^{\prime} X_{i j t}+\varepsilon_{i j t}
$$

where $\alpha_{i j}$ is a specific country-pair effect between trading partners that captures the effect of all time-invariant variables; and

$$
Y_{i j t}=\alpha_{0}+\beta^{\prime} X_{i j t}+\delta Z_{i j}+\varepsilon_{i j t}+\mu_{i j}
$$

where $\mu_{i j}$ is a country-pair-specific error term, assumed to have $E\left[\mu_{i j}\right]=0$, $\operatorname{Var}\left[\mu_{i j}\right]=\sigma_{\mu}^{2}$, and $\operatorname{Cov}\left[\mu_{i j}, \varepsilon_{i j}\right]=0$.

I define the independent variable $Y_{i j t}$ as imports of country i from country $\mathrm{j}$ in year t. The data set contains annual trade flows ${ }^{52}$ between 101 countries (see Appendix

\footnotetext{
${ }^{51}$ Economic Impact of U.S. Sanctions with Respect to Cuba: Chapter 3: "Overview of the Cuban Economy and the Impact of U.S. Sanctions," U.S. International Trade Commission, February 2001.

${ }^{52}$ Trade statistics were obtained from Statistics Canada=s World Trade Analyzer dataset.
} 
3a) for the time period 1996 to 2000. Numerous individual trading pairs were eliminated due to missing data, and the final data set consists of 9,230 country pairs. This translates to 46,150 trade flow observations over the five-year period.

The explanatory variables are divided into two groups, those that change through time and those that are constant. $\quad X_{i j t}^{\prime}=\left[x_{i t} x_{j t} \ldots\right]$ is a $1 \times 9$ row vector of country-specific variables that change through time. These include standard gravity model variables: GDPs per capita and the populations of both countries. ${ }^{53}$

I also include a variable to capture a Linder effect; the absolute value of the difference in the partners' per capita GDPs. This variable measures the economic distance between trading partners. One hypothesis of trade, the Linder hypothesis (1961), postulates that countries export products that are similar to those which they consume at home. In this way, the country is able to minimize the risk associated with the production of new products. The net result is that firms will produce products for export which will also appeal to the home market. Therefore, trade is higher among countries that have similar tastes and incomes. ${ }^{54}$ This is in contrast to other models of the determinates of trade that argue that differences in factor endowments, and not income, are the determinates of trade. Since a small absolute value difference indicates a country pair with similar income, I expect this variable to be negative. The closer the countries are in their economic development and income (all else equal) the more they

\footnotetext{
${ }^{53}$ These data were obtained from the World Bank=s Development Indicators Database.

54 See, for example, McPherson, Redfearn, and Tieslau (2000, 2001), and Thursby and Thursby (1987) for recent support of the Linder hypothesis in the context of the gravity trade model.
} 
will trade.

Next, I include a measure of trade freedom for each country, the Heritage Foundation=s Index of Economic Freedom. ${ }^{55}$ In this index, a higher value indicates less trade freedom. This index is constructed such that high levels of trade freedom indicate low levels of governmental, social, or political barriers to trade. Findings by Baldwin (1994), Boisso and Gerrantino (1997), and Hamilton and Winters (1992), among many others, support an expectation of a negative coefficients for this variable. In addition, I include the absolute value of the difference of the two trading partners= trade freedom index. Based on the Linder hypothesis, the coefficients of the trade freedom index variables are expected to be negative; the closer two countries are in terms of their trade freedom level, the more likely they are to trade.

Lastly, I include a variable to indicate both countries’ membership in a preferential trading agreement. This variable is based on World Trade Organization (WTO) records. It includes properly registered and recognized customs unions, free trade agreements, and service agreements. The included agreements are EC, BANG, ASEAN, ECO, GCC, LAIA, SPARTEC, MERCOSU, CEFTA, EFTA, CARICOM, CACM, CIS, BAFTA, NAFTA, PATCRA, CER, EAC, CEMAC, WAEMU, MSG, COMESA, SAPTA, and AFTA. In addition to the multilateral preferential trade agreements, individual trading agreements are included as reported by the WTO. Member countries enjoy the benefits of reduced transaction costs (such as tariffs),

\footnotetext{
${ }^{55}$ These data were obtained from the Heritage Foundation / Wall Street Journal Index of Economic Freedom. http://www.heritage.org.
} 
which would presumably lead to higher levels of trade. ${ }^{56}$ However, empirical evidence has also been presented which suggests that free trade agreement have no effect on trade. $^{57}$

$$
Z_{i j}^{\prime}=\text { is a } 1 \times 4 \text { row vector of time-invariant country-pair-specific variables. }
$$

These include the direct-line distance between capitals. ${ }^{58}$ I include this variable to be consistent with previous literature, which finds the effect to be negative; in general, the greater the distance between two trading partners, the higher transportation costs. In addition, I include a dummy variable indicating a common border. As is standard in the literature, I expect this variable to have a positive impact on trade.

I also include a dummy variable for a communist past. This variable takes on the value of one if both of the trading parties have a communist past and zero otherwise. I expect this variable to be negative; historically communist countries tend to have closed economies as compared to their free market counterparts. A different indictor variable takes on the value of one if both trading partners are not former communist countries, recognizing that free market countries are more open to trade.

The Hausman-Taylor method is an extension of the random-effects estimator (23). The main assumption of the Hausman-Taylor method is that the explanatory variables that are correlated with $\mu_{i j}$ can be identified. Equation (23) is rewritten as follows:

\footnotetext{
${ }^{56}$ See for example, Aitken (1973), Fidrmuc (1999), Frankel, Stein, and Wei (1995), and Yu and Zeitlow (1995).

${ }^{57}$ See for example, Ceglowski (2000).
} 


$$
Y_{i j t}=\alpha_{0}+\beta_{1}^{\prime} X 1_{i j t}+\beta_{2}^{\prime} X 2_{i j t}+\delta_{1} Z_{1_{i j}}+\delta_{2} Z 2_{i j}+\varepsilon_{i j t}+\mu_{i j}
$$

where X1 are the variables that are time-varying and uncorrelated with $\mu_{i j}$; X2 are timevarying and correlated with $\mu_{i j}$; Z1 are time-invariant and uncorrelated with $\mu_{i j}$; and Z2 are time-invariant and correlated with $\mu_{i j}$.

The presence of $\mathrm{X} 2$ and $\mathrm{Z} 2$ is the cause of bias in the random-effects estimator. The strategy proposed by Hausman and Taylor (1981) is to use information already contained in the model to instrument for the problematic variables, X2 and Z2. Hausman and Taylor show that the needed set of instrumental variables can be constructed as follows:

1) The group mean deviations of $X 1$ and $X 2$ can be used as instrumental variables for $\mathrm{X} 1$ and $\mathrm{X} 2$. This is based on the same logic as the fixed-effects estimator. The transformation to deviations from the group means removes the part of the disturbance term that is correlated with X2.

2) By definition, Z1 is uncorrelated with the error term and can therefore be included in the set of instrumental variables.

3) The final set of instrumental variables is the group means of X1. Since X1 is by definition uncorrelated with the error term, the group means of X1 are as

\footnotetext{
${ }^{58}$ These data were obtained from Direct-Line Distances International Edition.
} 
well. In addition, since the group means of X1 do not vary through time they can therefore be used as instruments for Z2. The model is identified as long as the number of variables in $\mathrm{X} 1$ is greater than the number of variables in $\mathrm{Z} 2$.

The selection of the variables that should be included in X2 and Z2 is not obvious. Hausman and Taylor (1981) suggest using economic intuition. For X2, I select the level of trade freedom for both countries. $\mu_{i j}$ is the portion of the error term that contains all country pair specific elements not included in the model, and could easily be correlated with the level of trade freedom. For example, the level of trade freedom could be correlated with other governmental or institutional characteristics that either promote or reduce trade, such as highly stable (or unstable) political systems or closed (open) ideology.

In addition, such factors as the availability of trade credit could substantially affect trade between nations and be correlated with the level of trade freedom. The Linder variable (the absolute value of the difference in GDP per capita) is also included in X2. This variable captures the differences in the wealth of the countries. This variable could be correlated with $\mu_{i j}$ because, for example, countries with similar wealth levels could have similar demographic, geographical, or cultural aspects which are included in $\mu_{i j}$, and not explicitly included in the model. Further, this variable could be correlated with the level of development of infrastructure, consumer preferences, and the ability to obtain hard currency. These are all factors which could determine trade flows, but are not explicitly modeled and are therefore included in the 
error term. The test to detect this correlation is the Hausman-Taylor test. As we will see in the next section, the Hausman-Taylor method allows to eliminate this problematic correlation through the use of instruments already included in the model.

For Z2, I select the communist past dummy and the non-communist past dummy variables. Obviously, there are common characteristics of a communist or noncommunist past that are not explicitly included in the model, such as the presence of informal trade barriers, the lack (or knowledge) of competitive markets, or the presence (or absence) of long standing relationships. These characteristics would be captured in $\mu_{i j}$ and could be correlated with the variables in $\mathrm{Z} 2$.

Therefore, it can be argued that these five variables are the cause of the rejection of the random effects model; each of these variables has the potential to be correlated with other political, social, or economic aspects not included in the model and captured by $\mu_{i j}$.

\section{C. Results}

The results are discussed in three sections. First, I summarize the various economic tests to determine the appropriateness of each of the estimators. Next, the parameter estimates are discussed, and finally, estimates of US-Cuban trade flows are given based on each estimator. 


\section{A. Comparison of the Estimators $=$ Econometric Properties}

Past research has shown that OLS is susceptible to heterogeneity bias. That is, if trading partners are heterogeneous in ways not accounted for in the model, and if that heterogeneity is somehow related to the variables that are included in the regression, then the resulting estimates will be biased. This bias can be detected by examining the model's residuals plotted against the level of trade. These residuals should be white noise, and therefore should be mean zero. For our data, the heterogeneity bias results in residuals which increase with the magnitude of trade flow. At low levels of trade, the residuals are consistently negative (trade is overestimated), and the errors are positive and increasing as trade increases (trade is underestimated). Figure 1 contains the residuals from OLS estimation. When graphed against imports, the residuals form the clear pattern described above. Figure 3 contains the residuals form the random-effects estimator. Although much less obvious, the pattern described above is still evident. In contrast, Figures 2 and 4 contain the residuals from the fixed-effects and HausmanTaylor methods, respectively. It is clear that for each of these estimation techniques, the heterogeneity bias is eliminated and the residuals are white noise.

The next step in selecting the appropriate estimator is to use an F-statistic to test for individual and time effects. If individual effects are present, then OLS is not appropriate and another method that allows for individual effects (fixed-effects, random-effects, or the Hausman-Taylor methods) should be selected. I find strong 
evidence indicating the presence of individual effects. ${ }^{59}$ The results of the F-test and the presence of heterogeneity bias are clear evidence against the use of OLS, suggesting that a more appropriate estimator should allow for individual effects.

Next, I test to determine if there is correlation between included variables in the random-effects model and the error terms. If correlation is detected, the random-effects estimator can be eliminated as a possible estimation technique. First I perform a Hausman (1978) test comparing the fixed and random-effects estimators. ${ }^{60}$ I conclude that there is correlation between the included variables and the error terms, and therefore fixed-effects is a better choice than random-effects.

I then conduct an additional Hausman (1978) test using the fixed-effects and the Hausman-Taylor method to determine if the instrumental variable technique has eliminated the correlation that plagued the random-effects estimator. ${ }^{61}$ I find that the correlation has been removed, and conclude that, of the two alternatives considered here, the Hausman-Taylor estimator is the better choice. That is, the problematic correlation between variables included in the model (X2 and Z2) and the individual component of the error term that introduced bias into the random-effects estimator has been removed through the use of instrumental variables.

\footnotetext{
${ }^{59}$ I use a F[9228,36903] statistic to test if all of the individual effects are equal across groups. The test statistic of 206.44 is far larger than the critical value, and we can conclude that there are indeed individual effects in the data and OLS estimation is not appropriate.

${ }^{60} \mathrm{~A}$ test statistic of 46.03 is far larger than the critical value of a chi-squared with 9 degrees of freedom.
} 


\section{B. Comparison of Parameter Estimates}

Table 3a contains the parameter estimates of the gravity model using the four different estimation techniques (equation 21-24). As expected, the parameter estimates for all the fixed-effects and Hausman-Taylor method are very similar. This confirms that I am able to separate the effects of time-invariant variables using the HausmanTaylor estimator without compromising the parameter estimates of the time-varying variables.

Comparing the parameter estimates for the fixed and random-effects estimators shows that if the random-effects estimator were chosen under the premise that the timeinvariant variables are crucial to the analysis, the time-varying parameter estimates would be compromised; all of the parameter estimates vary substantially.

Further, the Hausman-Taylor method is able to provide statistically significant parameter estimates for two out of the four time-invariant variables. Therefore, I am able to successfully estimate the effect of time-invariant explanatory variables that, under fixed-effects estimation, would be consolidated in the country-specific constant term.

In addition, it is of particular interest to note that in my out-of-sample approach, the distance variable is not statistically significant. This is consistent with the results of Egger (2002) who also finds the effect of distance (as measure by physical distance between capitals) to be insignificant in his critique of the in-sample trade projection

\footnotetext{
${ }^{61} \mathrm{~A}$ test statistic of 13.62 (less than the critical value of 16.92) indicates the hypothesis that the individual effects are uncorrelated with the other regressors in the model cannot be rejected.
} 
approach. These results clearly call into question the use of this type of measure in gravity-model estimation. As explored in Trumbull (2001):

\begin{abstract}
Why is DISTANCE the distance between New York City and the major city in the trading partner? Is all trade with all countries conducted through New York? Much of U.S. trade with Europe may be, but is trade with Mexico? What about Asia? I suspect that for Mexico and Asia, the distance measure may be off by a whole continent. Would Cuba's trade be with New York or Miami? This has to be biasing the results. The geographic center of the U.S. might make more sense (except for Europe), but even this would be unsatisfactory, for it is not geographic distance that matters but some measure of economic distance. Los Angeles is 1,300 kilometers further from Tokyo than is Moscow, but the economic distance is surely much closer.
\end{abstract}

Although the above is a criticism of a study which used the distance between the economic centers of country pairs to measure distance, the same criticism holds (and my be magnified) in using the capitals of countries to measure distance. This issue is addressed by the inclusion of variables such as the Linder variable and the use of the trade freedom index (and absolute value in the difference in the trade freedom indexes of the trading partners). These variables capture economic, political, and cultural differences, and prove to be much better determinates of trade when the model is correctly estimated. $^{62}$

It is also interesting to note that membership in a preferential trading agreement has a statistically significant effect for the OLS and random-effects methods, but not for

\footnotetext{
${ }^{62}$ Although the results presented here support the Linder Hypothesis, it should be noted others have found contradictory results when the role of transportation costs are introduced into the model. See, for example, Deardorff (1984).
} 
the Hausman-Taylor or fixed-effects methods. In many cases, countries that enter a preferential trading agreement have similar characteristics. In the random-effects and OLS specifications, this variable may be capturing effects that are included in the individual effects in the properly specified models (fixed-effects and Hausman-Taylor methods).

\section{Trade Flow Estimates}

I apply the out-of-sample technique to calculate trade flow potentials for US and Cuba. This method is straightforward for the OLS, random-effects, and HausmanTaylor estimators and is calculated as follows:

$$
\hat{Y}_{i j t}=\hat{\alpha}_{0}+\hat{\beta}^{\prime} X_{i j t}+\hat{\delta}^{\prime} Z_{i j}
$$

where the $\hat{\alpha}, \hat{\beta}^{\prime}$, and $\hat{\delta}^{\prime}$ are the coefficient estimates and $\hat{Y}$ is the predicted value of $Y$. The coefficient estimates for OLS and random-effects have been shown to be biased; however, the Hausman-Taylor estimates are not and I am therefore able to use the outof-sample method of trade projections and include time-invariant variables.

In the case of the fixed-effects estimator, the approach is much more complex, and relies on the ad hoc assignment of an individual dummy variable for the US -Cuba trading pairs. The trade flow estimate is achieved as follows:

$$
\hat{Y}_{i j t}=\hat{\alpha}_{i j}+\hat{\alpha}_{0}+\hat{\beta}^{\prime} X_{i j t}
$$

The constants from equation (26) can be recovered using the OLS normal equations as follows: 


$$
\begin{gathered}
\hat{\alpha}_{0}=\overline{\bar{Y}}-\overline{\overline{X^{\prime}} \beta} \\
\hat{\alpha}_{i j}=\left(\overline{Y_{i j}}-\overline{\bar{Y}}\right)-\left(\overline{X_{i j}}-\overline{\bar{X}}\right)
\end{gathered}
$$

where the individual specific mean is $\overline{Y_{i j}}=\frac{1}{n} \sum_{t=1}^{T} Y_{i j t}$; and the overall mean is $\overline{\bar{Y}}=\frac{1}{n T} \sum_{i j=1}^{n} \sum_{t=1}^{T} Y_{i j t}$. The same notation is followed for X. All of the needed information is present in the data set except for $\overline{Y_{i j}}$. for Cuba. As a proxy, I substitute the individualspecific mean for the Dominican Republic, the country that arguably most closely matches Cuba. This underscores the ad hoc nature using the out-of-sample method with the fixed-effects estimator.

Table 3b contains the trade-flow estimates for each technique, along with the 95 percent confidence interval for the estimation. ${ }^{63}$ The OLS and random-effects estimates are very similar, and tend to be less than those of fixed-effects and Hausman-Taylor estimates. Although the parameter estimates are very similar for the fixed-effects and Hausman-Taylor estimates, the trade projections are quite different. This highlights the benefits of using the Hausman-Taylor method, which yields a more precise estimate than fixed-effects due to the inclusion of more explanatory variables. In addition, the Hausman-Taylor method does not require an ad hoc specification of the individualspecific constant term for Cuba.

Table 3c places the trade-potential projections in both historical and regional

\footnotetext{
${ }^{63}$ A confidence interval is not included for the fixed-effects estimator projection due to the ad hoc estimation procedure.
} 
perspectives. The trade flow percentages included in this table are based on the assumption that 50 percent of the trade projected between the US and Cuba would displace existing Cuban trade. ${ }^{64}$ In the case of imports, the OLS and random-effects estimators consistently underestimate the US-Cuban trade flow (48 percent) as compared to the historical US-Cuban trading pattern (70 percent) and that of the Dominican Republic (62 percent), the country most like Cuba in the region. The projections based on fixed-effects estimation (72 percent) seem to be more reasonable, but overestimate the level of imports. On the other hand, the Hausman-Taylor method produces estimates that are nearly identical to regional trading patterns (65 percent compared to 62 percent for the Dominican Republic) and very similar to the historical US-Cuban relationship.

In terms of Cuban export projections, each of the estimation techniques produce estimates that are reasonably close to those of the regional trading patterns and the historical relation between the US and Cuba. However, the fixed-effects and HausmanTaylor estimators produce projections considerably higher than those of the OLS and the random-effects estimators.

It is important to keep in mind that the Hausman-Taylor and the fixed-effects methods are the only estimators that properly model the individual effects in the data. The consistently lower projections of the OLS and random-effects estimators may be

\footnotetext{
${ }^{64}$ For reference, Appendix 3b contains the percentages of trade that would be with the US assuming various level of displacement. Determining the amount of trade that would be displaced by US trade is a complicated issue, and beyond the scope of this paper. The USITC, Economic Impact of U.S. Sanctions
} 
due to the various forms of bias introduced with these methods. Based on the historical Cuban data and trading patterns of the region (especially the Dominican Republic), I conclude that the Hausman-Taylor estimator produces the most plausible trade potential predictions. In addition, the Hausman-Taylor method is the only estimator with projections that are reasonable for both imports and exports.

\section{D. Conclusion}

In my analysis, I compare several methods for estimating the unrealized USCuban trade potential in the context of the gravity model of trade. I find the seldomused Hausman-Taylor method to be the superior choice for estimating trade flows using the out-of-sample approach. The Hausman-Taylor method is ideal because it allows for the inclusion of time-invariant variables in trade projections and circumvents the problem of an ad hoc estimation of the country-specific dummy variable needed for a projection based on the fixed-effects estimator. In addition, based on a Hausman (1978) specification test comparing the Hausman-Taylor method and the fixed-effects estimator, the Hausman-Taylor method proved to be a superior specification given these data. Examining the trade-potential projections of the various estimators in both historical and regional contexts, it is clear that the Hausman-Taylor estimator produces more plausible projections than the OLS, random-effects, and fixed-effects estimators. This result holds for both Cuban imports and exports.

with Respect to Cuba, circumvented this issue with the ad hoc assumption that US-Cuban trade should be restricted to a percentage of current Cuban trade levels. 
It is interesting that my results, as do those of Egger (2002), call into question the use of physical distance in the gravity model. The use of the distance between the capitals or economic centers of two countries does not seem to reflect important issues involved in the likelihood of trade, such as transportation costs and political environment.

An issue that was not addressed in this study is the amount of trade displacement that would occur if the US-Cuban trading relationship were based on economic fundamentals and not political factors. That is, to what extent would free trade between the US and Cuba merely substitute for trade already occurring with Europe? I leave this topic for future research. 


\section{Conclusion}

The study of empirical trade estimation has been a staple in international economics literature since the early 1960s. I focus on three current topics in empirical trade estimation. In chapter 1, I use a time-series approach and in the context of the effect of exchange-rate volatility on trade, provide both theoretical and empirical explanations for positive volatility effects. My results show a clear pattern; when the effect of exchange-rate uncertainty on trade volume is positive [negative] for importers, the effect for exporters is negative [positive]. In addition, the U.K. provides evidence that trade balance is an important factor in determining the effect of volatility. If changes in the sign of trade balance are not taken into account, the effect of volatility may go undetected. Finally, the sensitivity of imports and exports to exchange-rate volatility is affected similarly by changes in market conditions; trade is more sensitive to volatility when the trade terms are expected to improve.

In chapter 2, I turn to cross-sectional analysis and the use of the gravity model in empirical trade estimation. Following a growing trend in the literature, I examine the impact of adding non-standard variables, ones that measure cultural or ideological differences, to the basic gravity model. In the context of United States trade with Latin America, I find that in certain instances, informal barriers to trade may exist.

Specifically, I show that in the case of Brazil, Nicaragua, and El Salvador, as the number of foreign-born peoples in the United States increases, U.S. exports to their country of origin increases. This finding sheds important light on the fact that the 
determinants of trade may go beyond standard economic and descriptive variables.

In Chapter 3, I expand the literature concerning the correct estimation of technique for the gravity model. I provide evidence that when time-invariant variables are of interest, the Hausman-Taylor estimation technique should be considered. In this specific application, the Hausman-Taylor method for estimating the unrealized USCuban trade potential outperformed the OLS, fixed-effects, and random-effects methods using the out-of-sample approach. The Hausman-Taylor method is ideal because it allows for the inclusion of time-invariant variables in trade projections and circumvents the problem of an ad hoc estimation of the country-specific dummy variable needed for a projection based on the fixed-effects estimator. In addition, it removes the correlation between the error term and included variables which often plagues random-effects estimation. 


\section{Tables}

Table 1a. United Kingdom parameter estimates

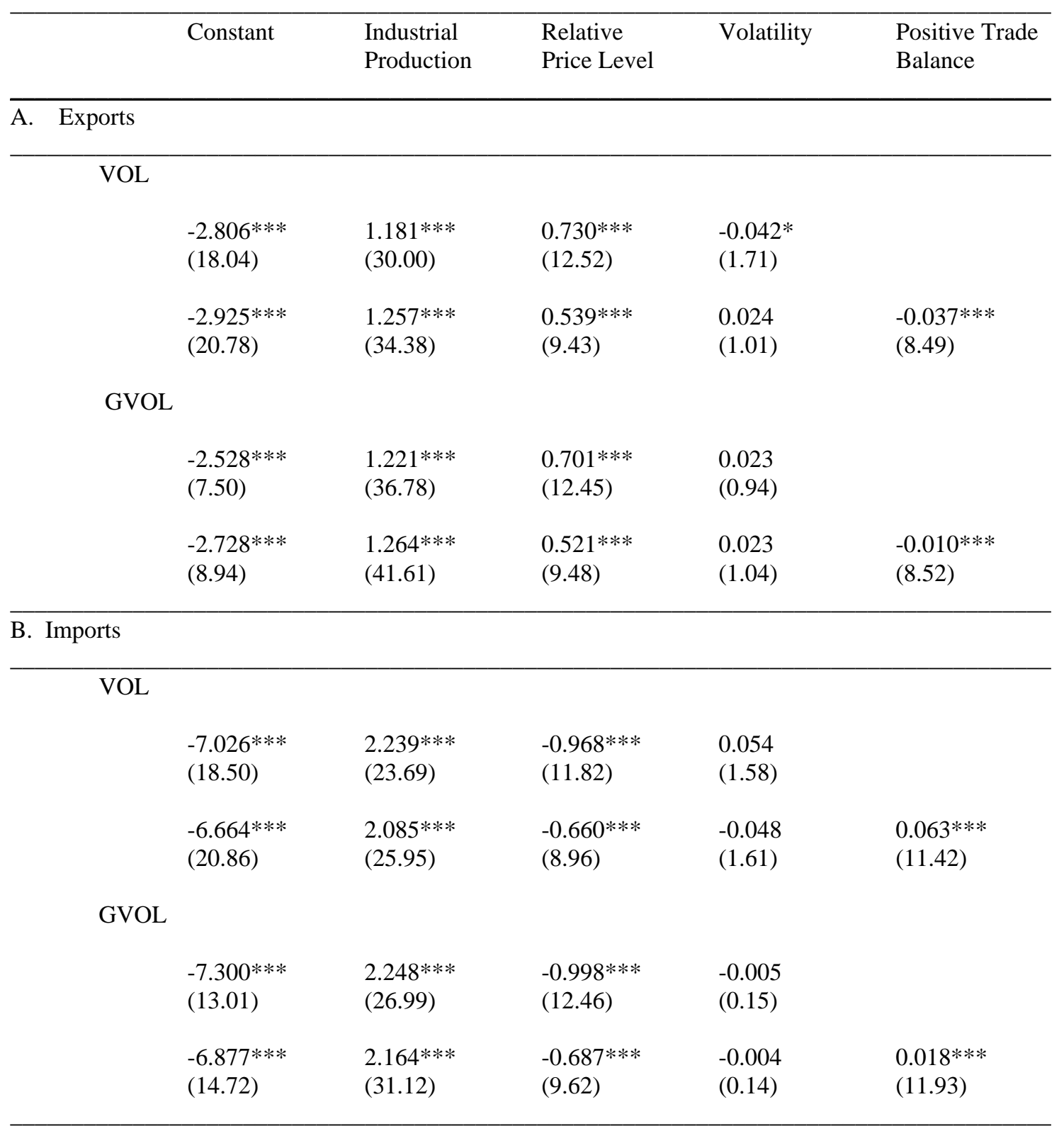

*** denotes significance at the $1 \%$ level

** denotes significance at the $5 \%$ level

*denotes significance at the $10 \%$ level 
Table 1b. Parameter estimates

Country

Constant

Industrial

Relative

Volatility

Positive

Production

Price Level

Trade

Balance

A. Canada

Exports

$-1.572 * * *$

$1.390 * * *$

$1.004 * * *$

$0.034 * *$

NA

(Pre-NAFTA)

(7.57)

(30.70)

(14.56)

(2.12)

(Post-NAFTA)

$-1.191 * * *$

$1.308 * * *$

0.233

(1.49)

$0.031^{*}$

$(2.72)$

(12.65)

$-1.480 * * *$

$0.045^{* * *}$

NA

Imports

$-2.731 * * *$
$(10.05)$

$1.614^{* * *}$

(22.39)

(2.76)

(Post-NAFTA)

$-18.17 * * *$

4.919***

$-1.275^{* * *}$

$-0.042 *$

(1.99)

B. Germany

(10.62)

(12.96)

(7.35)

NA

Exports

$-4.108 * * *$

$1.513^{* * *}$

$0.407 * * *$

$-0.068 * * *$

(10.95)

(3.20)

(GVOL)

$-3.210 * * *$

$1.492 * * *$

$0.367 * * *$

0.044

(10.04)

(1.40)

Imports

$-9.065 * * *$

$2.820 * * *$

$-1.205 * * *$

$0.155^{* * *}$

(27.54)

(6.23)

(GVOL)

$-9.239 * * *$

$2.967 * * *$

$-1.250 * * *$

$0.084 * *$

NA

C. Japan

(14.75)

(30.89)

(28.98)

(2.19)

Exports

0.749*

$0.966 * * *$

$0.376^{* * *}$

$-0.101 * * *$

NA

(1.89)

(21.17)

(8.53)

(4.79)

Imports

$-4.529 * * *$

2.370 ***

$-0.753^{* * *}$

$0.176^{* * *}$

NA

D. United Kingdom

(4.83)

(15.93)

(9.31)

(5.22)

Exports

$-2.925 * * *$

$1.257^{* * *}$

0.539***

0.024

(9.43)

(1.01)

$-0.04 * * *$

(VOL)

$-2.728 * * *$

$1.264 * * *$

$0.521^{* * * *}$

0.023

(9.48)

(1.04)

$-0.01 * * *$

(8.94)

(41.61)

$-0.660 * * *$

$-0.048$

Imports

$-6.664 * * *$

$2.085 * * *$

(8.96)

(1.61)

0.06***

(20.86) (25.95)

$-0.687 * * *$

$-0.004$

(11.42)

(GVOL)

$-6.877 * * *$
$(14.72)$

2.164***

(9.62)

(0.14)

$0.02 * * *$

(11.93)

*** denotes significance at the $1 \%$ level

** denotes significance at the 5\% level

*denotes significance at the $10 \%$ level 
Table 1c. Import parameter estimates

\begin{tabular}{lllll}
\hline Country & Constant & $\begin{array}{l}\text { Industrial } \\
\text { Production }\end{array}$ & $\begin{array}{l}\text { Relative } \\
\text { Price Level }\end{array}$ & Volatility \\
\hline A. Canada & & & & \\
Full sample & $-1.274^{* * *}$ & $1.248^{* * *}$ & $-1.185^{* * *}$ & $-0.042^{* * *}$ \\
& $(4.61)$ & $(23.11)$ & $(19.16)$ & $(2.81)$ \\
Sub-sample 1 & $-1.426^{* * *}$ & $1.257^{* * *}$ & $-1.259^{* * *}$ & $-0.061^{* * *}$ \\
& $(3.93)$ & $(17.27)$ & $(13.65)$ & $(3.24)$ \\
Sub-sample 2 & & & & -0.006 \\
& $-1.088^{* *}$ & $1.246^{* * *}$ & $-1.158^{* * *}$ & $(0.19)$
\end{tabular}

B. Germany

\begin{tabular}{|c|c|c|c|c|}
\hline Full sample & $\begin{array}{l}-2.430 * * * \\
(6.26)\end{array}$ & $\begin{array}{l}1.300^{* * *} \\
(13.44)\end{array}$ & $\begin{array}{l}-0.891 * * * \\
(15.05)\end{array}$ & $\begin{array}{l}0.046 \\
(1.24)\end{array}$ \\
\hline Sub-sample 1 & $\begin{array}{l}-2.406 * * * \\
(4.96)\end{array}$ & $\begin{array}{l}1.326 * * * \\
(10.89)\end{array}$ & $\begin{array}{l}-0.780 * * * \\
(10.23)\end{array}$ & $\begin{array}{l}0.081 * \\
(1.72)\end{array}$ \\
\hline Sub-sample 2 & $\begin{array}{l}-2.785^{* * *} \\
(4.43)\end{array}$ & $\begin{array}{l}1.372^{* * *} \\
(8.71)\end{array}$ & $\begin{array}{l}-0.929 * * * \\
(9.93)\end{array}$ & $\begin{array}{l}0.046 \\
(0.76)\end{array}$ \\
\hline Full sample & $\begin{array}{l}5.354^{* * *} \\
(19.30)\end{array}$ & $\begin{array}{l}0.181^{* * *} \\
(5.43)\end{array}$ & $\begin{array}{l}-0.705 * * * \\
(22.15)\end{array}$ & $\begin{array}{l}0.086 * * * \\
(4.44)\end{array}$ \\
\hline Sub-sample 1 & $\begin{array}{l}5.450 * * * \\
(15.23)\end{array}$ & $\begin{array}{l}0.148^{* * * *} \\
(3.34)\end{array}$ & $\begin{array}{l}-0.713 * * * \\
(16.78)\end{array}$ & $\begin{array}{l}0.097 * * * \\
(3.69)\end{array}$ \\
\hline Sub-sample 2 & $\begin{array}{l}5.220 * * * \\
(11.47)\end{array}$ & $\begin{array}{l}0.208^{* * * *} \\
(3.84)\end{array}$ & $\begin{array}{l}-0.706 * * * \\
(13.92)\end{array}$ & $\begin{array}{l}0.080 * * \\
(2.54)\end{array}$ \\
\hline
\end{tabular}

D. United Kingdom

$\begin{array}{lllll}\text { Full sample } & \begin{array}{l}-2.589 * * * \\ (12.40)\end{array} & \begin{array}{l}1.243^{* * *} \\ (21.18)\end{array} & \begin{array}{l}-1.146 * * * \\ (19.47)\end{array} & \begin{array}{l}0.012 \\ (0.56)\end{array} \\ \text { Sub-sample 1 } & \begin{array}{l}\text {-2.906*** } \\ (11.35)\end{array} & \begin{array}{l}1.339 * * * \\ (19.23)\end{array} & \begin{array}{l}-1.137 * * * \\ (15.29)\end{array} & \begin{array}{l}0.047^{*} \\ (1.70)\end{array} \\ & & & & \\ \text { Sub-sample 2 } & -2.055^{* * *} & 1.089 * * * & -1.105^{* * *} & -0.025 \\ & (5.77) & (10.44) & (11.58) & (0.50)\end{array}$

*** denotes significance at the $1 \%$ level

** denotes significance at the 5\% level

*denotes significance at the $10 \%$ level 
Table 1d. Export parameter estimates

\begin{tabular}{|c|c|c|c|c|}
\hline Country & Constant & $\begin{array}{l}\text { Industrial } \\
\text { Production }\end{array}$ & $\begin{array}{l}\text { Relative } \\
\text { Price Level }\end{array}$ & Volatility \\
\hline \multicolumn{5}{|l|}{ A. Canada } \\
\hline Full sample & $\begin{array}{l}-3.812^{* * *} \\
(9.37)\end{array}$ & $\begin{array}{l}1.961^{* * *} \\
(23.59)\end{array}$ & $\begin{array}{l}0.917 * * * \\
(11.44)\end{array}$ & $\begin{array}{l}0.069^{* * * *} \\
(3.85)\end{array}$ \\
\hline Sub-sample 1 & $\begin{array}{l}-3.930 * * * \\
(6.10)\end{array}$ & $\begin{array}{l}2.022 * * * \\
(15.73)\end{array}$ & $\begin{array}{l}0.894 * * * \\
(8.11)\end{array}$ & $\begin{array}{l}0.109 * * * \\
(3.19)\end{array}$ \\
\hline Sub-sample 2 & $\begin{array}{l}-3.641^{* * *} \\
(6.13)\end{array}$ & $\begin{array}{l}1.909 * * * \\
(15.32)\end{array}$ & $\begin{array}{l}0.917 * * * \\
(6.81)\end{array}$ & $\begin{array}{l}0.051^{*} \\
(1.92)\end{array}$ \\
\hline \multicolumn{5}{|l|}{ B. Germany } \\
\hline Full sample & $\begin{array}{l}-8.715^{* * *} \\
(11.37)\end{array}$ & $\begin{array}{l}2.468 * * * \\
(15.13)\end{array}$ & $\begin{array}{l}0.279 * * * \\
(4.76)\end{array}$ & $\begin{array}{l}-0.101^{* * *} \\
(3.41)\end{array}$ \\
\hline Sub-sample 1 & $\begin{array}{l}-10.462 * * * \\
(8.93)\end{array}$ & $\begin{array}{l}2.820 * * * \\
(11.15)\end{array}$ & $\begin{array}{l}0.256^{* * *} \\
(3.10)\end{array}$ & $\begin{array}{l}-0.140^{* * *} \\
(3.17)\end{array}$ \\
\hline Sub-sample 2 & $\begin{array}{l}-7.434^{* * *} \\
(6.45)\end{array}$ & $\begin{array}{l}2.233^{* * * *} \\
(9.08)\end{array}$ & $\begin{array}{l}0.304^{* * *} \\
(3.31)\end{array}$ & $\begin{array}{l}-0.048 \\
(1.08)\end{array}$ \\
\hline \multicolumn{5}{|l|}{ C. Japan } \\
\hline Full sample & $\begin{array}{l}-3.380^{* * *} \\
(5.77)\end{array}$ & $\begin{array}{l}2.013 * * * \\
(19.62)\end{array}$ & $\begin{array}{l}0.428^{* * *} \\
(8.79)\end{array}$ & $\begin{array}{l}0.032 \\
(1.05)\end{array}$ \\
\hline Sub-sample 1 & $\begin{array}{l}-2.428 * * * \\
(2.71)\end{array}$ & $\begin{array}{l}1.890^{* * *} \\
(12.20)\end{array}$ & $\begin{array}{l}0.488^{* * * *} \\
(6.70)\end{array}$ & $\begin{array}{l}0.083^{*} \\
(1.80)\end{array}$ \\
\hline Sub-sample 2 & $\begin{array}{l}-4.132 * * * \\
(5.04)\end{array}$ & $\begin{array}{l}2.114^{* * *} \\
(14.22)\end{array}$ & $\begin{array}{l}0.376^{* * * *} \\
(5.73)\end{array}$ & $\begin{array}{l}0.012 \\
(0.30)\end{array}$ \\
\hline \multicolumn{5}{|l|}{ D. United Kingdom } \\
\hline Full sample & $\begin{array}{l}-10.731^{* * *} \\
(13.91)\end{array}$ & $\begin{array}{l}2.955^{* * * *} \\
(15.32)\end{array}$ & $\begin{array}{l}0.362 * * * \\
(3.81)\end{array}$ & $\begin{array}{l}-0.038 \\
(1.19)\end{array}$ \\
\hline Sub-sample 1 & $\begin{array}{l}-10.450 * * * \\
(9.90)\end{array}$ & $\begin{array}{l}2.826 * * * \\
(10.57)\end{array}$ & $\begin{array}{l}0.511 * * * \\
(4.02)\end{array}$ & $\begin{array}{l}-0.072 \\
(1.63)\end{array}$ \\
\hline Sub-sample 2 & $\begin{array}{l}-10.614^{* * *} \\
(9.29)\end{array}$ & $\begin{array}{l}2.952^{* * *} \\
(10.49)\end{array}$ & $\begin{array}{l}0.243^{*} \\
(1.71)\end{array}$ & $\begin{array}{l}-0.037 \\
(0.78)\end{array}$ \\
\hline
\end{tabular}

*** denotes significance at the $1 \%$ level

** denotes significance at the $5 \%$ level

*denotes significance at the $10 \%$ level 
Table 2a. Parameter Estimates by Country

\begin{tabular}{|c|c|c|c|c|c|c|c|}
\hline Country & Per Capita GSP & Per Capita GDP & Country Pop. & State Pop. & Freedom Index & Foreign Born & \\
\hline & & & & & & FB1 & FB2 \\
\hline Panel A. & & & & & & & \\
\hline Latin America & $\begin{array}{l}-1.06 \\
(1.28)\end{array}$ & $\begin{array}{l}0.10 \\
(0.53)\end{array}$ & $\begin{array}{l}1.83^{*} \\
(1.70)\end{array}$ & $\begin{array}{l}3.59 * * * \\
(3.43)\end{array}$ & $\begin{array}{l}1.33 * * * \\
(5.94)\end{array}$ & $\begin{array}{l}0.23^{* * *} \\
(3.31)\end{array}$ & NA \\
\hline Panel $B$. & & & & & & & \\
\hline Argentina & $\begin{array}{l}-1.36 \\
(1.57)\end{array}$ & $\begin{array}{l}0.11 \\
(0.54)\end{array}$ & $\begin{array}{l}2.90 * * \\
(2.50)\end{array}$ & $\begin{array}{l}3.87 * * * \\
(3.57)\end{array}$ & $\begin{array}{l}1.20^{* * *} \\
(5.19)\end{array}$ & $\begin{array}{l}0.25 * * * \\
(3.59)\end{array}$ & $\begin{array}{l}0.11 \\
(0.26)\end{array}$ \\
\hline Bolivia & $\begin{array}{l}-1.32 \\
(1.53)\end{array}$ & $\begin{array}{l}0.00 \\
(0.01)\end{array}$ & $\begin{array}{l}2.57^{* *} \\
(0.28)\end{array}$ & $\begin{array}{l}3.91^{* * *} \\
(3.62)\end{array}$ & $\begin{array}{l}1.33^{* * *} \\
(5.94)\end{array}$ & $\begin{array}{l}0.19 * * * \\
(2.74)\end{array}$ & $\begin{array}{l}0.45 \\
(1.37)\end{array}$ \\
\hline Brazil & $\begin{array}{l}-0.64 \\
(0.75)\end{array}$ & $\begin{array}{l}0.41^{*} \\
(1.72)\end{array}$ & $\begin{array}{l}2.70 * * \\
(2.40)\end{array}$ & $\begin{array}{l}3.30 * * * \\
(3.05)\end{array}$ & $\begin{array}{l}1.19 * * * \\
(5.14)\end{array}$ & $\begin{array}{l}0.17 * * \\
(2.43)\end{array}$ & $\begin{array}{l}1.27 * * * \\
(3.38)\end{array}$ \\
\hline Chile & $\begin{array}{l}-0.91 \\
(1.05)\end{array}$ & $\begin{array}{l}0.09 \\
(0.43)\end{array}$ & $\begin{array}{l}1.92 * \\
(1.71)\end{array}$ & $\begin{array}{l}3.43^{* * *} \\
(3.15)\end{array}$ & $\begin{array}{l}1.35^{* * *} \\
(5.89)\end{array}$ & $\begin{array}{l}0.25 * * * \\
(3.44)\end{array}$ & $\begin{array}{l}-0.10 \\
(0.34)\end{array}$ \\
\hline Colombia & $\begin{array}{l}-0.77 \\
(0.90)\end{array}$ & $\begin{array}{l}0.10 \\
(0.53)\end{array}$ & $\begin{array}{l}1.76^{*} \\
(1.65)\end{array}$ & $\begin{array}{l}3.06^{* * *} \\
(2.84)\end{array}$ & $\begin{array}{l}1.31 * * * \\
(5.82)\end{array}$ & $\begin{array}{l}0.24 * * * \\
(3.53)\end{array}$ & $\begin{array}{l}-0.71 \\
(1.41\end{array}$ \\
\hline Costa Rica & $\begin{array}{l}-1.35 \\
(1.58)\end{array}$ & $\begin{array}{l}-0.04 \\
(0.17)\end{array}$ & $\begin{array}{l}1.50 \\
(1.39)\end{array}$ & $\begin{array}{l}3.54 * * * \\
(3.29)\end{array}$ & $\begin{array}{l}1.46^{* * *} \\
(6.24)\end{array}$ & $\begin{array}{l}0.27 * * * \\
(3.74)\end{array}$ & $\begin{array}{l}-0.11 \\
(0.44)\end{array}$ \\
\hline Dominion Rep. & $\begin{array}{l}-1.17 \\
(1.37)\end{array}$ & $\begin{array}{l}0.15 \\
(0.72)\end{array}$ & $\begin{array}{l}1.63 \\
(1.50)\end{array}$ & $\begin{array}{l}3.50^{* * *} \\
(3.25)\end{array}$ & $\begin{array}{l}1.35^{* * *} \\
(6.00)\end{array}$ & $\begin{array}{l}0.25 * * * \\
(3.58)\end{array}$ & $\begin{array}{l}-0.22 \\
(-0.74)\end{array}$ \\
\hline Ecuador & $\begin{array}{l}-1.35 \\
(1.58)\end{array}$ & $\begin{array}{l}-0.10 \\
(0.44)\end{array}$ & $\begin{array}{l}2.17 * * \\
(2.00)\end{array}$ & $\begin{array}{l}3.98^{* * *} \\
(3.69)\end{array}$ & $\begin{array}{l}1.23^{* * *} \\
(5.28)\end{array}$ & $\begin{array}{l}0.23^{* * *} \\
(3.27)\end{array}$ & $\begin{array}{l}0.23 \\
(0.89)\end{array}$ \\
\hline El Salvador & $\begin{array}{l}-1.25 \\
(0.85)\end{array}$ & $\begin{array}{l}0.24 \\
(1.18)\end{array}$ & $\begin{array}{l}1.85^{*} \\
(1.72)\end{array}$ & $\begin{array}{l}4.00 * * * \\
(3.71)\end{array}$ & $\begin{array}{l}1.43^{* * * *} \\
(6.28)\end{array}$ & $\begin{array}{l}0.25^{* * * *} \\
(3.40)\end{array}$ & $\begin{array}{l}0.36^{*} \\
(1.66)\end{array}$ \\
\hline
\end{tabular}


Table 2a. Parameter Estimates by Country (CONT)

\begin{tabular}{|c|c|c|c|c|c|c|c|}
\hline Country & Per Capita GSP & Per Capita GDP & Country Pop. & State Pop. & Freedom Index & Foreign Born & \\
\hline & & & & & & FB1 & FB2 \\
\hline Honduras & $\begin{array}{l}-0.47 \\
(0.56)\end{array}$ & $\begin{array}{l}0.15 \\
(0.78)\end{array}$ & $\begin{array}{l}0.72 \\
(0.58)\end{array}$ & $\begin{array}{l}3.03^{* * *} \\
(2.81)\end{array}$ & $\begin{array}{l}1.40 * * * \\
(6.17)\end{array}$ & $\begin{array}{l}0.20 * * * \\
(2.76)\end{array}$ & $\begin{array}{l}0.39 \\
(1.42)\end{array}$ \\
\hline Mexico & $\begin{array}{l}-1.05 \\
(-1.22)\end{array}$ & $\begin{array}{l}0.03 \\
(0.14)\end{array}$ & $\begin{array}{l}2.63 * * \\
(2.35)\end{array}$ & $\begin{array}{l}3.74 * * * \\
(3.44)\end{array}$ & $\begin{array}{l}1.50 * * * \\
(6.42)\end{array}$ & $\begin{array}{l}0.17 * * \\
(2.26)\end{array}$ & $\begin{array}{l}0.15 \\
(0.64)\end{array}$ \\
\hline Nicaragua & $\begin{array}{l}-1.12 \\
(1.34)\end{array}$ & $\begin{array}{l}0.14 \\
(0.73)\end{array}$ & $\begin{array}{l}-1.54 \\
(1.14)\end{array}$ & $\begin{array}{l}3.67 * * * \\
(3.50)\end{array}$ & $\begin{array}{l}0.53^{*} \\
(1.82)\end{array}$ & $\begin{array}{l}0.23^{* * *} \\
(3.39)\end{array}$ & $\begin{array}{l}1.31 * * * \\
(3.00)\end{array}$ \\
\hline Panama & $\begin{array}{l}-0.92 \\
(1.06)\end{array}$ & $\begin{array}{l}0.10 \\
(0.52)\end{array}$ & $\begin{array}{l}1.82^{*} \\
(1.68)\end{array}$ & $\begin{array}{l}3.47 * * * \\
(3.19)\end{array}$ & $\begin{array}{l}1.32 * * * \\
(5.79)\end{array}$ & $\begin{array}{l}0.22 * * * \\
(3.07)\end{array}$ & $\begin{array}{l}0.35 \\
(0.74)\end{array}$ \\
\hline Peru & $\begin{array}{l}-1.19 \\
(1.40)\end{array}$ & $\begin{array}{l}0.04 \\
(0.19)\end{array}$ & $\begin{array}{l}1.33 \\
(1.24)\end{array}$ & $\begin{array}{l}3.66 * * * \\
(3.44)\end{array}$ & $\begin{array}{l}1.80 * * * \\
(7.10)\end{array}$ & $\begin{array}{l}0.25 * * * \\
(3.57)\end{array}$ & $\begin{array}{l}-0.00 \\
(0.00)\end{array}$ \\
\hline Venezuela & $\begin{array}{l}-1.07 \\
(1.24)\end{array}$ & $\begin{array}{l}0.20 \\
(1.00)\end{array}$ & $\begin{array}{l}2.00^{*} \\
(1.86)\end{array}$ & $\begin{array}{l}3.73 * * * \\
(3.44)\end{array}$ & $\begin{array}{l}1.20 * * * \\
(5.14)\end{array}$ & $\begin{array}{l}0.24 * * * \\
(3.38)\end{array}$ & $\begin{array}{l}-0.15 \\
(0.44)\end{array}$ \\
\hline \multicolumn{8}{|l|}{ Panel C. } \\
\hline & & & & & & $\mathrm{RC}$ & ESNB \\
\hline Robustness & $\begin{array}{l}-0.55 \\
(0.61)\end{array}$ & $\begin{array}{l}0.50 * * \\
(2.01)\end{array}$ & $\begin{array}{l}0.49 * \\
(0.33)\end{array}$ & $\begin{array}{l}3.67 * * * \\
(3.23)\end{array}$ & $\begin{array}{l}0.51 \\
(1.60)\end{array}$ & $\begin{array}{l}0.03 \\
(0.48)\end{array}$ & $\begin{array}{l}0.71^{* * *} \\
(4.24)\end{array}$ \\
\hline
\end{tabular}

*** denotes significance at the $1 \%$ level

** denotes significance at the $5 \%$ level

*denotes significance at the $10 \%$ level 
Table 3a. Parameter Estimates

\begin{tabular}{|c|c|c|c|c|}
\hline & OLS & Random Effects & Fixed Effects & HTM \\
\hline Constant & $\begin{array}{l}-498,047 * * * \\
(3.60)\end{array}$ & $\begin{array}{l}-307,484 * * \\
(2.31)\end{array}$ & NA & $\begin{array}{l}-12,298 * * \\
(2.27)\end{array}$ \\
\hline Per capita GDP 1 & $\begin{array}{l}124.91 * * * \\
(44.27)\end{array}$ & $\begin{array}{l}107.20 * * * \\
(31.41)\end{array}$ & $\begin{array}{l}92.48^{* * * *} \\
(20.09)\end{array}$ & $\begin{array}{l}90.66 * * * \\
(21.30)\end{array}$ \\
\hline Per capita GDP 2 & $\begin{array}{l}126.79 * * * \\
(44.97)\end{array}$ & $\begin{array}{l}87.83 * * * \\
(25.73)\end{array}$ & $\begin{array}{l}57.47 * * * \\
(12.48)\end{array}$ & $\begin{array}{l}57.23 * * * \\
(13.43)\end{array}$ \\
\hline Population 1 & $\begin{array}{l}2.29 * * * \\
(19.43)\end{array}$ & $\begin{array}{l}2.90 * * * \\
(11.77)\end{array}$ & $\begin{array}{l}9.35 * * * \\
(10.49)\end{array}$ & $\begin{array}{l}8.28 * * * \\
(11.94)\end{array}$ \\
\hline Population 2 & $\begin{array}{l}2.21 * * * \\
(18.76)\end{array}$ & $\begin{array}{l}2.70 * * * \\
(10.95)\end{array}$ & $\begin{array}{l}8.45 * * * \\
(9.47)\end{array}$ & $\begin{array}{l}7.70 * * * \\
(11.172)\end{array}$ \\
\hline Trade Freedom Index 1 & $\begin{array}{l}2,551 \\
(0.130)\end{array}$ & $\begin{array}{l}-574.49 \\
(0.07)\end{array}$ & $\begin{array}{l}2,141 \\
(0.29)\end{array}$ & $\begin{array}{l}2,110 \\
(0.31)\end{array}$ \\
\hline Trade Freedom Index 2 & $\begin{array}{l}23,778 \\
(1.22)\end{array}$ & $\begin{array}{l}-4,656 \\
(0.64)\end{array}$ & $\begin{array}{l}1,112 \\
(0.15)\end{array}$ & $\begin{array}{l}531.46 \\
(0.08)\end{array}$ \\
\hline $\begin{array}{l}\text { Preferential Trading } \\
\text { Agreement }\end{array}$ & $\begin{array}{l}542,381 * * * \\
(7.57)\end{array}$ & $\begin{array}{l}99,771^{* *} \\
(2.36)\end{array}$ & $\begin{array}{l}40,184 \\
(0.92)\end{array}$ & $\begin{array}{l}49,566 \\
(1.22)\end{array}$ \\
\hline $\begin{array}{l}\text { Abs value in the diff. } \\
\text { of trade freedom index }\end{array}$ & $\begin{array}{l}44,480 * * \\
(2.42)\end{array}$ & $\begin{array}{l}-10,944^{*} \\
(1.89)\end{array}$ & $\begin{array}{l}-12,553 * * \\
(2.16)\end{array}$ & $\begin{array}{l}-12,298 * * \\
(2.26)\end{array}$ \\
\hline Linder Variable & $\begin{array}{l}-106.93 * * * \\
(37.94)\end{array}$ & $\begin{array}{l}-61.45^{* * *} \\
(19.04)\end{array}$ & $\begin{array}{l}-36.89 * * * \\
(9.28)\end{array}$ & $\begin{array}{l}-36.69 * * * \\
(9.89)\end{array}$ \\
\hline Distance & $\begin{array}{l}-42.52 * * * \\
(8.91)\end{array}$ & $\begin{array}{l}-63.48 * * * \\
(9.72)\end{array}$ & NA & $\begin{array}{l}-5.76 \\
(0.09)\end{array}$ \\
\hline Border & $\begin{array}{l}2,476,733^{* * *} \\
(19.17)\end{array}$ & $\begin{array}{l}2,719,254 * * * \\
(9.69)\end{array}$ & NA & $\begin{array}{l}4,146,348 * * * \\
(3.25)\end{array}$ \\
\hline Both communist & $\begin{array}{l}-242,931 \\
(1.26)\end{array}$ & $\begin{array}{l}-337,678 \\
(0.80)\end{array}$ & NA & $\begin{array}{l}-85,808,059 * * \\
(2.27)\end{array}$ \\
\hline Both non-communist & $\begin{array}{l}-77,441 \\
(1.53)\end{array}$ & $\begin{array}{l}70,477 \\
(0.64)\end{array}$ & NA & $\begin{array}{l}3,113,753 \\
(0.80)\end{array}$ \\
\hline
\end{tabular}


Table 3b. Cuban Trade Flow Estimates by Estimation Type

\begin{tabular}{|c|c|c|c|c|}
\hline & Estimate & $95 \%$ Confidence Interval & Estimate & 95\% Confidence Interval \\
\hline \multicolumn{5}{|c|}{ A. OLS } \\
\hline$\underline{\text { Year }}$ & $\underline{\text { Imports }}$ & & $\underline{\text { Exports }}$ & \\
\hline $\begin{array}{l}1996 \\
1997 \\
1998 \\
1999 \\
2000\end{array}$ & $\begin{array}{l}1,277,734 \\
1,315,419 \\
1,368,189 \\
1,433,318 \\
1,518,495\end{array}$ & $\begin{array}{l}{[-6,716,202 \text { to } 9,271,671]} \\
{[-6,678,585 \text { to } 9,309,423]} \\
{[-6,625.882 \text { to } 9,362,261]} \\
{[-6,560,832 \text { to } 9,427,470]} \\
{[-6,475,751 \text { to } 9,512,743]}\end{array}$ & $\begin{array}{l}1,311,215 \\
1,346,497 \\
1,397,081 \\
1,459,884 \\
1,542,631\end{array}$ & $\begin{array}{l}{[-6,682,733 \text { to } 9,305,165]} \\
{[-6,647,518 \text { to } 9,340,513]} \\
{[-6,597,002 \text { to } 9,391,165]} \\
{[-6,534,279 \text { to } 9,454,047]} \\
{[-6,451,627 \text { to } 9,451,627]}\end{array}$ \\
\hline \multicolumn{5}{|c|}{ B. Fixed Effects } \\
\hline$\underline{\text { Year }}$ & $\underline{\text { Imports }}$ & & $\underline{\text { Exports }}$ & \\
\hline $\begin{array}{l}1996 \\
1997 \\
1998 \\
1999 \\
2000\end{array}$ & $\begin{array}{l}4,044,965 \\
4,109,447 \\
4,173,640 \\
4,246,623 \\
4,338,762\end{array}$ & $\begin{array}{l}\text { NA } \\
\text { NA } \\
\text { NA } \\
\text { NA } \\
\text { NA }\end{array}$ & $\begin{array}{l}2,775230 \\
2,894,033 \\
3,006,350 \\
3,129,873 \\
3,277,064\end{array}$ & $\begin{array}{l}\text { NA } \\
\text { NA } \\
\text { NA } \\
\text { NA } \\
\text { NA }\end{array}$ \\
\hline \multicolumn{5}{|c|}{ B. Random Effects } \\
\hline$\underline{\text { Year }}$ & $\underline{\text { Imports }}$ & & Exports & \\
\hline $\begin{array}{l}1996 \\
1997 \\
1998 \\
1999 \\
2000\end{array}$ & $\begin{array}{l}1,381,652 \\
1,430,868 \\
1,488,983 \\
1,157,575 \\
1,643,680\end{array}$ & $\begin{array}{l}{[107,916 \text { to } 2,655,389]} \\
{[156,163 \text { to } 2,705,573]} \\
{[213,364 \text { to } 2,764,601]} \\
{[280,938 \text { to } 2,834,211]} \\
{[365,844 \text { to } 2,921,516]}\end{array}$ & $\begin{array}{l}1,940,450 \\
2,018,533 \\
2,102,360 \\
2,198,031 \\
2,313,378\end{array}$ & $\begin{array}{l}{[666,585 \text { to } 3,214,326]} \\
{[743,695 \text { to } 3,293,370]} \\
{[826,606 \text { to } 3,378,114]} \\
{[921,256 \text { to } 3,474,806]} \\
{[1,035,399 \text { to } 3,591,357]}\end{array}$ \\
\hline \multicolumn{5}{|c|}{ C. HTM } \\
\hline$\underline{\text { Year }}$ & $\underline{\text { Imports }}$ & & $\underline{\text { Exports }}$ & \\
\hline $\begin{array}{l}1996 \\
1997 \\
1998 \\
1999 \\
2000\end{array}$ & $\begin{array}{l}2,919,444 \\
2,980,790 \\
3,042,531 \\
3,112,863 \\
3,201,581\end{array}$ & $\begin{array}{l}{[1,637,495 \text { to } 4,201,394]} \\
{[1,695,710 \text { to } 4,265,870]} \\
{[1,754,744 \text { to } 4,330,318]} \\
{[1,822,158 \text { to } 4,403,568]} \\
{[1,907,264 \text { to } 4,495,899]}\end{array}$ & $\begin{array}{l}3,959,888 \\
4,071,960 \\
4,178,775 \\
4,296,516 \\
4,436,632\end{array}$ & $\begin{array}{l}{[2,673,640 \text { to } 5,246,136]} \\
{[2,782,517 \text { to } 5,361,404]} \\
{[2,886,574 \text { to } 5,470,976]} \\
{[3,001,347 \text { to } 5,591,685]} \\
{[3,137,780 \text { to } 5,735,483]}\end{array}$ \\
\hline
\end{tabular}


Table 3c. Country Comparison of Percentage Trade with the United States, 2000

\begin{tabular}{|lll|}
\hline Country & Imports & Exports \\
\hline Cuba OLS* & 47 & 63 \\
Cuba FE* & 72 & 79 \\
Cuba RE* & 48 & 72 \\
Cuba HTM* & 65 & 83 \\
Cuba in $1958^{* *}$ & 70 & 67 \\
Argentina & 16 & 11 \\
Barbados & 33 & 3 \\
Bolivia & 20 & 26 \\
Brazil & 21 & 23 \\
Colombia & 26 & 40 \\
Costa Rica & 39 & 41 \\
Dominican Republic & 62 & 77 \\
Ecuador & 25 & 36 \\
El Salvador & 35 & 14 \\
Guatemala & 41 & 31 \\
Haiti & 56 & 61 \\
Honduras & 77 & 33 \\
Jamaica & 41 & 17 \\
Mexico & 68 & 85 \\
Nicaragua & 25 & 31 \\
Panama & 40 & 11 \\
Paraguay & 13 & 2 \\
Peru & 20 & 25 \\
Uruguay & 13 & 6 \\
Venezuela & 29 & 55 \\
\hline
\end{tabular}

* Assumes 50 percent trade displacement.

** United Nations Economic Commission for Latin America (ECLAC), Economic Survey of Latin America, 1963, (New York: United Nations, 1965), p.273. 


\section{FIGURES}

\section{Figure 1a: US Trade Balance with Canada}

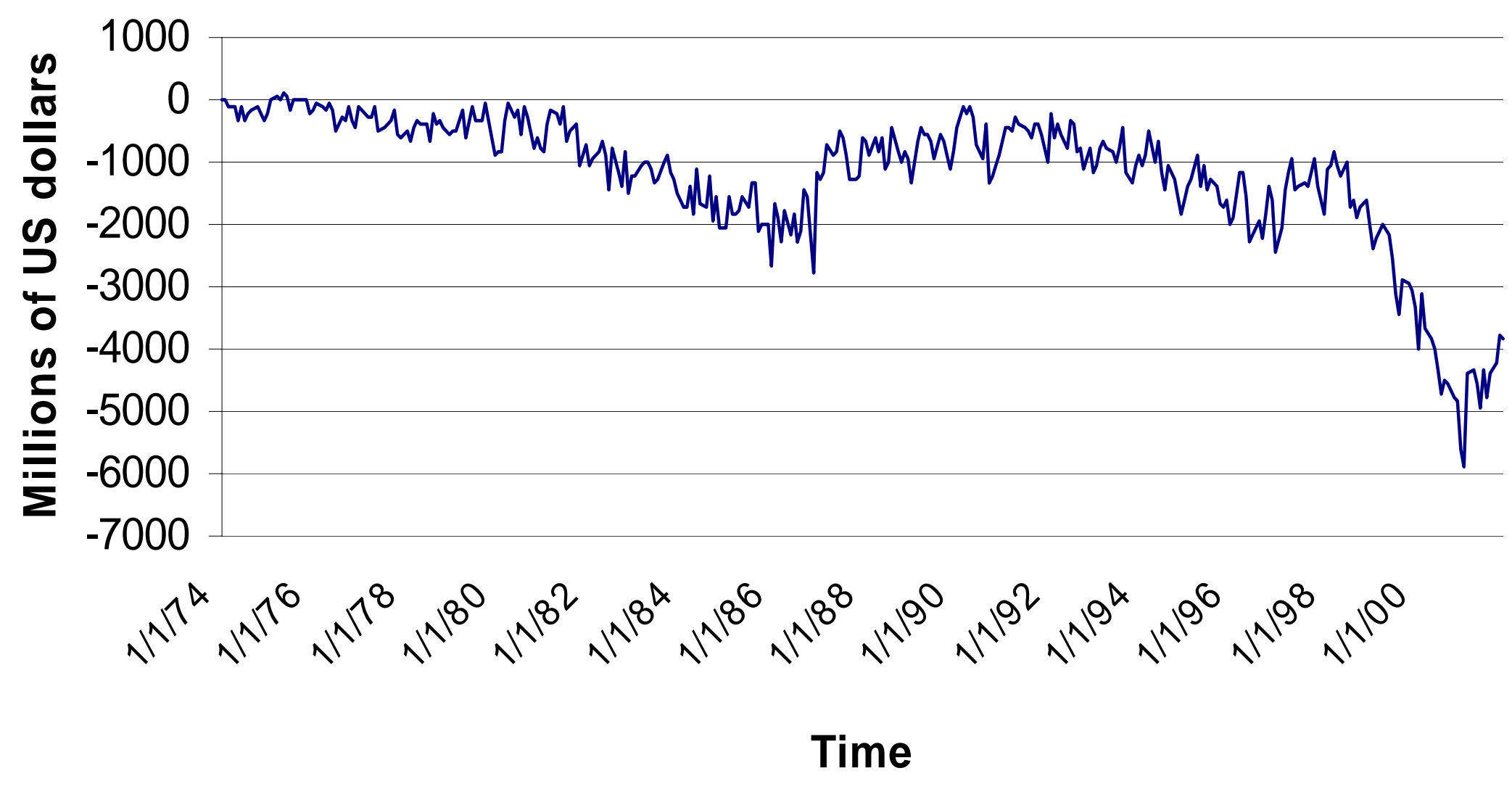




\section{Figure 1b: US Trade Balance with Germany}

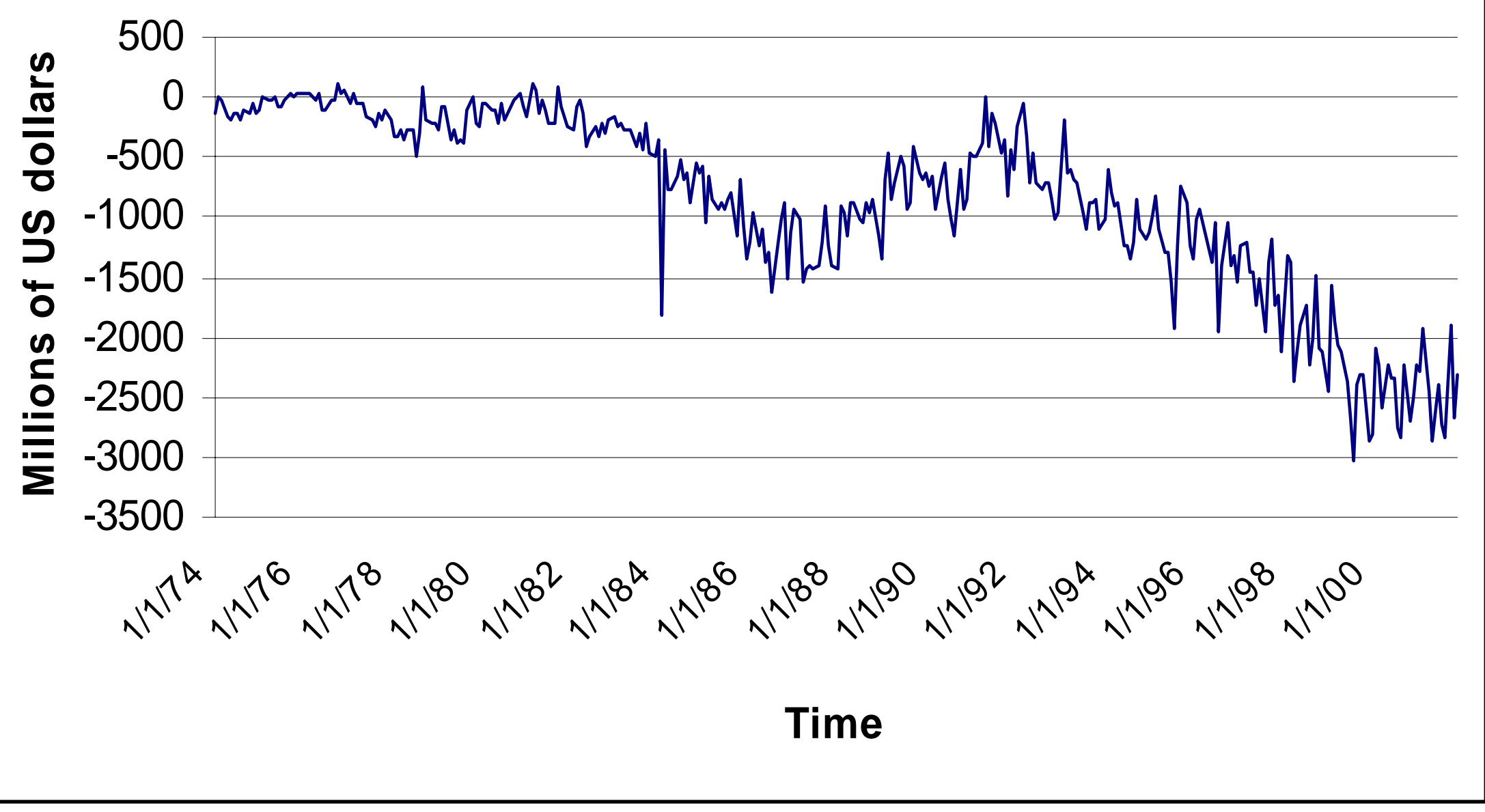




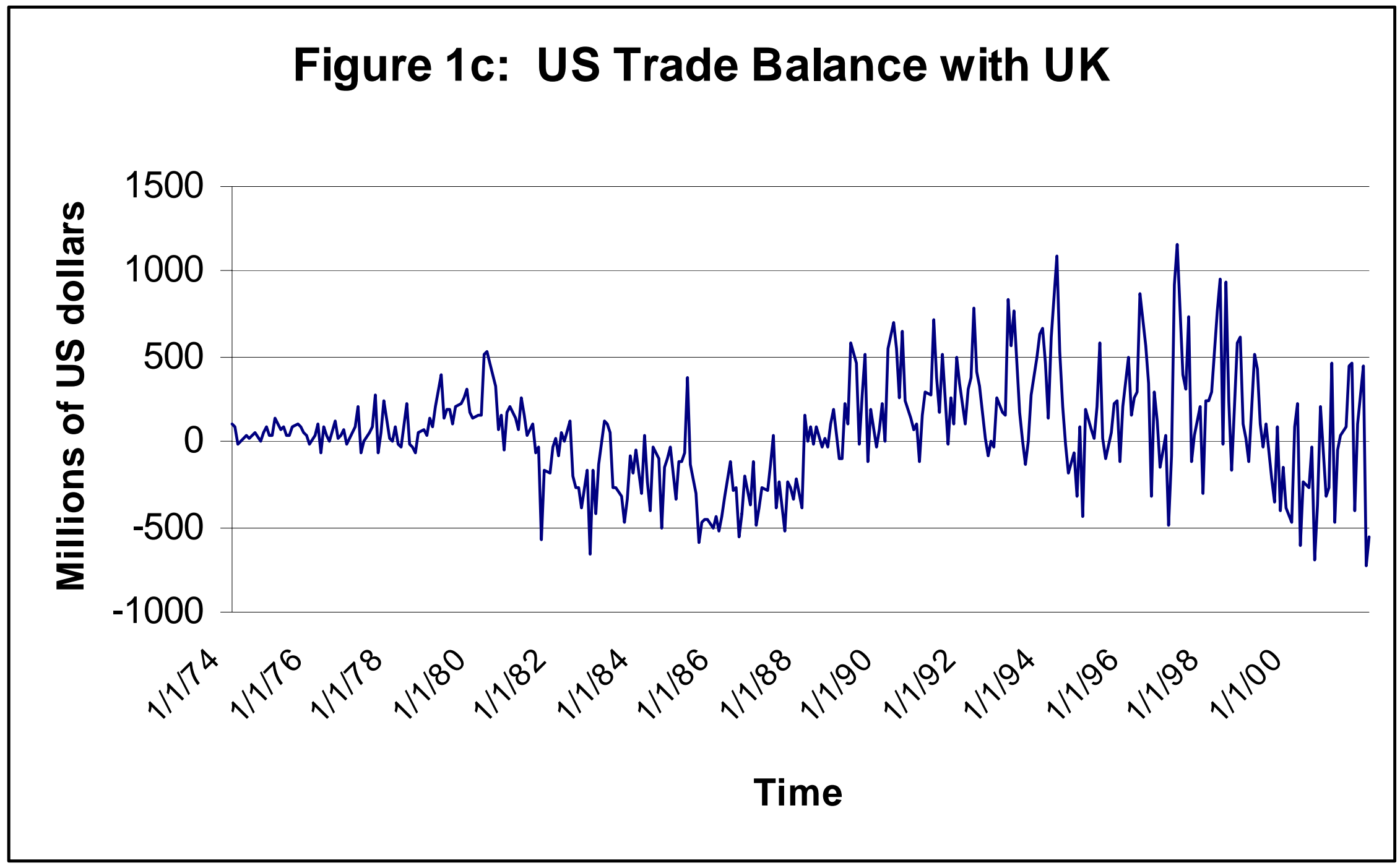




\section{Figure 1d: US Trade Balance with Japan}

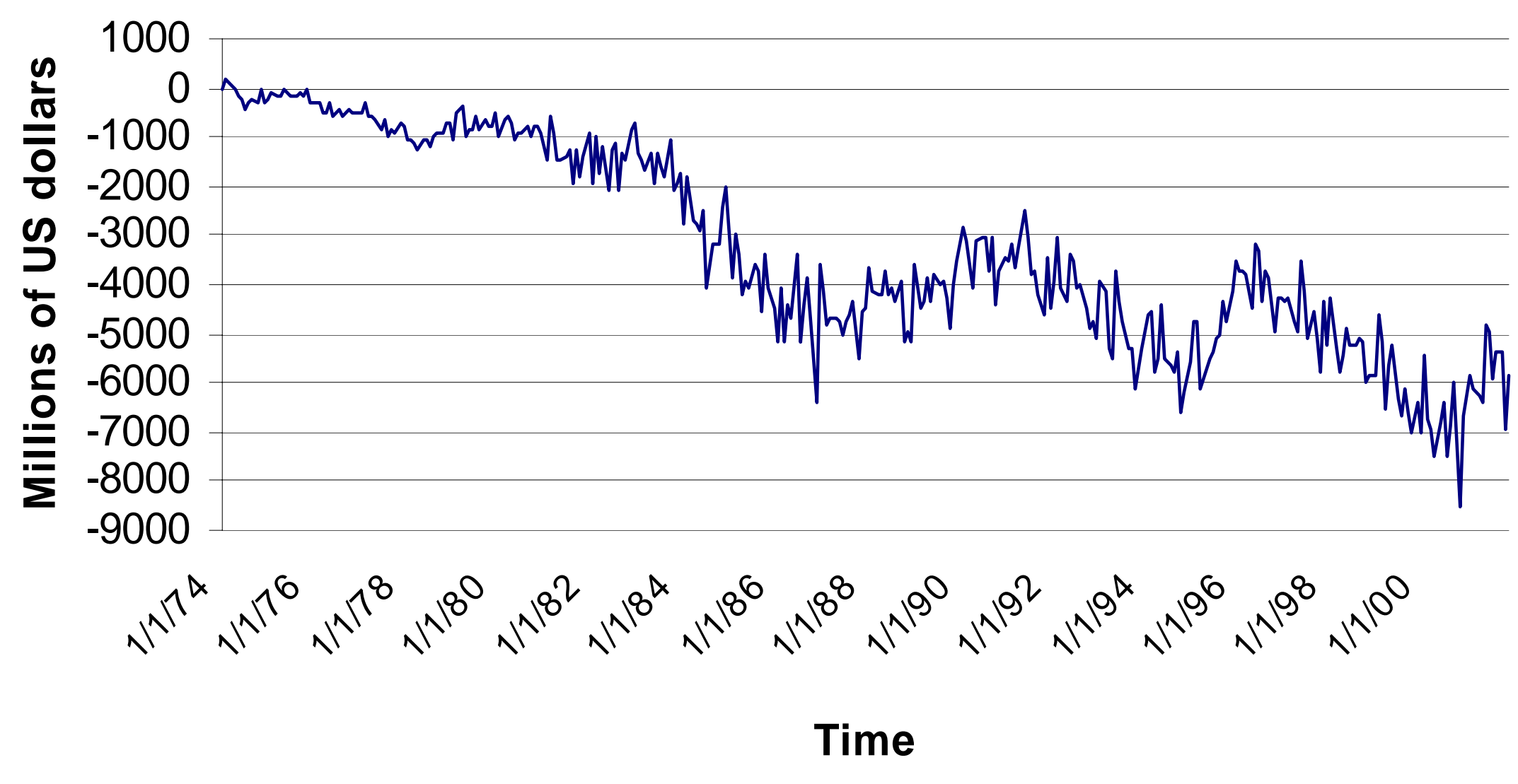


Figure 1e: US Real Trade Balance with Canada

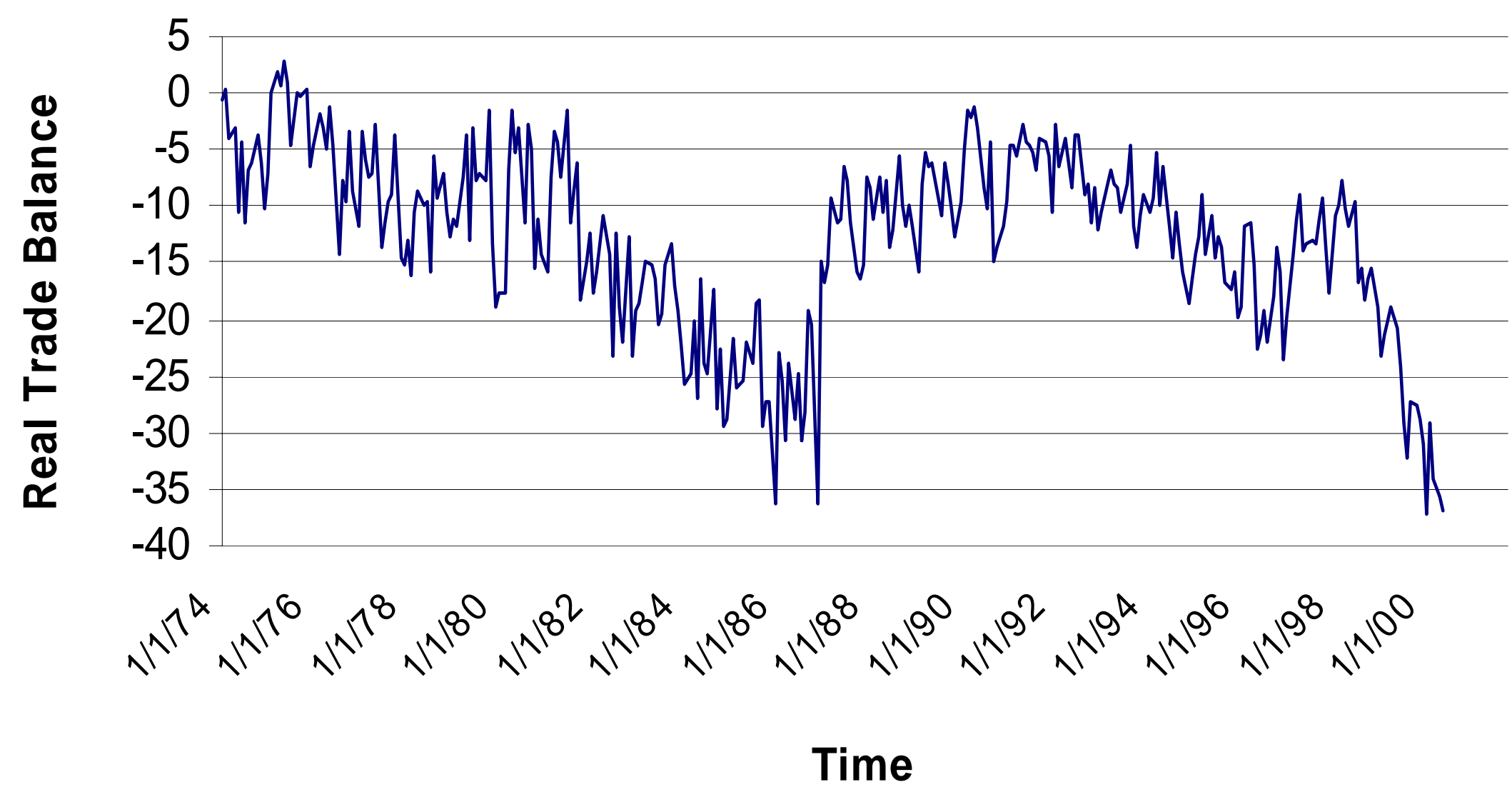




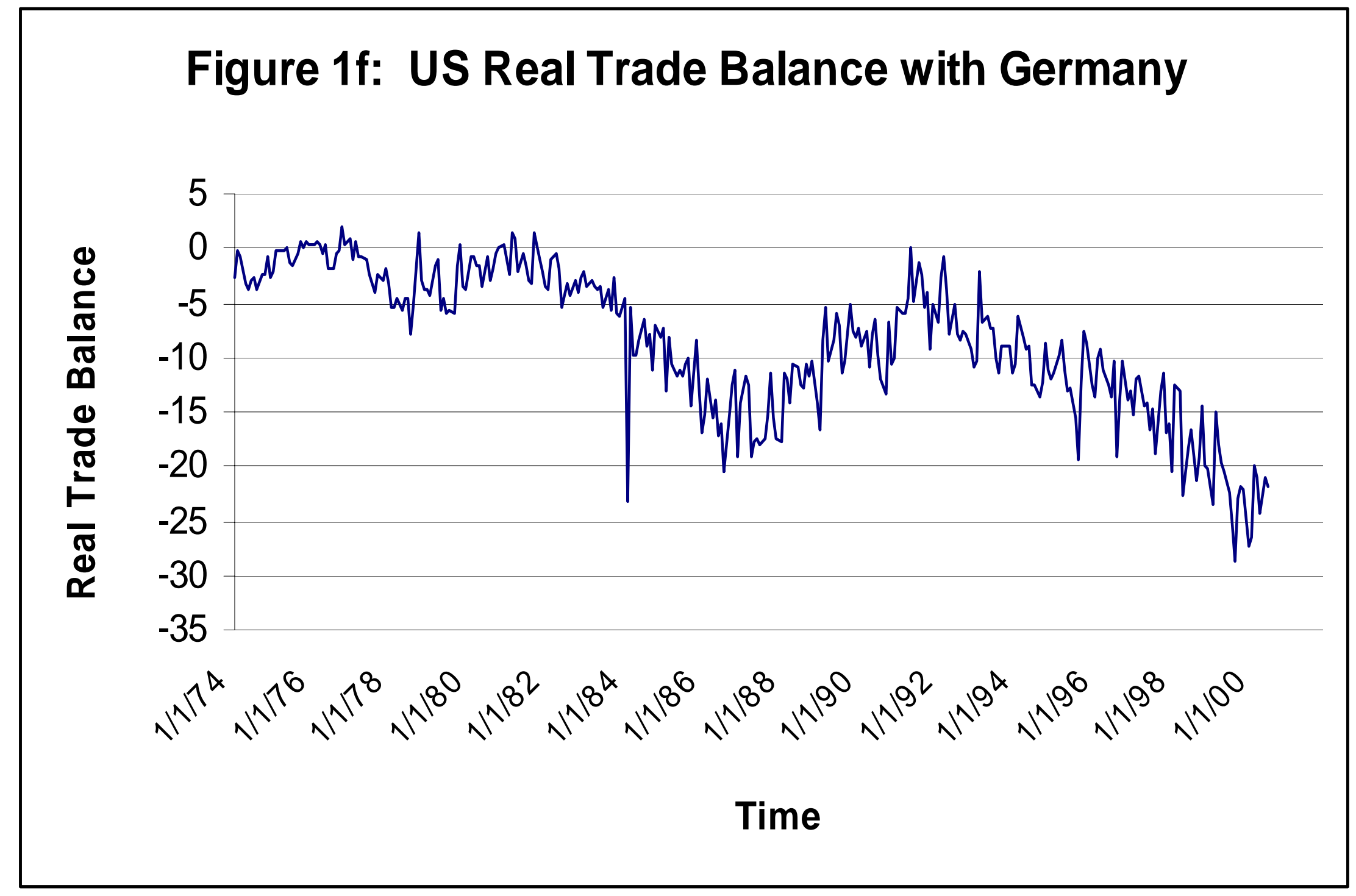




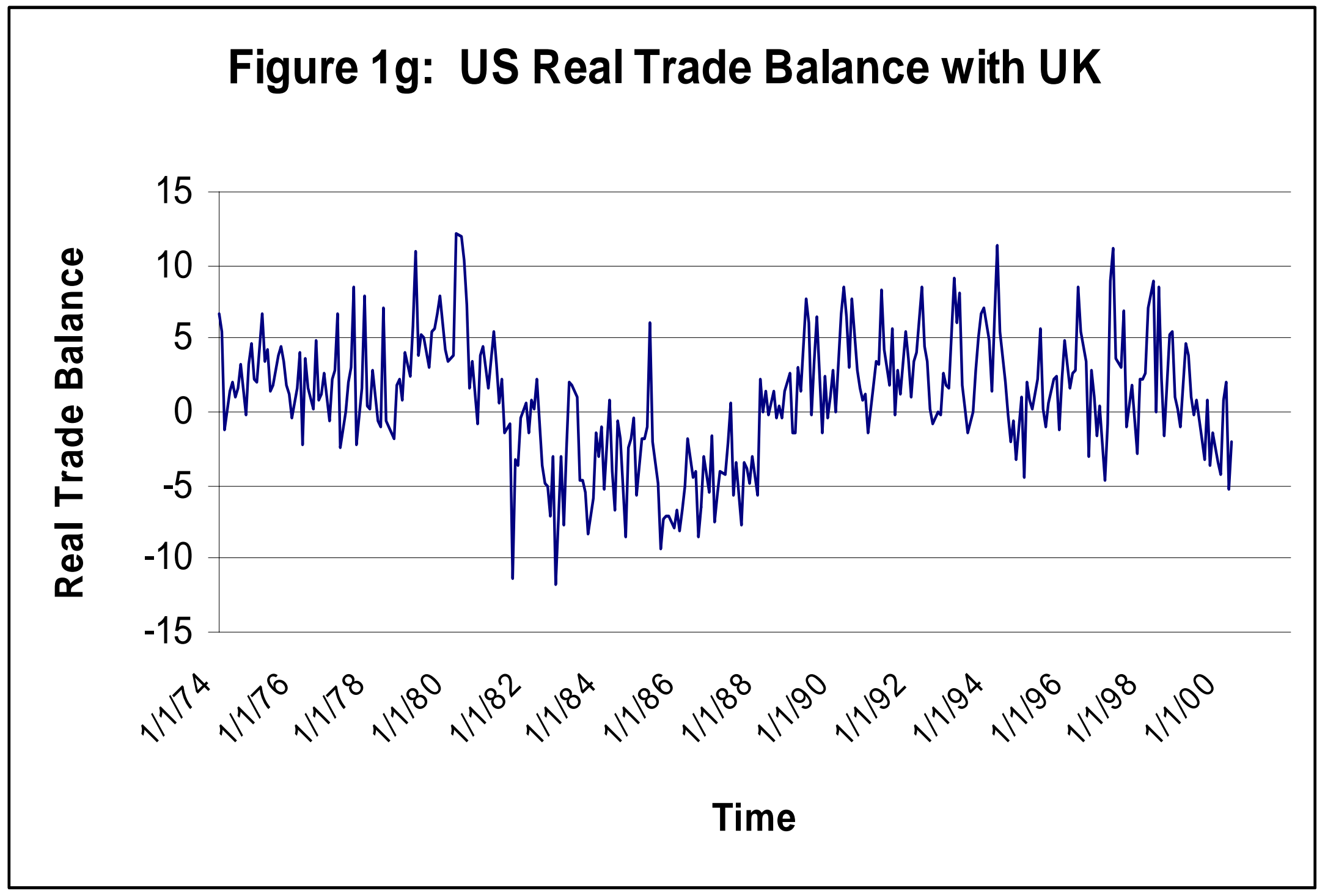




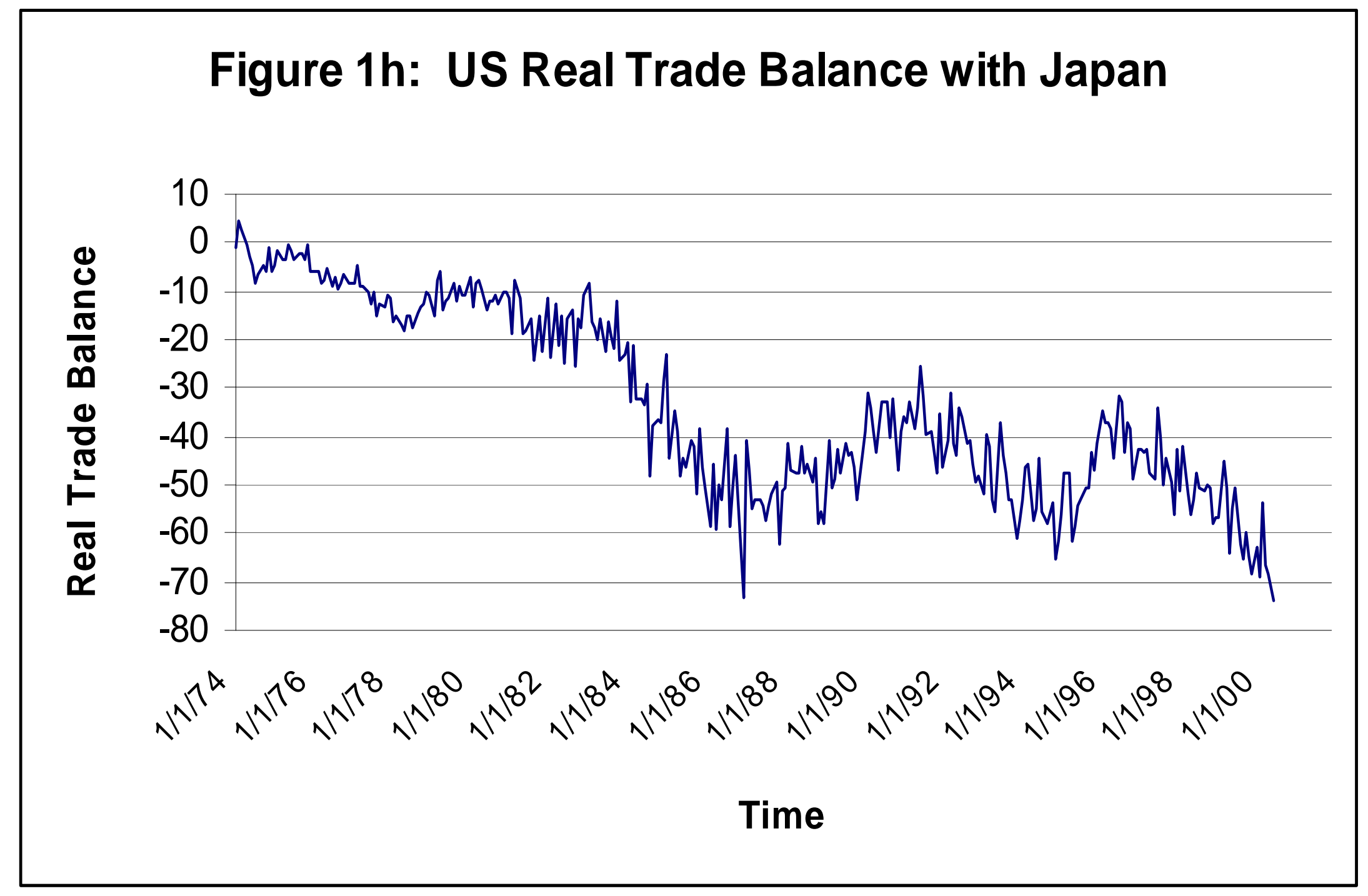


Figure 2a: Latin American Ethnic Population by Country (percent)

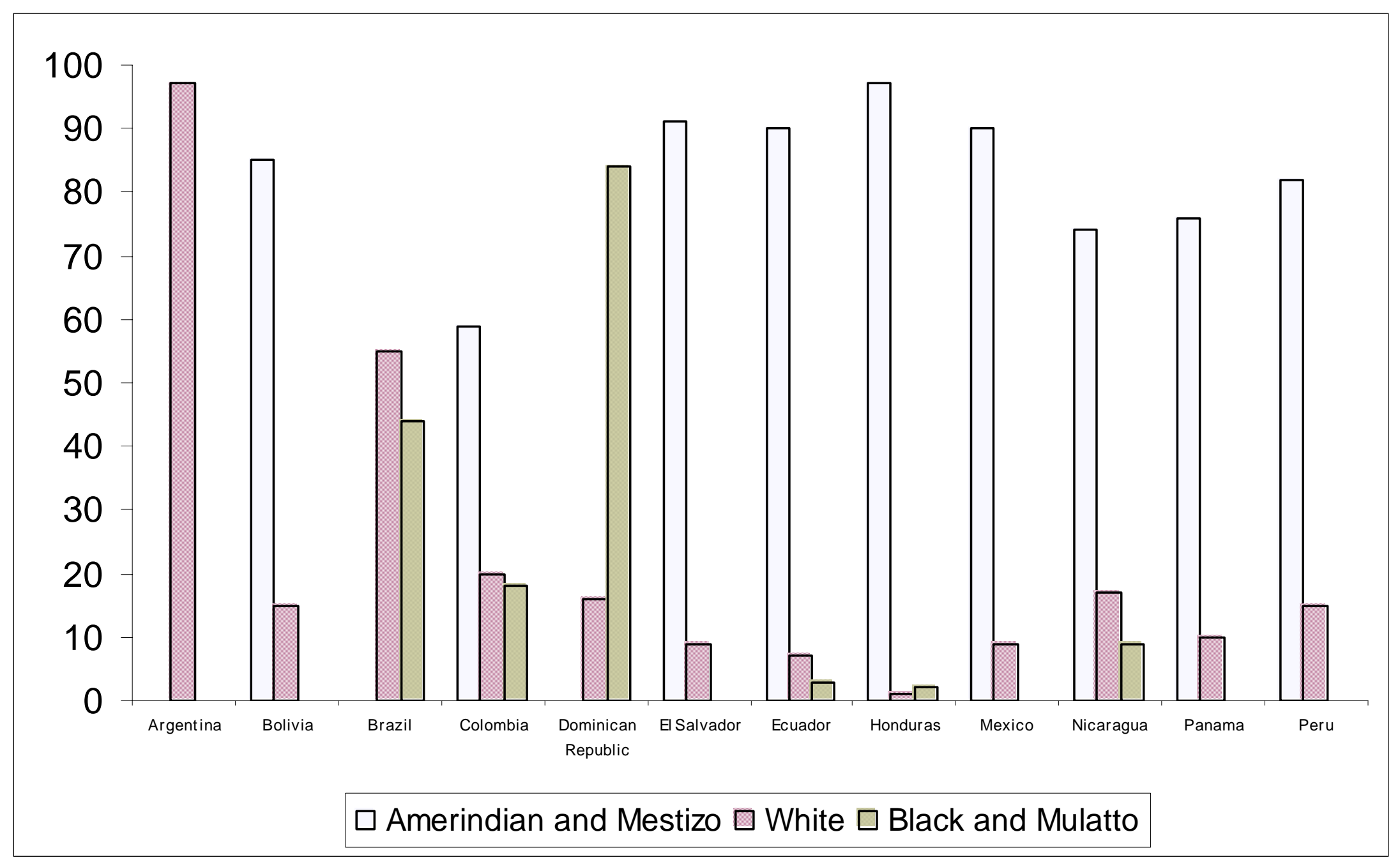


Figure 3a. OLS Residuals Vs. Trade Flow

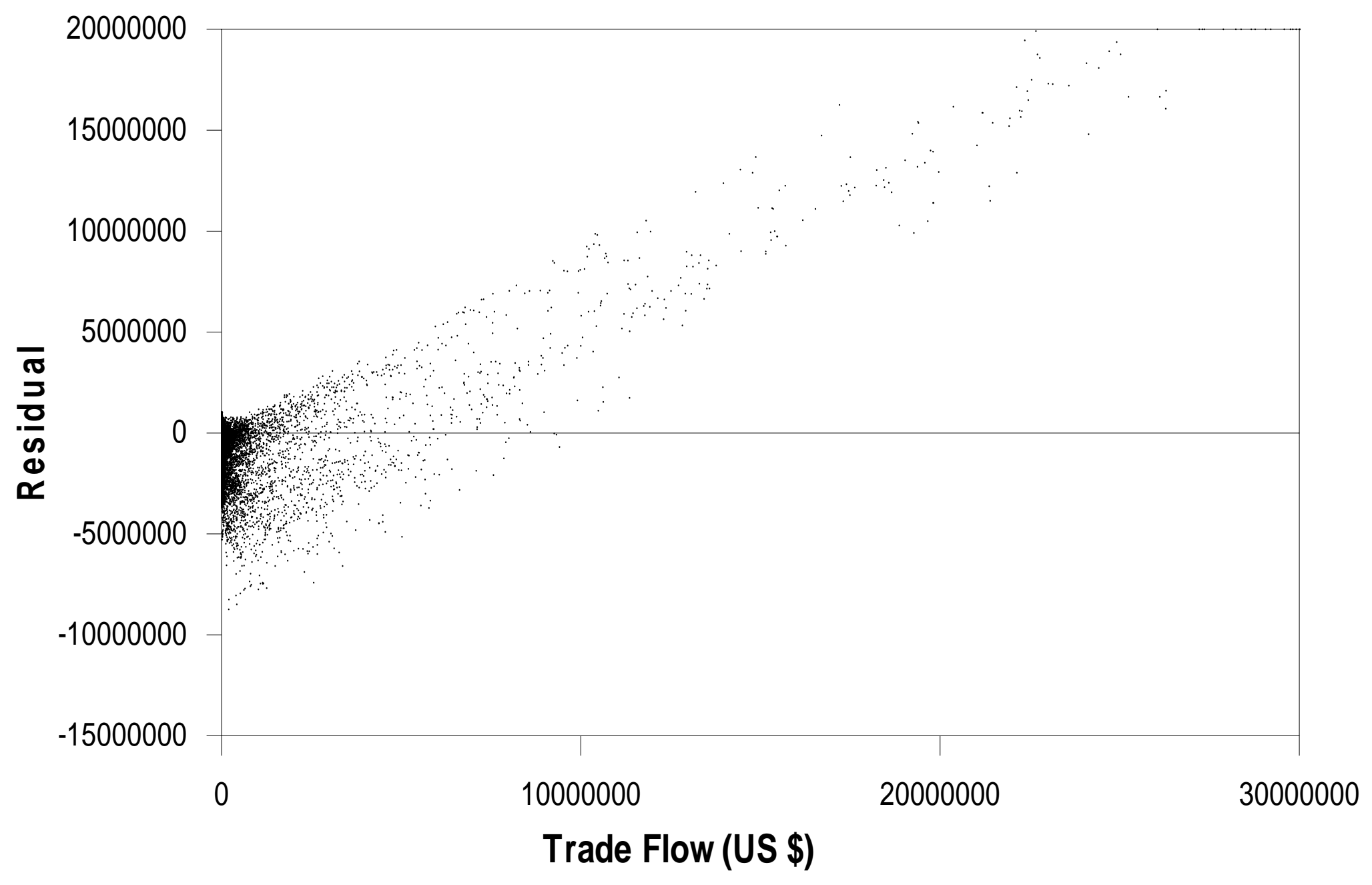


Figure 3b. Fixed-Effects Residuals Vs. Trade Flow

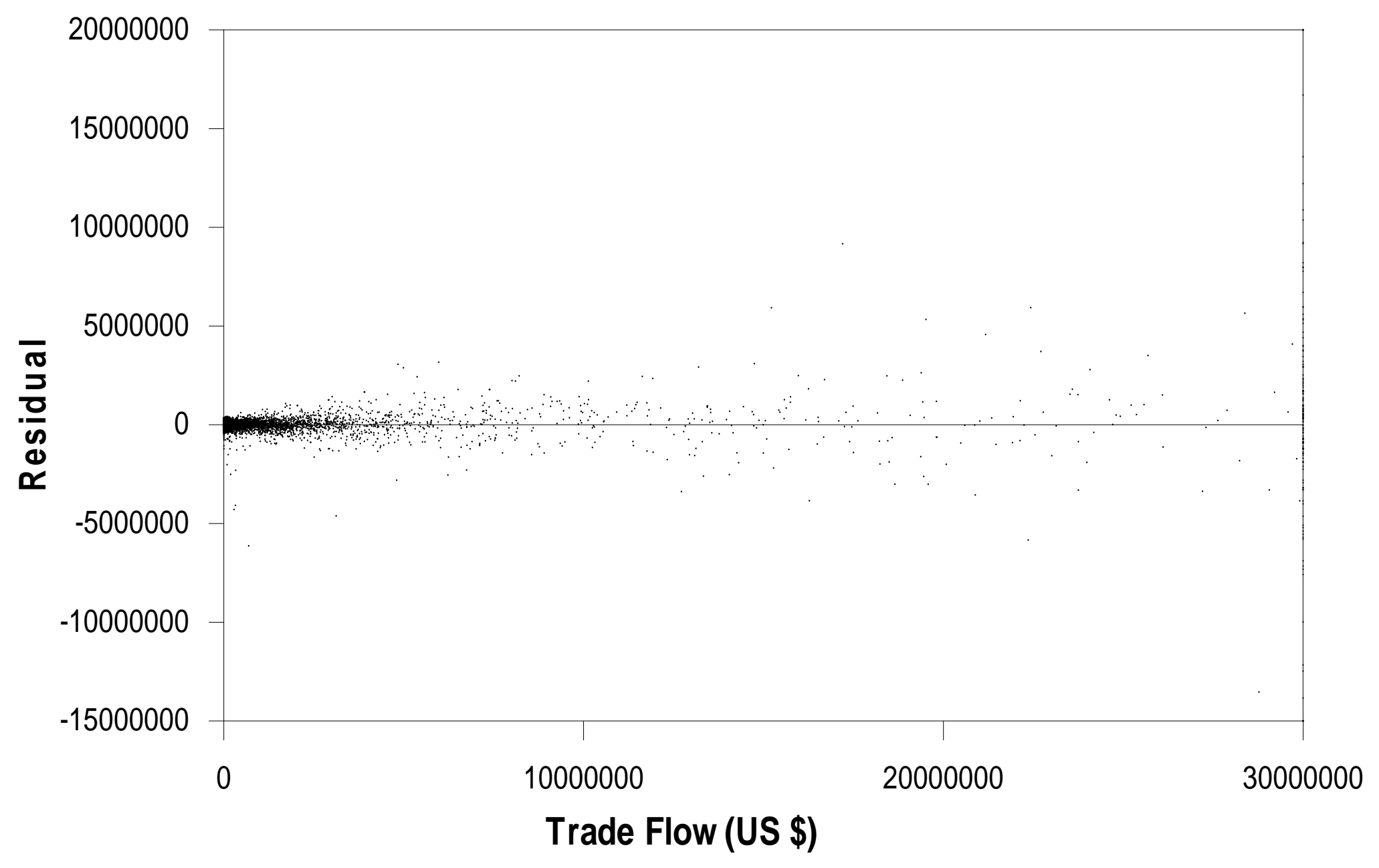


Figure 3c. Random-Effects Residuals Vs. Trade Flow

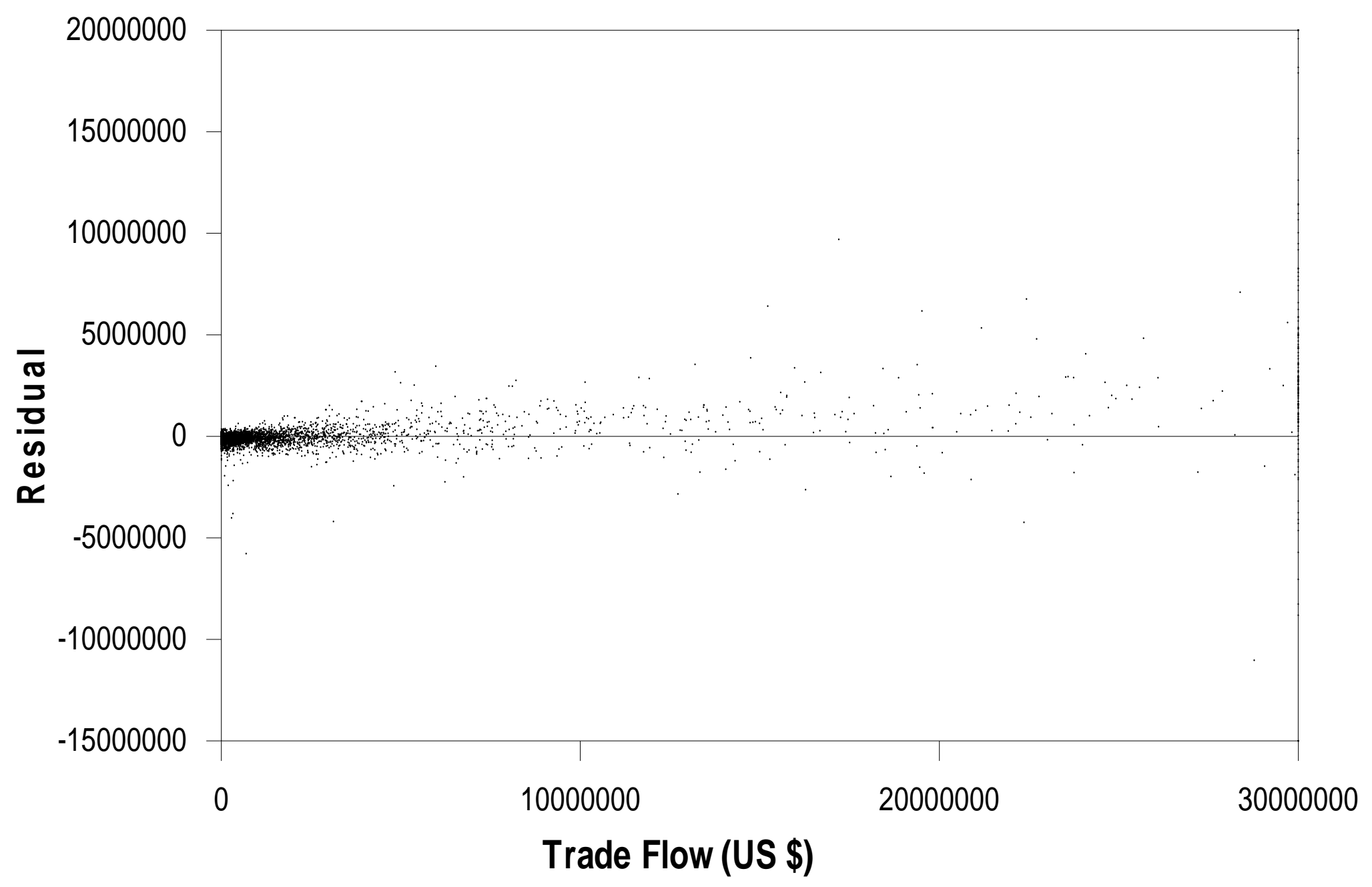


Figure 3d. Hausman-Taylor Method Residual Vs. Trade Flow

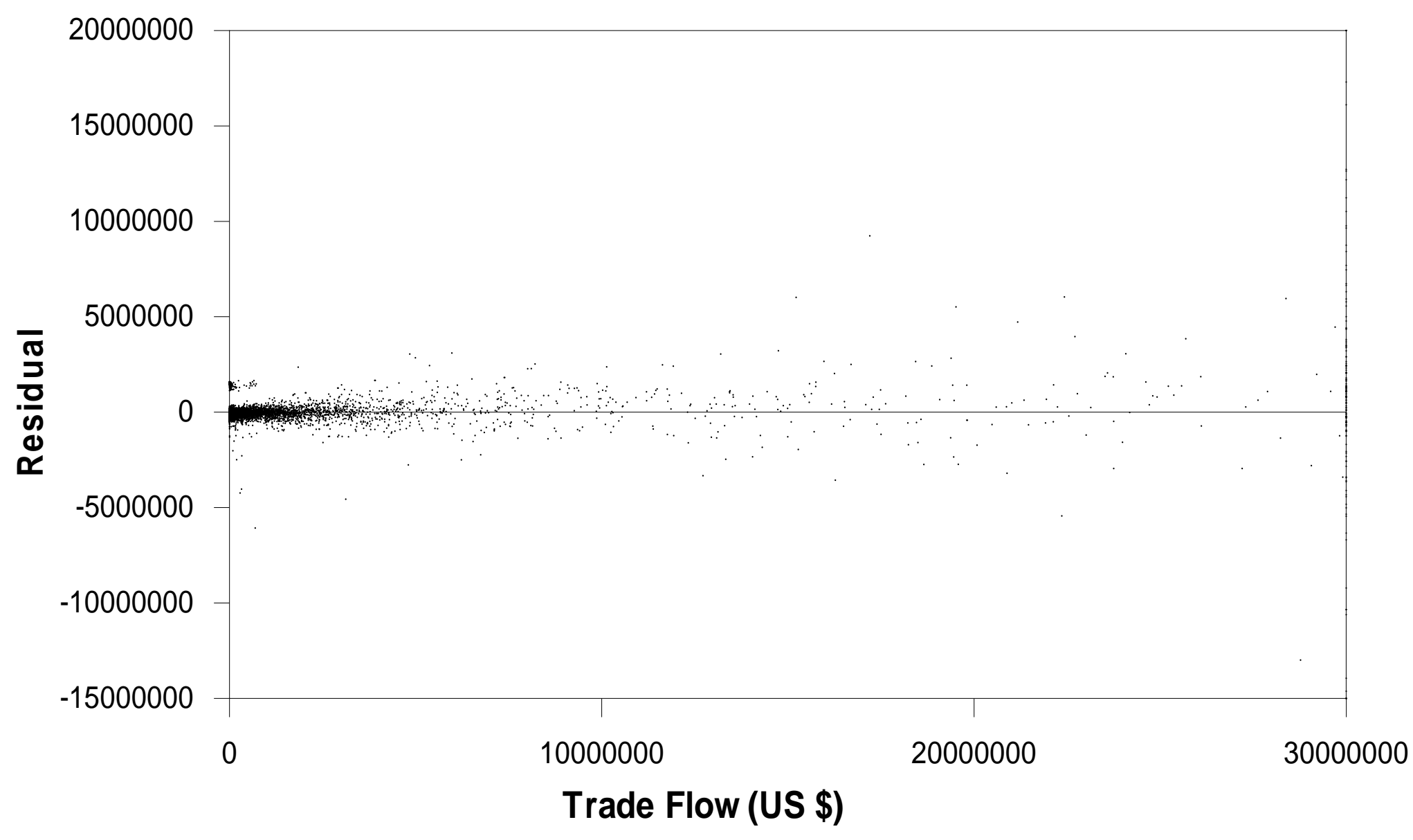




\section{Appendix}

\section{Appendix 1a. Derivation of equation (13)}

\section{1) Starting from:}

The optimal solution for the importer:

$$
Y_{i}=a_{i}-f
$$

The optimal solution for the exporter:

$$
X_{i}=f-d_{i}
$$

The definition of trade balance:

$$
T B=\sum_{i=1}^{m} X_{i}-\sum_{i=1}^{n} Y_{i}
$$

2) Substitute equations (3) and (6) into equation (12)

$$
T B=m f-\sum_{i=1}^{m} d_{i}-\sum_{i=1}^{n} a_{i}+n f
$$

3) Simplify equation (A1) to get:

$$
T B=(m+n) f-D-A
$$

where $D=\sum_{i=1}^{m} d_{i}$ and $A=\sum_{i=1}^{n} a_{i}$ 
4) Derive the Risk premium $R=(\varepsilon-f)$

Starting from the optimal solutions and the marking clearing condition:

$$
\begin{gathered}
L=(\varepsilon-f) / \alpha \sigma^{2}+Y \\
K=(\varepsilon-f) / \alpha \sigma^{2}-X \\
H=(\varepsilon-f) / \alpha \sigma^{2} \\
\sum_{i=1}^{n} l_{i}+\sum_{i=1}^{m} k_{i}+\sum_{i=1}^{s} h_{i}-F=0
\end{gathered}
$$

It follows that :

$$
\begin{aligned}
& \sum_{i=1}^{n} L_{i}=(e-f) / \sigma^{2} \sum_{i=1}^{n}\left(\alpha_{i}\right)+\sum_{i=1}^{n} Y_{i} \\
& \sum_{i=1}^{m} K_{i}=(e-f) / \sigma^{2} \sum_{i=1}^{m}\left(\alpha_{i}\right)-\sum_{i=1}^{n} X_{i} \\
& \sum_{i=1}^{S} H_{i}=(e-f) / \sigma^{2} \sum_{i=1}^{s}\left(\alpha_{i}\right)
\end{aligned}
$$

Therefore, equation (11) can be re-written as:

$$
(e-f) / \sigma^{2}(1 / \Omega)-(T B)-F=0
$$

Where TB is defined as in equation (12) and $(1 / \Omega)=\sum \alpha_{i}$ is a measure of aggregate risk aversion.

Rearranging terms:

$$
R=(e-f)=(T B+F) \sigma^{2} \Omega
$$


5. Find $\partial f / \partial \sigma^{2}$

Substitute the definition of TB derived in equation (A1a):

$$
(e-f)=\sigma^{2} \Omega((m+n) f-D-A+F)
$$

Solve for $f$ :

$$
f=\left[e+\sigma^{2} \Omega(D+A-F)\right] /\left[1+\Omega \sigma^{2}(m+n)\right]
$$

Take the derivative of $f$ with respect to $\sigma^{2}$

$$
\partial f / \partial \sigma^{2}=\frac{\left\{\left[\Omega(D+A-F)\left(1+\Omega \sigma^{2}(m+n)\right]-\left[e+\Omega \sigma^{2}(D+A-F)\right] \Omega(m+n)\right\}\right.}{\left(1+\Omega \sigma^{2}(m+n)\right)^{2}}
$$

Simplify terms:

$$
\partial f / \partial \sigma^{2}=\frac{\{[\Omega(D+A)-e(m+n)-F\}}{\left(1+\Omega \sigma^{2}(m+n)\right)^{2}}
$$

Add and Subtract $((m+n) f) /\left[1+\Omega \sigma^{2}(m+n)\right]^{2}$

$$
\partial f / \partial \sigma^{2}=\frac{\{[\Omega(D+A)-(m+n) f+(m+n) f-e(m+n)-F\}}{\left(1+\Omega \sigma^{2}(m+n)\right)^{2}}
$$

Substitute the definition of TB from equation (A1a):

$$
\partial f / \partial \sigma^{2}=\frac{[-\Omega(T B+F)+\Omega(m+n)(f-e)]}{\left(1+\Omega \sigma^{2}(m+n)\right)^{2}}
$$


Noting that $-R=(f-e)=-(T B+F) \sigma^{2} \Omega$, substitute in definition of R from equation (A4):

$$
\partial f / \partial \sigma^{2}=\frac{\left[-\Omega(T B+F)-\Omega^{2}(m+n)(T B+F)\right]}{\left(1+\Omega \sigma^{2}(m+n)\right)^{2}}
$$

Simplify terms:

$$
\partial f / \partial \sigma^{2}=\frac{-\Omega(T B+F)\left(1+\Omega^{2} \sigma^{2}(m+n)\right)}{\left(1+\Omega \sigma^{2}(m+n)\right)^{2}}
$$

Reduce the fraction:

$$
\partial f / \partial \sigma^{2}=\frac{-\Omega(T B+F)}{\left(1+\Omega \sigma^{2}(m+n)\right)}
$$

6. Find $\partial Y / \partial \sigma^{2}$ and $\partial X / \partial \sigma^{2}$

Taking the derivative of equation (3) with respect to $\sigma^{2}$ yields:

$$
\partial Y / \partial \sigma^{2}=-\partial f / \partial \sigma^{2}
$$

Which yields:

$$
\partial Y / \partial \sigma^{2}=\frac{\Omega(T B+F)}{\left(1+\Omega \sigma^{2}(m+n)\right)}
$$

Likewise, taking the derivative of equation (6) with respect to $\sigma^{2}$ yields:

$$
\partial X / \partial \sigma^{2}=\partial f / \partial \sigma^{2}
$$

Which yields:

$$
\partial X / \partial \sigma^{2}=\frac{-\Omega(T B+F)}{\left(1+\Omega \sigma^{2}(m+n)\right)}
$$


7. Prove equation (13)

By inspecting equations (A9a and A10a) we find that:

$$
-\partial Y / \partial \sigma^{2}=\partial X / \partial \sigma^{2}=\frac{-\Omega(T B+F)}{\left(1+\Omega \sigma^{2}(m+n)\right)}
$$

Equation (A11) is exactly equation (13) and therefore equation (13) is proven. 
Appendix 3a: Country List

\begin{tabular}{|c|c|c|c|}
\hline Algeria & Egypt & Jordan & Philippines \\
\hline Angola & El Salvador & Kenya & Poland \\
\hline Argentina & Ethiopia & Korea Republic & Portugal \\
\hline Australia & Fiji & Kuwait & Saudi Arabia \\
\hline Austria & Finland & Madagascar & Senegal \\
\hline Bahamas & France & Malawi & Sierra Leone \\
\hline Bahrain & Gabon & Malaysia & Singapore \\
\hline Bangladesh & Germany & Mali & South Africa \\
\hline Barbados & Ghana & Malta & Spain \\
\hline Belgium-Lux & Greece & Mauritania & Sri Lanka \\
\hline Benin & Guatemala & Mexico & Sudan \\
\hline Bolivia & Guinea & Morocco & Suriname \\
\hline Brazil & Guyana & Mozambique & Sweden \\
\hline Burkina Faso & Haiti & Nepal & Switzerland \\
\hline Burundi & Honduras & Netherlands & Tanzania \\
\hline Canada & Hong Kong & New Zealand & Trinidad Tbg \\
\hline Chile & Hungary & Nicaragua & Tunisia \\
\hline China & India & Niger & Turkey \\
\hline Colombia & Indonesia & Nigeria & Uganda \\
\hline Congo & Iran & Norway & UK \\
\hline Costa Rica & Ireland & Pakistan & Uruguay \\
\hline Cyprus & Israel & Panama & USA \\
\hline Denmark & Italy & Papua N Guinea & Venezuela \\
\hline Dominican Rp & Jamaica & Paraguay & Yemen \\
\hline \multirow[t]{2}{*}{ Ecuador } & Japan & Peru & Zambia \\
\hline & & & Zimbabwe \\
\hline
\end{tabular}


Appendix 3b. Estimated Cuban Trade with US by Percent Trade Displacement (Year 2000 in Billions of Current US \$)

\begin{tabular}{|c|c|c|c|c|c|c|c|c|}
\hline \multicolumn{8}{|c|}{ A. Exports } & \\
\hline Dis. & $\underline{\text { Total }}$ & $\begin{array}{l}\text { OLS } \\
\text { \% US }\end{array}$ & $\underline{\text { Total }}$ & \% US & $\underline{\text { Total }}$ & \% US & $\underline{\text { Total }}$ & \% US \\
\hline $0 \%$ & $\$ 3.3$ & $45 \%$ & $\$ 5.1$ & $65 \%$ & $\$ 3.7$ & $56 \%$ & $\$ 6.2$ & $71 \%$ \\
\hline $25 \%$ & $\$ 2.9$ & $53 \%$ & $\$ 4.7$ & $71 \%$ & $\$ 3.2$ & $63 \%$ & $\$ 5.8$ & $77 \%$ \\
\hline $50 \%$ & $\$ 2.4$ & $63 \%$ & $\$ 4.2$ & $79 \%$ & $\$ 2.8$ & $72 \%$ & $\$ 5.3$ & $83 \%$ \\
\hline $75 \%$ & $\$ 2.0$ & $77 \%$ & $\$ 3.8$ & $88 \%$ & $\$ 2.5$ & $84 \%$ & $\$ 4.9$ & $91 \%$ \\
\hline $100 \%$ & $\$ 1.5$ & $83 \%$ & $\$ 3.3$ & $100 \%$ & $\$ 2.3$ & $100 \%$ & $\$ 4.4$ & $100 \%$ \\
\hline \multicolumn{9}{|c|}{ B. Imports } \\
\hline & & OLS & \multicolumn{2}{|c|}{ Fixed Effects } & \multicolumn{2}{|c|}{ Random Effects } & \multicolumn{2}{|l|}{ HTM } \\
\hline Dis. & $\underline{\text { Total }}$ & \% US & $\underline{\text { Total }}$ & \% US & $\underline{\text { Total }}$ & \% US & $\underline{\text { Total }}$ & \% US \\
\hline $0 \%$ & $\$ 4.9$ & $31 \%$ & $\$ 7.7$ & $56 \%$ & $\$ 5.0$ & $32 \%$ & $\$ 6.6$ & $44 \%$ \\
\hline $25 \%$ & $\$ 4.1$ & $37 \%$ & $\$ 6.9$ & $63 \%$ & $\$ 4.2$ & $39 \%$ & $\$ 5.8$ & $51 \%$ \\
\hline $50 \%$ & $\$ 3.4$ & $48 \%$ & $\$ 6.0$ & $72 \%$ & $\$ 3.4$ & $48 \%$ & $\$ 4.9$ & $61 \%$ \\
\hline $75 \%$ & $\$ 3.4$ & $48 \%$ & $\$ 5.2$ & $83 \%$ & $\$ 3.4$ & $48 \%$ & $\$ 4.1$ & $76 \%$ \\
\hline $100 \%$ & $\$ 3.4$ & $48 \%$ & $\$ 4.3$ & $100 \%$ & $\$ 3.4$ & $48 \%$ & $\$ 3.4$ & 79\% \\
\hline
\end{tabular}




\section{References}

Aitken, N.D., 1973. "The Effect of the EEC and EFTA on European Trade: A Temporal Cross-Section Analysis." American Economic Review, 63(5), 881-892.

Anderson, J.E. and Wincoop, E., 2003. AGravity with Gravitas: A Solution to the Border Puzzle.@ American Economic Review, 93 (1), 170-92.

Aristotelous, K., 2001. “Exchange-Rate Volatility, Exchange-Rate regime, and Trade volume: Evidence from the UK-US export function (1889-1999).” Economic Letters 72, 87-94.

Arize, A.C., 1997. "Foreign Trade and Exchange-Rate Risk in the G-7 Countries: Cointegration and Error-Correction Models.” Review of Financial Economics 6, 95-112.

Arize, A.C., Osang, T., and Slottje, D.J., 2000. "Exchange-Rate Volatility and Foreign Trade: Evidence from Thirteen LCD=s.” Journal of Business and Economic Statistics 18, 10-17.

Asseery, A. and Peel, D.A., 1991. “The Effects of Exchange-Rate Volatility on Exports.” Economic Letters 37, 173-177.

Bailey, M..J., Tavlas, G.S., and Ulan, M., 1987. "The Impact of Exchange-Rate Volatility on Export Growth: Some Theoretical Considerations and Empirical Results.” Journal of Policy Modeling 9(1), 225-243.

Baldwin, R., 1994. In: Towards an Integrated Europe, Center for Economic Policy Research, London.

Belanger, D., Gutierrez, S., Racette, D. and Raynauld, J., 1992. "The Impact of Exchange-Rate Variability on Trade Flows: Further Results on Sectoral U.S. Imports From Canada." North American Journal of Economics and Finance 3, 888-92.

Boisso, D. and Ferrantino, M., 1997. "Economic Distance, Cultural Distance, and Openness in International Trade: Empirical Puzzles.” Journal of Economic Integration 12(4), 456-484.

Bollerslev, T., 1990. "Modelling the Coherence in Short-run Nominal Exchange Rates: A Multivariate Generalized ARCH Model. "Review of Economics and Statistics 72(3), 498-505 .

Broll, U. and Eckwert, B., 1999. "Exchange-Rate Volatility and International Trade. Southern Economic Journal 66(1), 178-185. 
Brulhart, M. and Kelly M., 1999. AIreland=s Trading Potential with Central and Eastern European Countries: A Gravity Study. \& Economic and Social Review 30 (2), 159-74.

Caballero, R. and Corbo V., 1989. "The Effect of Real Exchange-Rate Uncertainty on Exports: Empirical Evidence." The World Bank Economic Review 3, 263-278.

Caporale, T. and Doroodian, K., 1994. "Exchange-Rate Variability and the Flow of International Trade.” Economic Letters 46, 49-54.

Ceglowski, J. 2000. "Has the Border Narrowed?" The North American Journal of 'Economics and Finance, 11, 61-74.

Cheng, I and Wall, H., 2002. "Controlling for heterogeneity in gravity models of trade." Federal Reserve Bank of St. Louis Working Papers, 99-010.

Chowdhury, A.R., 1993. "Does Exchange-Rate Volatility Depress Trade Flows? Evidence from Error-Correction Models.” The Review of Economics and Statistics 75(4), 700-706.

Cushman, D.O., 1988. "U.S. bilateral Trade Flows and Exchange Risk During the Floating Period.” Journal of International Economics 24, 317-330.

De Grauwe, P., 1987. "International Trade and Economic Growth in the European Monetary System." European Economic Review 31(1), 389-98.

1988. "Exchange-Rate Variability and the Slowdown in Growth of International Trade." International Monetary Fund Staff Papers 35(1), 63-84

De Grauwe, P. and Bellefroid, B. de, 1986. "Long Run Exchange-Rate Volatility and International Trade." Real Financial Linkages Among Open Economies, 1987.

Deardorff, Alan, 1984. "Testing Trade Theories and Predicting Trade Flows." Handbook of International Economics (1), 467-517.

Doyle, E., 2001. “Exchange-Rate Volatility and Irish-UK Trade, 1972-1992.” Applied Economics 33, 249-265.

Dunlevy, J.A., 2003. "Interpersonal Networks in International Trade: Evidence on the Role of Immigrants in Promoting Exports from the American States." Working paper.

Egger, P., 2000. AA Note on the Proper Econometric Specification of the Gravity Equation. \& Economic Letters, 66, 25-31.

---------- 2002. AAn Econometric View of the Estimation of Gravity Models and the Calculation of Trade Potentials. \& World Economy, 25(2), 297-312. 
Fidrmuc, J., 1999. "Trade Diversion in 'Left outs' in Eastward Enlargement of the European Union: the Case of Slovakia." Europe-Asia Studies, 51(4), 1999.

Frankel J., Stein E., and Wei, S., 1995. "Trading Blocs and the Americas: The Natural, the Unnatural, and the Supernatural." Journal of Development Economics, 47, 61-95.

Girma, S. and Yu, Z., 2002. "The Link Between Immigration and Trade: Evidence from the United Kingdom." Weltwirshaftliches Archiv, 138(1), 115-130.

Gould, D., 1994. "Immigrant Links to the Home Country: Empirical Implications for U.S. Bilateral Trade Flows.” Review of Economics and Statistics, 76, 302-316.

Granovetter, M.S., 1973. "The Strength of Weak Ties." American Journal of Sociology, 78(6), 1360-1380.

Greif, A., 1993. "Contract Enforceability and Economic Institutions in Early Trade: The Maghribi Traders’ Coalition.” American Economic Review, 83(3), 525-548.

Gros, D. and Gonciarz, A., 1996. AA Note of the Trade Potential of Central and Eastern Europe. \& European Journal of Political Economy, 12, 709-21.

Hamilton, C.B. and L.A. Winters,1992. AOpening Up International Trade with Eastern Europe.@ Economic Policy 14, 77-116.

Hausman, J., 1978. ASpecification Tests in Econometrics.@ Econometrica, 46, 12511271.

Hausman, J. and W. Taylor, 1981. APanel data and Unobservable Individual Effects. @ Econometrica 49, 1377-1398.

Head, K. and Ries, J., 1998. "Immigration and Trade Creation: Econometric Evidence from Canada." Canadian Journal of Economics 31(1), 47-62.

Helliwell, J.F., 1998. How Much Do National Borders Matter? Brookings Institute, Washington D.C.

Helliwell, J.F. and Verdier, J., 2001. AMeasuring International Trade Distances: a New Method Applied to Estimate Provincial Border Effects in Canada.@ Canadian Journal of Economics, 34 (4), 1024-41.

Hillberry, R.H., 2002. “Aggregation Bias, Compositional Change, and the Border Effect.” Canadian Journal of Economics, 35(3), 517-30. 
Kenen, P. and Rodrik, D., 1986. "Measuring and Analyzing the Effects of Short-Term Volatility of Real Exchange Rates." Review of Economics and Statistics (Notes). 311-315.

Klein, M.W., 1990. Sectorial Effects of Exchange-Rate Volatility on United States Exports.” Journal of International Money and Finance 9, 299-308

Koray, F. and Lastrapes, W.D., 1989. "Real Exchange-Rate Volatility and U.S. Bilateral Trade: a VAR Approach.” The Review of Economics and Statistics (Notes), 708712.

Kroner, K.F. and Lastrapes, W.D., 1993. “The Impact of Exchange-Rate Volatility on International Trade: Reduced Form Estimates Using the GARCH-In-Mean Model.” Journal of International Money and Finance 12, 298-318.

Lastrapes, W.D. and Koray, F., 1990. “Exchange-Rate Volatility and U.S. Multilateral Trade Flows.” Journal of Macroeconomics 12, 341-362.

Linder, Staffan, 1961. "An Essay on Trade and Transformation." Upsala: Almqvist and Wiksells)

Matyas, L. 1997. AProper Econometric Specification of the Gravity Model.@ The World Economy, 20 (3), 363-368.

McKenzie, M.D., 1999. “The Impact of Exchange-Rate Volatility on International Trade Flows.” Journal of Economic Surveys 13, 71-106.

McKenzie, M.D. and Brooks, R.D., 1997. “The Impact of Exchange-Rate Volatility on German-US Trade Flows.” Journal of International Financial Markets, Institutions and Money 7, 73-87.

McPherson, M.A., Redfearn, M.R., and Tieslau, M.A., 2000. "A Re-Examination of the Linder Hypothesis: A Ramdom-Effects Tobit Approach." International Economic Journal 14(3), 123-36 2001. "International Trade and Developing Countries: An Empirical Investigation of the Linder Hypothesis." Applied Economics 33(5), 649-57

McPherson, M.Q. and Trumbull, W.N., 2003. "What if U.S.-Cuban Trade Were Based on Economic Fundamentals Instead of Political Policy? Estimating Potential Trade with Cuba," Association for the Study of the Cuban Economy Conference Proceedings, Coral Gables, Florida. Forthcoming.

Medhora, R., 1990. "The Effect of Exchange-Rate Variability on Trade: The Case of the West African Monetary Union's Imports." World Development 18(2), 313-24. 
Neumann, M.,1995. "Real Effects of Exchange-Rate Volatility.” Journal of International Money and Finance 14, 417-426.

Nilsson, L., 2000. ATrade Integration and the EU Economic Membership Criteria.@ European Journal of Political Economy, 16 (4), 807-27.

Pakko, M.R. and Wall, H.J., 2001. AReconsidering the Trade-Creating Effects of a Currency Union. @ Federal Reserve Bank of St. Louis Review, 83 (5), 37-45.

Poyhonen, J., 1963. AA Tentative Model for Volume in Trade Between Countries. @ Weltwirtschaftliches Archiv, 90, 91-113.

Pozo, S., 1992. “Conditional Exchange-Rate Volatility and the Volume of International Trade: Evidence from the Early 1900's.” The review of Economics and Statistics, 325-329.

Qian, Y. and Varangis, P., 1994. “Does Exchange-Rate Volatility Hinder Growth?” Empirical Economics 19, 371-396.

Rauch, J. E. and Casella, A., 1998. “Overcoming Informal Barriers to International Resource Allocation: Price and Group Ties.” National Bureau of Economic Research Working Paper No. 6628.

Rauch, J. E. and Trindade, V., 2002. “Ethnic Chinese Networks in International Trade.” Review of Economics and Statistics 84(1), 116-30

Rapp, T.A. and Reddy, N.N., 2000. “The Effect of Real Exchange-Rate Volatility on Bilateral Sector Exports.” The Journal of Economics 26, 87-104.

Senhadji and Montenegro, 1999. "Time Series Analysis of Export Demand Equations: a Cross-Sectional Analysis”. IMF Staff Papers 3, 259-273.

Sercu, P., 1992. “Exchange Risk, Exposure, and the Option to Trade.” Journal of International Money and Finance 11, 579-593.

Sercu, P. and Vanhulle, C., 1992. "Exchange-Rate Volatility, International Trade, and the Value of the Exporting Firms. Journal of Banking and Finance 16, 155-182.

Tinbergen, J., 1962. In: Shaping the World Economy: Suggestions for an International Economic Policy, Twentieth Century Fund, New York.

Thursby, J. and Thursby, M., 1987. "Bilateral Trade Flows, the Linder Hypothesis, and Exchange Risk." The Review of Economics and Statistics 69, 488-495.

Trumbull, W., 2001. AImperfect methodology but the right results? The USITC Report on the Economic Impact of U.S. Sanctions with Respect to Cuba. \& Cuba in Transition, 11, 105-109. 
Viaene, J. and de Vries, C.G., 1992. "International Trade and Exchange-Rate Volatility.” European Economic Review 36, 1311-1321.

Wagner, D., Head, K., and Reis, J., 2002. "Immigration and the Trade of Provinces." Scottish Journal of Political Economy 49(5), 507-525.

Wall, H.J., 2000. AGravity Model Specification and the Effects of the Canada-U.S. Border. @ Federal Reserve Bank of St. Louis Working Paper, 2000-024A.

------------1999. "Using the Gravity Model to Estimate the Costs of Protection." Federal Reserve Bank of St. Louis Review 81(1), 33-40.

Wang, Z.K. and Winters, L.A., 1991. AThe Trading Potential for Eastern Europe. @ discussion paper, 610, Center for Economic Policy Research, London.

Wolf, H.C., 2000. A(Why) Do Borders Matter for Trade@, Intranational Macroeconomics, 112-28.

Yu, C.J. and Zietlow, D.S., 1995. "The Determinants of Bilateral Trade Among AsiaPacific Countries." ASEAN Economic Bulletin 11(3), 298-305. 